University of Rhode Island

DigitalCommons@URI

Open Access Master's Theses

2017

\title{
A Coupled Wave-Surge Modeling Study in Rhode Island Coastal Waters
}

Marissa J. Torres

University of Rhode Island, itsxmarissa480@uri.edu

Follow this and additional works at: https://digitalcommons.uri.edu/theses

\section{Recommended Citation}

Torres, Marissa J., "A Coupled Wave-Surge Modeling Study in Rhode Island Coastal Waters" (2017). Open Access Master's Theses. Paper 1065.

https://digitalcommons.uri.edu/theses/1065

This Thesis is brought to you for free and open access by DigitalCommons@URI. It has been accepted for inclusion in Open Access Master's Theses by an authorized administrator of DigitalCommons@URI. For more information, please contact digitalcommons-group@uri.edu. 
A COUPLED WAVE-SURGE MODELING STUDY IN RHODE ISLAND COASTAL WATERS

BY

MARISSA J. TORRES

A THESIS SUBMITTED IN PARTIAL FULFILLMENT OF THE

REQUIREMENTS FOR THE DEGREE OF

MASTER OF SCIENCE

IN

OCEAN ENGINEERING 
MASTER OF SCIENCE THESIS

$\mathrm{OF}$

MARISSA J. TORRES

APPROVED:

Thesis Committee:

$\begin{array}{ll}\text { Major Professor } & \text { M. Reza Hashemi } \\ & \text { Malcolm Spaulding } \\ & \text { Isaac Ginis } \\ & \text { Stéphan Grilli } \\ & \text { Nasser H. Zawia } \\ & \text { DEAN OF THE GRADUATE SCHOOL }\end{array}$

UNIVERSITY OF RHODE ISLAND

2017 


\begin{abstract}
This thesis is comprised of two manuscripts, both of which involve investigating the sensitivity of storm surge in Rhode Island coastal waters. The first study details the effect of wave-induced enhanced bottom friction on surge for a simple case study. The second study sheds light on the impact of using different hurricane wind models to simulate storm surge and waves.

The interaction of waves and circulation (tide and surge) is characterized by the effect of storm surge and currents on waves, and the effect of waves on storm surge and currents. Quantifying this effect for a given area may be important for storm surge prediction purposes. As a result of wave-induced near-bed orbital velocities, the bed roughness will increase for storm surge propagation. Here, a sensitivity analysis was performed for Rhode Island coastal waters. A method developed by Soulsby (2006) was implemented to compute the increased bottom friction (i.e. drag coefficient) due to the effect of waves. Further, the interaction between waves and currents are incorporated in a coupled ADCIRC+SWAN model (which does not have this process). The storm surge was simulated with and without considering the impact of waves on the bottom roughness. Preliminary results indicate that enhanced bottom friction is largest in wavedominant areas, compared with areas where currents are strong. In other words, if the wave induced shear stresses are higher than the current induced bed shear stresses, the bottom friction increases significantly. A case study for Hurricane Irene (2011) shows that although the effect is considerable on increasing the Manning coefficient, storm surge is not that sensitive to enhanced bottom friction.

The second study deals with the effect of wind models on storm surge. Storm surge and wave models are routinely used to assess the impact of hurricanes/cyclones for emergency preparedness. While these models are forced by wind fields, generated by meteorological models in hindcast or forecast mode, selecting a wind model which
\end{abstract}


can accurately resolve the wind field, especially near the hurricane/cyclone core, is a challenging task. We use several wind hindcast models to force a coupled wave and storm surge model for selected hurricanes, including Bob (1991), Irene (2011) and Sandy (2012). The resulting simulated storm surge and wave parameters are compared to observations. The wind models include the European Center for Medium-Range Weather Forecasts (ECMWF), the Northeast Coastal Ocean Forecasting System (NECOFS) based on the Weather Research and Forecasting (WRF) model, and parametric wind based on National Hurricane Center (NHC) datasets. Storm surge and waves are best predicted using ECMWF wind for Hurricane Irene, parametric wind for Hurricane Bob, and NECOFS WRF winds for Hurricane Sandy. Our results show that a wind model, which has an error in peak wind speed of less than $20 \%$ when compared with observations, could lead to convincing storm surge of wave predictions. The impact of using a poor wind model can result in error as high as $50 \%$ in storm surge and wave predictions. There is no unique "best" wind model for all hindcast applications. This choice depends on the nature of the hurricane, in particular, the ability to adequately characterize the spatial structure of the wind forcing field. Therefore, storm track and storm scale should be considered in selecting a wind model. 


\section{ACKNOWLEDGMENTS}

I would first like to thank my major professor, Dr. M Reza Hashemi, for taking me on as a Master's student and providing me the opportunity to study coastal flood and storm surge modeling. This research would not be what it is today without your guidance, support, and encouragement during my time in the program. A special thank you to my committee members, Dr. Malcolm Spaulding, Dr. Isaac Ginis, and Dr. Stéphan Grilli, who reviewed the second manuscript in this thesis for submission to the ASCE Journal of Waterway, Port, Coastal, and Ocean Engineering. With the addition of Dr. John King, I'd like to thank each of you for working with me during the final moments leading up to my defense (i.e. sorry for the last minute rush!).

A thank you is in order to the Northeastern Regional Association of Coastal Ocean Observing Systems (NERACOOS) Coastal Resilience Project (0005266) for partially funding this research during the summer months, as well as the University of Rhode Island Graduate School for providing funding during my second year in the program.

I extend my deepest gratitude to my peers who have helped me, encouraged me, consoled me, and dealt with me along this journey: Scott, Lauren, Regina, Wendy, Missy, Jake, Boma, Ali, Soroush, Matt, Pat, Chris, and Aaron. I would not be where I am today without your support, whether it be technical or emotional. A special thank you to Dr. Chris Baxter for your unyielding support throughout my undergraduate and graduate career from writing letters of recommendation to advocating on my behalf to receive funding. The same goes for Chuck Watson, for without you and the series of opportunities you've presented me, I wouldn't be where I am today. Lastly, a thousand thank you's to our department secretary Gail for always keeping the students and faculty on track and providing moral support where its needed.

Most importantly, I'd like to thank my parents and sister for the continued encouragement, patience, and understanding they have given me over the years. I would not be 
the person I am today without your support and love. Thank you for instilling in me the desire to learn and to give it my all when faced with life's challenges.

The skills that I have gained I will carry with me to my next adventure, and the memories that I have made I will carry with me for a lifetime. URI has provided me with countless opportunities and experiences that have shaped me and prepared me for the road ahead. I may not have all the answers, but I know for a fact that I will never stop learning and seeking truth.

- Marissa J. Torres 


\section{TABLE OF CONTENTS}

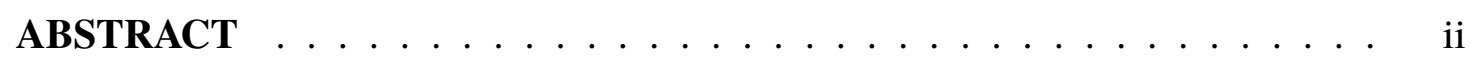

ACKNOWLEDGMENTS . . . . . . . . . . . . . . . . iv

TABLE OF CONTENTS $\ldots \ldots \ldots \ldots \ldots \ldots \ldots$ vi

LIST OF FIGURES $\ldots \ldots \ldots \ldots \ldots \ldots \ldots \ldots \ldots$ viii

LIST OF TABLES $\ldots \ldots \ldots \ldots \ldots \ldots \ldots \ldots \ldots \ldots \ldots$ xii

\section{MANUSCRIPT}

1 Effect of wave-induced enhanced bottom friction on storm surge $\ldots \quad$. .

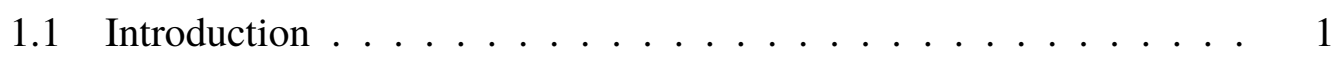

1.2 Methods . . . . . . . . . . . . . . . . . 4

1.2.1 Formulation of enhanced bottom friction $\ldots \ldots \ldots$

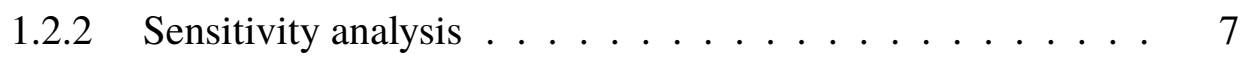

1.2.3 Coupled wave-current model . . . . . . . . . . . . 9

1.2 .4 Case study . . . . . . . . . . . . . . . . 11

1.2.5 Model validation . . . . . . . . . . . . . 15

1.3 Results. . . . . . . . . . . . . . . . 18

1.3 .1 Orbital velocity . . . . . . . . . . . . . . . . . 19

1.3.2 Enhanced bottom friction . . . . . . . . . . . . . 20

1.3.3 Case study: sensitivity of storm surge to enhanced bottom friction ................... 22

1.4 Discussion . . . . . . . . . . . . . . . . . . . 24

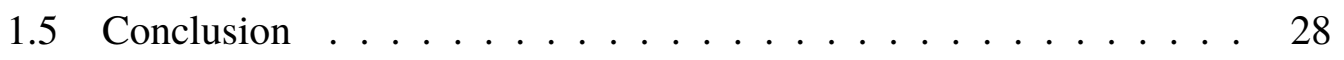




\section{Page}

List of References . . . . . . . . . . . . . . . . . 30

2 The role of hurricane wind models in accurate simulation of storm surge and waves . . . . . . . . . . . . . . . . . . 33

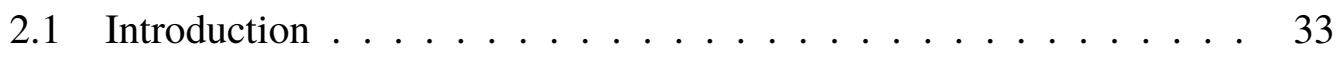

2.2 Methods ........................ 36

2.2.1 Study area ..................... 36

2.2.2 Details of the Selected Hurricanes . . . . . . . . . . 38

2.2.3 Sources of data ............... 40

2.2 .4 Model . . . . . . . . . . . . . . . . . . 42

2.2 .5 Wind Forcing . . . . . . . . . . . . . . . . . 44

2.3 Results ...................... 46

2.3.1 Simulation of historical hurricanes . . . . . . . . . . . 48

2.4 Discussion ........................ 56

2.5 Conclusions .......................... 62

List of References . . . . . . . . . . . . . . . . . 65

\section{APPENDIX}

A List of variables in Manuscript $1 \ldots \ldots$. . . . . . . . . . . . 68

B List of abbreviations/acronyms in Manuscript $2 \ldots \ldots$. . . . . . . 70

BIBLIOGRAPHY . . . . . . . . . . . . . . . . . 72 


\section{LIST OF FIGURES}

$\begin{array}{ll}\text { Figure } & \text { Page }\end{array}$

1.1 Flow chart of steps completed in this study. . . . . . . . . . . . 4

1.2 Flow chart of formulation of enhanced bottom friction followed in this study. . . . . . . . . . . . . . . . . 6

1.3 Relationship between wave height and wave period from NDBC 44097 observations during the month of May 2017 (black dots); the relation for a fully developed sea (Eq. 1.8; [18]) and by linear wave theory (LWT) have also been plotted. . . . . . . . . . . . . . 8

1.4 Location of coastal tidal gauges (blue dots) and wave stations (black dots) focused in Rhode Island; subfigure in upper right-hand corner shows zoomed-in view of RI southern shore validation stations (red box); subfigure in lower right-hand corner shows track of Hurricane Irene in the computational domain from 06:00 GMT August 28, 2011 to 00:00 GMT August 29, 2011 . . . . . . . . . . . . .

1.5 (a) Complete ADCIRC model domain based on NECOFS GOM4 mesh (recreated with increased resolution in RI) and bathymetry (color scale in $\mathrm{m}$ ) over the Atlantic continental shelf with the study area outlined as a red box, and (b) zoomed in view of mesh and bathymetry around Rhode Island . . . . . . . . . . . . . .

1.6 Snapshot of simulated contours focused in Rhode Island and time series comparison with observations during Hurricane Irene; (a) average and maximum significant wave height $H_{S}[\mathrm{~m}]$ compared with (b) observations from NOAA NDBC 44097 (located at black circle); (c) average and maximum peak period $T_{p}$ [sec] compared with $(\mathrm{d})$ observations at the same location. . . . . . . . . . . . .

1.7 Snapshot of simulated near-bed root-mean-square wave orbital velocity focused in Rhode Island during Hurricane Irene; (a) contours of average and maximum wave orbital velocity $U_{r m s}$ in $\mathrm{m} / \mathrm{s}$, and (b) comparison of simulated (SWAN; Eq. 1.9) and calculated (Soulsby; Eq. 1.7) $U_{r m s}$ at a single location (black circle, $h=54 \mathrm{~m}$ ). . . . . 
1.8 Contour of near-bed root-mean-square wave orbital velocity $U_{r m s}$ (Eq. 1.7) as a function of significant wave height $H_{s}$, zero-crossing period $T_{z}$, and water depth $h \ldots \ldots \ldots \ldots$

1.9 Sensitivity of enhanced bottom drag coefficient $\epsilon$ to current velocity $u_{c}$, near-bed root-mean-square wave orbital velocity $U_{r m s}$, and bottom roughness $k_{s} \ldots \ldots \ldots \ldots \ldots \ldots$

1.10 Contours of maximum (a) simulated depth-averaged current velocity $u_{c, \max }[\mathrm{m} / \mathrm{s}]$ and (b) calculated root-mean-square wave orbital velocity $U_{r m s, \max }[\mathrm{m} / \mathrm{s}]($ Eq. 1.7$)$ for RI study area. . . . . . . . . .

1.11 Contour of estimated ratio of enhanced bottom friction to original bottom friction $\epsilon$ in the presence of combined waves and currents for RI study area (left); contour of water depths in RI region from Fig. 1.5 b for reference (right). . . . . . . . . . . . . .

1.12 Maximum water elevation for Hurricane Irene in RI without (a) and with (b) enhanced bottom friction; (c) shows water elevation of (b)-(a); areas of no change are gray for emphasis. . . . . . . . . .

1.13 Transect of bathymetry, root-mean-square orbital velocity, current velocity, ratio of bottom drag coefficient $\epsilon$, and difference in water elevation between the enhanced and original simulation $\Delta \xi$ during the peak of Hurricane Irene; (a) transect line over bathymetry contour and (b) water depth, orbital and current velocities, and $\epsilon$ as a function of distance from beginning of transect line. . . . . . . . . . .

2.1 Study area including locations of wind, wave, and surge observations/hindcast stations; note most coastal stations along southern RI coastline are only available for Hurricane Irene; see Appendix for list of abbreviations. . . . . . . . . . . . .

2.2 (a) Complete ADCIRC model domain based on NECOFS GOM4 mesh (recreated with increased resolution in RI) and bathymetry (color scale in $\mathrm{m}$ ) over the Atlantic continental shelf with the study area outlined as a red box, and (b) zoomed in view of mesh and bathymetry around Rhode Island . . . . . . . . . . . . 
2.3 Track of (a) Hurricane Bob (1991) with radius of maximum wind $(\mathrm{RMW})$ in $(\mathrm{km})$ presented for each position along the U.S. east coast, (b) Hurricane Irene (2011) with RMW presented for every other position, and (c) Hurricane Sandy (2012) with RMW for every other position; Tracks and RMW were defined by NHC EBT for each respective storm. . . . . . . . . . . . . .

2.4 Simulated wind fields for various hurricanes based on three wind models; Hurricane Bob for (a) NHC Extended Best Track (EBT) and (b) ECMWF wind models; Hurricane Irene for (c) NHC EBT and (d) ECMWF wind models; (e,f,g) Hurricane Sandy for (e) NHC EBT, (f) ECMWF, and (g) NECOFS WRF wind models; Tracks shown by the dashed line were defined by NHC EBT for each respective storm. . . . . . . . . . . . . . . .

2.5 Comparison of observed and simulated wind speed and atmospheric pressure at the sea surface time series, respectively, at BUZM3 for Hurricane Bob (a,b), Hurricane Irene (c,d), and Hurricane Sandy (e,f); see Fig. 2.1 for wind observation/hindcast locations. . . . . .

2.6 Hurricane Irene nearshore comparisons of observed and simulated wind speeds, water elevation, and significant wave height; $(a, b)$ wind speed at WF stations in Ninigret Pond and Point Judith, RI; (c,d) water elevation at USGS tidal gauges in Skip's Dock and Quonochontaug Breachway (RI); (e,f) wave height at WHG wave gauges in Charlestown and Westerly, RI; see Fig. 2.1 for nearshore observation/hindcast locations; see Figure 2.9 for RMSE values. . . . . . 52

2.7 Comparison of observed and simulated water elevation time series $(\mathrm{m}, \mathrm{msl})$ at NOAA tidal gauges in Newport and Providence, RI, respectively, for Hurricane Bob (a,b), Hurricane Irene (c,d), and Hurricane Sandy (e,f); see Fig. 2.1 for surge observation/hindcast locations. . . . . . . . . . . . . . . 5 54

2.8 Comparison of observed/hindcast and simulated wave time series at WIS Station 63079 and NDBC Buoy 44097; (a) Hurricane Bob WIS hindcast comparison, (b,c) Hurricane Irene NDBC Buoy and WIS hindcast comparison, respectively, and (d,e) Hurricane Sandy NDBC Buoy and WIS hindcast comparison, respectively; see Fig. 2.1 for wave observation/hindcast locations. . . . . . . . . . . 57 
2.9 Bar graph of root-mean-square error (RMSE) between observed and simulated storm surge (sampled 12 hours prior to and post peak surge) for each wind model by station location for Hurricanes (a) Bob (1991), (b) Irene (2011) and (c) Sandy (2012). . . . . . . . . . 59

2.10 Close up of the storm tracks for Hurricane Bob (solid line) on August 18, 1991 at 1800 GMT, Hurricane Irene (dashed line) on August 28, 2012 at 1800, and Hurricane Sandy (dash-dotted line) on October 29,2012 at 1800 with radius of maximum wind circumferences shown over the study area with (a) ECMWF and (b) NECOFS WRF wind model grids shown; Tracks and RMW were defined by NHC EBT for each respective storm. . . . . . . . . . . . . . 61 


\section{LIST OF TABLES}

Table

Page

1.1 Mean depth-averaged observed $u_{c, o b}$ and simulated $u_{c, s i m}$ current velocity nearshore during Hurricane Irene; percent error is computed as $\left(\frac{u_{c, o b}-u_{c, s i m}}{u_{c, o b}}\right) 100 \ldots \ldots \ldots \ldots \ldots \ldots$. . . . . . . . . . 16

2.1 Extreme water levels recorded in Newport, RI for significant storm surge events (tidesandcurrents.noaa.gov). . . . . . . . . . . 37

2.2 Outline of the historical hurricanes, wind models, and observation/hindcast stations used in this research; see Fig. 2.1 for observations/hindcast locations. . . . . . . . . . . . . . .

2.3 Skill assessment of ADCIRC for tides at the Newport and Providence stations with root-mean-square errors shown; RMSE for M2 tidal constituent $\left(0.0013 \mathrm{~m}\right.$ amplitude, $4.74^{\circ}$ phase $)$ and $\mathrm{S} 2$ constituent $\left(0.0194 \mathrm{~m}\right.$ and $\left.3.63^{\circ}\right)$. . . . . . . . . . . . . . . . .

2.4 Comparison of maximum observed and modeled wind speeds $(\mathrm{m} / \mathrm{s})$ for various hurricanes at selected wind stations; percent error in parentheses (negative value signify underestimation, and positive values overestimation); see Fig. 2.1 for observation/hindcast locations. 53

2.5 Comparison of maximum observed and simulated water levels (tide + surge; m, msl) for various hurricanes at selected surge stations; percent error in parentheses (negative value signify underestimation, and positive values overestimation); see Fig. 2.1 for observation/hindcast locations; see Fig. 2.9 for RMSE values. . . . . . . . 55

2.6 Comparison of maximum observed and simulated significant wave height $(\mathrm{m})$ for various hurricanes at selected wave stations; percent error in parentheses (negative value signify underestimation, and positive values overestimation); see Fig. 2 .1 for observation/hindcast locations. . . . . . . . . . . . . . . . 58 


\section{MANUSCRIPT 1}

\section{Effect of wave-induced enhanced bottom friction on storm surge}

\subsection{Introduction}

The interaction of waves and circulation (tide and surge) is characterized by the effect of storm surge and currents on waves, and the effect of waves on storm surge and currents. Fro example, in the presence of currents, the frequency of waves will either decrease (with current), or increase (against current) to a stationary observer, which is known as the Doppler shift. In return, waves induce a force on the circulation in the form of radiation stresses, affecting water levels and currents, especially nearshore (wave set-up). Additionally, several studies have shown that the bottom roughness increases for currents due to the interaction of waves within the bottom boundary layer (see $[1,2,3]$ ).

Advances in numerical modeling and unstructured meshes have provided the ability to examine wave-current interactions in areas of complex geometry. The national network of operational forecast systems employed by the National Oceanic and Atmospheric Administration (NOAA; tidesandcurrents.noaa.gov) utilize several three-dimensional circulation and wave models such as the "Regional Ocean Modeling System" (ROMS), the "Finite-Volume Community Ocean Model" (FVCOM), and the "Semi-implicit EulerianLagrangian Finite Element" (SELFE) model. On a local scale, the Federal Emergency Management Agency (FEMA) employs the "ADvanced CIRCulation" hydrodynamic model (ADCIRC; [4]) for flood insurance maps in Atlantic and Gulf Coast states. Such a circulation model computes water level and depth-averaged currents, and can be easily coupled with a wave model. Simulating WAves Nearshore (SWAN) is a popular spectral wave model that solves the spectral action balance equation [5]. By coupling ADCIRC and SWAN, water elevation (including surge) is incorporated in the solution of waves and, in return, wave forces (including wave set-up) are incorporated in the solution of surge. However, the effect of waves on the enhancement of bottom friction is ignored in 
the present coupled model.

In recent years, the influence of waves on storm surge and surge on waves has been a topic of discussion in the scientific community. Huang et al. (2010; [6]) investigated wave-surge interactions for a hypothetical hurricane in the Tampa Bay, Florida area using FVCOM for circulation and SWAN for waves. Considering the complex bathymetry in the region, the effect of storm surge on waves was more significant than the influence of wave-induced forces on surge. In the northeast US, Sun et al. (2013; [7]) performed a case study for Hurricane Bob (1991), and noted that the contribution of wave-induced forces improved the surge simulation along the southern shore of Rhode Island by 10$25 \mathrm{~cm}$ utilizing the coupled current-wave model FVCOM-SWAVE, where SWAVE is a modified version of SWAN for implementation over an unstructured grid.

The nonlinear interaction between the wave and current boundary layers at the sea floor induces a change in the bed shear stress. In the presence of waves, added turbulence in the wave bottom-boundary layer causes what appears to be an increase in the bottom roughness to the current. The bottom-boundary layers are represented by the currentonly and wave-only bed shear stresses, which are controlled by the near-bed current and wave orbital velocities, respectively. The expression for calculating near-bed wave orbital velocity is of most importance because of its contributions to the wave-induced shear stress in the nonlinear interaction. Soulsby proposed a method for calculating orbital velocity beneath waves in 1987 [8] given wave height, period and water depth, which was further summarized and compared with several additional methods in 2006 [9]. Not included in [9] are studies by Wilberg et al. (2008; [10]), Elfrink et al. (2006; [11]) and You (2009; [12]) in which wave orbital velocities are estimated, derived, and statistically distributed, respectively, in nearshore regions where field measurements were available for comparison.

In addition, the effect of wave-current interactions on bed shear stress has been in- 
vestigated in recent years. When comparing two different expressions of bottom friction dissipation in a coupled wave-surge simulation, Rosales et al. (2008; [13]) found that the maximum bottom stress was doubled with inclusion of wave-current interactions, concluding the selection of such an expression is significant in determining the shear stress. Bing-chen and Hau-Jin (2007; [14]) introduced wave-enhanced bottom shear stress based on a form of Grant and Madsen [15] into a coupled hydrodynamic-wave model (COHERENS-SWAN), and found that the inclusion of random waves produced a lower bottom shear stress than the case without random waves, highlighting the differences between one way and two way interaction of waves and currents. Both Huang (2010) and Sun (2013) compared the results from a coupled wave-circulation model with those of a current-only and/or wave-only model to assess the role of wave-current interaction in storm surge simulation.

The present study focuses on (1) quantifying the contribution of waves to the bottom stress based on the coupled wave-circulation model (ADCIRC+SWAN), (2) formulating an enhanced bottom friction from the wave-induced forces, (3) applying the enhanced bottom friction to the coupled model under the same conditions, and (4) assessing the effect of enhanced bottom friction on storm surge in Rhode Island coastal waters (Fig. 1.1). The sensitivity of the enhancement of the bottom friction coefficient to wave forces is assessed for a range of realistic current and bottom roughness characteristics. In addition, a case study is presented to quantify the effect of the enhanced bottom drag coefficient on storm surge prediction using the coupled ADCIRC+SWAN model. Formulations proposed by Soulsby (1993; [1]) in determining the enhanced bottom friction are described in Section 1.2, along with a description of the assumptions we made and the model settings we used. Section 1.3 illustrates the relationships between wave climate, near-bed wave orbital velocity, and other location-specific conditions, as well as their contributions to the enhancement of bottom friction. A discussion and 


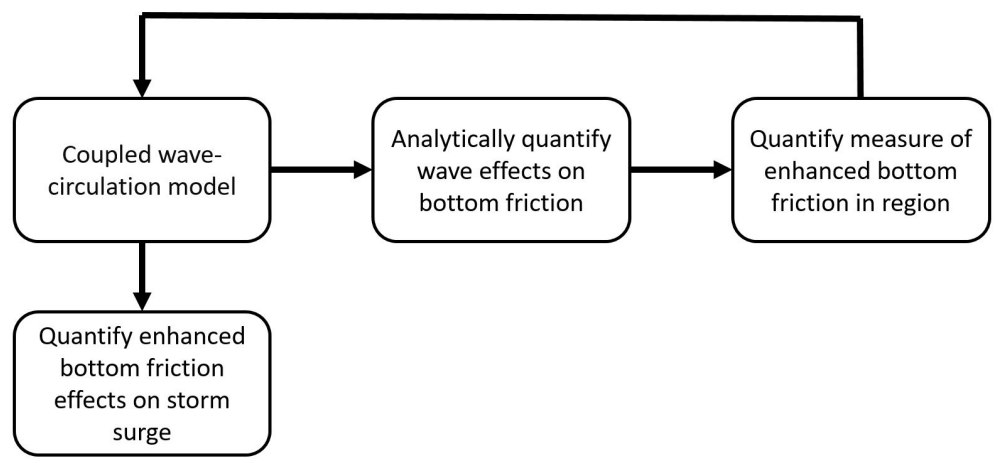

Fig. 1.1. Flow chart of steps completed in this study.

summary are provided in Sections 1.4 and 1.5.

\subsection{Methods}

\subsubsection{Formulation of enhanced bottom friction}

As the interaction of the wave and current boundary layers leads to the enhancement of the bed shear stress, the friction force in the momentum equation changes, which can lead to a change in water elevation and storm surge. In terms of the bottom boundary layer, the effects of wave-current interaction have been studied in previous research with respect to sediment transport applications (see $[1,2,3,16])$. This study focuses on the sensitivity of the bottom friction to such interactions, and its significance to storm surge prediction.

The enhancement of bottom friction in a given area is a result of the nonlinear interaction between the wave and current bottom-boundary layers. The amount of enhancement depends on the current- and wave-induced shear stresses, $\tau_{c}$ and $\tau_{w}$, respectively, which can be quantified as a mean bed shear stress, $\tau_{m}$ (Eq. 1.1 ; [2]) in the combined wave-current flow field. The mean bed shear stress was empirically derived from eight different bottom-boundary layer models; details of this formulation can be found in [2]. 


$$
\frac{\tau_{m}}{\tau_{c}}=\left[1+1.2\left(\frac{\tau_{w}}{\tau_{c}+\tau_{w}}\right)^{3.2}\right]
$$

with, $\quad \tau_{m}=\rho C_{D}^{*} u_{c}^{2}, \quad \tau_{c}=\rho C_{D} u_{c}^{2}$

The mean $\left(\tau_{m}\right)$ and pure-current $\left(\tau_{c}\right)$ shear stresses are proportional to the square of the depth-averaged current velocity $u_{c}$, as well as the bottom drag coefficient in the presence and absence of waves, $C_{D}^{*}$ and $C_{D}$, respectively (Eq. 1.2). Depth-averaged current velocities can be based on measured values from current meters or simulated values from a circulation model. The ratio of the combined wave-current bottom drag coefficient to pure-current drag coefficient, Eq. 1.1 can be rewritten as the measure of enhanced drag in a given area $(\epsilon)$ :

$$
\epsilon=\frac{\tau_{m}}{\tau_{c}}=\left[1+1.2\left(\frac{\lambda}{1+\lambda}\right)^{3.2}\right]=\frac{C_{D}^{*}}{C_{D}}, \quad \epsilon \leq 2.2
$$

where $\lambda$ is the ratio of the wave-induced shear stress to the current-induced shear stress, $\lambda=\frac{\tau_{w}}{\tau_{c}}$. Intuitively, we know that in regions of weak currents $\left(u_{c} \rightarrow 0\right)$, the current-induced shear stress is small $\left(\tau_{c} \rightarrow 0\right)$, where the same applies to the near-bed orbital velocity and wave-induced shear stress. From Equation 1.3, we can see that $\epsilon$ is primarily dominated by $\tau_{w}$, and therefore in cases of weak currents and strong waves, $\epsilon$ approaches a maximum value of 2.2. Thus the calculation of the near-bed root-meansquare (r.m.s.) wave orbital velocity $U_{r m s}$ is of the utmost importance to determine the magnitude of the wave-induced bed shear stress:

$$
\begin{aligned}
\tau_{w} & =\frac{1}{2} \rho f_{w} U_{r m s}^{2} \\
f_{w} & =0.237\left(\frac{A}{k_{s}}\right)^{-0.52} \\
A & =\frac{U_{r m s} T_{z}}{2 \pi}
\end{aligned}
$$




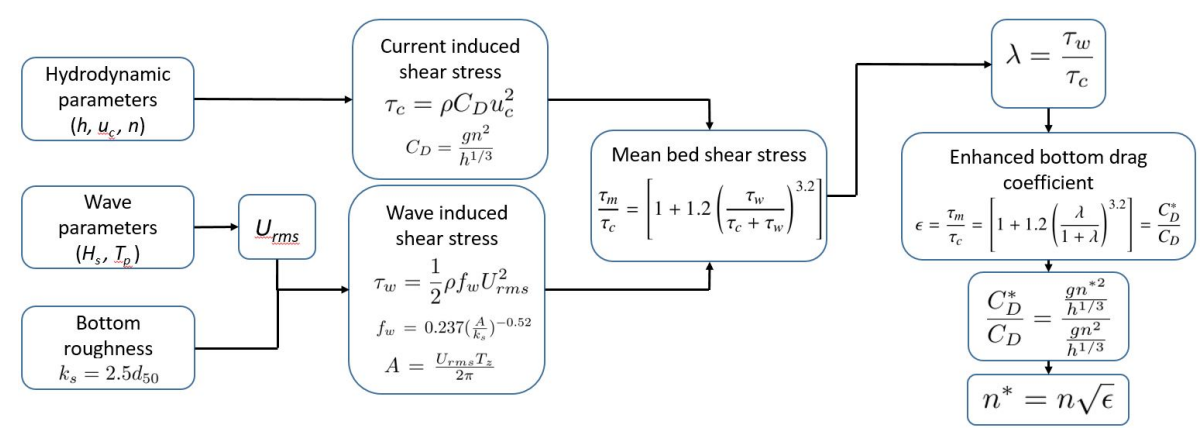

Fig. 1.2. Flow chart of formulation of enhanced bottom friction followed in this study.

Here, $f_{w}$ is the friction factor, $A$ is the semi-orbital wave excursion, $k_{s}$ is the Nikuradse bottom roughness $\left(k_{s}=2.5 d_{50}\right)$ for mean sediment grain size diameter $d_{50}$, and $T_{z}$ is the zero-crossing period $\left(T_{z}=0.781 T_{p} ;[2]\right)$, where $T_{p}$ is the peak wave period.

In addition to linear wave theory, the estimation of $U_{r m s}$ has been approached in several studies (see $[8,9,11,10,12])$ in which near-bed orbital velocities can be approximated analytically using other measured wave parameters from observational buoys, theoretical wave parameters from an idealized wave spectra, or simulated surface wave parameters from a spectral wave model. Of these, the exponential approximation discussed by Soulsby (1987 and 2006, [8, 9]) describes the near-bed r.m.s. orbital velocity as the variance of the bottom velocity spectrum based on a Joint North Sea Wave Project (JONSWAP) spectrum of a particular sea-state:

$$
U_{r m s}=\left(\frac{H_{s}}{4}\right)\left(\frac{g}{h}\right)^{1 / 2} \exp \left\{-\left[\frac{3.65}{T_{z}}\left(\frac{h}{g}\right)^{1 / 2}\right]^{2.1}\right\}
$$

with significant wave height $H_{s}$, zero-crossing period $T_{z}$, water depth $h$, and gravitational acceleration $g$. Details of this formulation can be found in [8].

Lastly, the combined wave-current and pure current bottom drag coefficients can be related to other friction factors such as the Manning's $n$ quadratic friction coefficient. Since $C_{D}=g n / h^{1 / 3}$, the enhanced Manning coefficient is $n^{*}=n \sqrt{\epsilon}$ [17]. Figure 1.2 outlines the process of the formulation of enhanced bottom friction used in this study. 
It should be noted that the process outlined here can be completed using measured/observed values of $H_{s}, T_{p}, d_{50}, u_{c}$, and $U_{r m s}$ from wave buoys, current meters, etc., or by using simulated values from a circulation or wave model.

\subsubsection{Sensitivity analysis}

From the previous section, we know that the enhanced bottom friction is a function of depth-averaged current velocity, bottom roughness, water depth, near-bed r.m.s. wave orbital velocity, significant wave height, and peak/average wave period. If these governing parameters are known, we can estimate/predict the level of enhancement expected in any given region. Furthermore, the sensitivity of the expected enhanced bottom friction to varying wave, current, and bottom roughness conditions can be assessed. It is important to first understand the relationship the governing parameters (i.e. $H_{s}, T_{p}, h, U_{r m s}$, $u_{c}$, and $k_{s}$ ) have with each other, and determine a reasonable range of realistic values to assess the sensitivity of the enhanced bottom friction.

Depending on the sea state of a given area, the wave height and wave period can be dependent or independent. In the case of fully developed seas, the equation governing the growth of waves with fetch is described by Eq. 1.8 in the Coastal Engineering Manual [18] for peak period $T_{p}$ and energy-based significant wave height $H_{m o}$. The one-to-one relation for fully developed seas is close to that derived from linear wave theory for peak period and significant wave height $H_{s}$ (Fig. 1.3). However, a one-to-one relationship is not always the case. A wave period can also correspond to several wave heights and vice versa, which can be seen by plotting observed surface wave parameters from offshore buoys (see Fig. 1.3, where wave height and period are plotted for the NOAA National Data Buoy Center (NDBC) buoy 44097 near Rhode Island). In this case, the empirical relationships fail to capture the long period waves corresponding to small wave heights experienced in nature, because the sea state is not always a fully developed sea. 


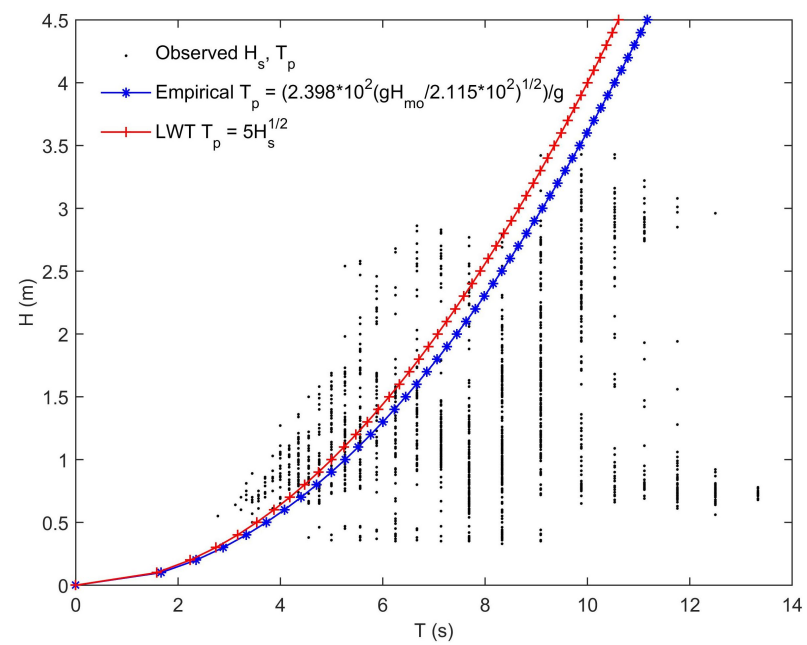

Fig. 1.3. Relationship between wave height and wave period from NDBC 44097 observations during the month of May 2017 (black dots); the relation for a fully developed sea (Eq. 1.8; [18]) and by linear wave theory (LWT) have also been plotted.

$$
T_{p}=\frac{2.398 \times 10^{2} \sqrt{\frac{g H_{m_{o}}}{2.115 \times 10^{2}}}}{g}
$$

Accordingly, a range of wave heights and periods based on the wave climate in our region can be applied to the sensitivity of the enhancement of bottom friction via the near-bed r.m.s. orbital velocity. $U_{r m s}$ is a function of significant wave height, zerocrossing period, and water depth (i.e. $\left.U_{r m s}\left(H_{s}, T_{z}, h\right)\right)$, which can be expressed using Eq. 1.7 given a range of realistic values. In doing so, the expected magnitude of near-bed orbital velocity can be estimated for any known depth, wave height or wave period ${ }^{1}$. This sensitivity analysis was completed for variable significant wave height ( $H_{s}=0$ to $\left.10 \mathrm{~m}\right)$, three zero-crossing periods $\left(T_{z}=6,10,14 \mathrm{~s}\right)$, and variable water depth ( $h=0$ to $\left.50 \mathrm{~m}\right)$. A simple wave breaking criterion was applied assuming solitary waves, where $H_{s}$ does not propagate over depths less than $0.78 h$ [2].

Lastly, the expected level of enhanced bottom friction $\epsilon$ (Eq. 1.3) for a given area can be estimated. A sensitivity analysis is performed for a range of feasible bottom

${ }^{1}$ The ability to estimate $U_{r m s}$ for a set of wave conditions is also important for the protection of submerged objects on the sea floor, such as Acoustic Doppler Current Profilers (ADCPs). 
roughness $k_{s}$, current velocity $u_{c}$, and near-bed r.m.s wave orbital velocity $U_{r m s}$ values based on the study region. Sediment grain size diameters representing medium to very coarse sand $\left(d_{50}=0.25,0.5,0.75\right.$, and $\left.1.0 \mathrm{~mm}\right)$ are selected, which correspond to bottom roughness values of $k_{s}=0.000625 \mathrm{~m}, 0.00125 \mathrm{~m}, 0.001875 \mathrm{~m}$, and 0.0025 $\mathrm{m}$, respectively $\left(k_{s}=2.5 d_{50} ;[1]\right)$. Depth-averaged current velocity is varied from 0.1 $\mathrm{m} / \mathrm{s}$ to $1.0 \mathrm{~m} / \mathrm{s}$, representative of values measured and/or estimated in the literature (see $[19,20])$. The near-bed r.m.s. wave orbital velocity varied from 0 to $1.5 \mathrm{~m} / \mathrm{s}$ when based on varying wave climate, which agreed with velocities measured/estimated in $[11,12]$.

\subsubsection{Coupled wave-current model ADCIRC}

The ADvanced CIRCulation hydrodynamic model solves the equations of motion for a kinetic fluid on a rotating body, formulated using traditional hydrostatic pressure and Boussinesq approximations that have been discretized in space by the Galerkin finiteelement method and in time by the three-level finite-difference method [4]. The surface water elevation is computed by the depth-integrated continuity equation found in the "General Wave Continuity Equation" (GWCE), and depth-integrated current velocity is computed from the non-conservative momentum equations [4]. ADCIRC is forced along the open ocean boundary primarily by water elevation and surface stress (i.e. wind).

\section{SWAN}

Simulation WAves Nearshore (SWAN) is a third-generation spectral model that computes wave conditions based on the conservation of the wave action density, which is conserved in the presence of ambient currents. SWAN takes into account wavecurrent interactions via radiation stresses in shallow water, and includes the formulations for wave generation by wind, nonlinear wave-wave interactions, and dissipation due to whitecapping, bottom friction, and depth-induced breaking [21]. Surface waves induced water particle motion through the water column to the sea floor, giving rise to friction 
in the turbulent bottom boundary layer. This dissipation of wave energy due to bottom friction depends on the near-bed r.m.s. wave orbital velocity $U_{r m s}$, in which SWAN provides its solution as a function of the energy density spectrum, water depth, and wave period (Eq. 1.9; [21]).

$$
U_{r m s}^{2}=\frac{1}{2 \pi} \int_{0}^{2 \pi} \int_{0}^{\infty} \frac{\sigma^{2} E(\sigma, \theta)}{\sinh ^{2} k d} d \sigma d \theta
$$

\section{Coupled ADCIRC+SWAN model}

As mentioned, the enhancement of bottom friction due to waves is not included in the present version of the ADCIRC+SWAN model. Here, we manually modified the spatially variable friction $\left(n^{*}=n \sqrt{\epsilon}\right)$ of ADCIRC based on the wave field computed by SWAN. The process can be automated, but here we studied the sensitivity of storm surge to this effect.

The enhancement of bottom shear stress, and thus bottom friction, is a result of the interaction of the wave field with the current bottom boundary layer. Computation of wave-current interactions, including wave set-up and set-down, in coupled models [22] provides more accurate predictions of waves and storm surge, as concluded by Huang et al. (2010; [6]). The ADCIRC+SWAN coupled wave-circulation model is used in this study. The coupling of ADCIRC and SWAN is carried out in parallel on identical sub-meshes using intra-model communication on the same computational core [22], in which SWAN is treated as subroutine. At each node, SWAN is passed wind speeds, water levels, and currents computed by ADCIRC, which are averaged each time step and used to recalculate the water depth and related wave processes such as wave propagation and depth-induced breaking. In return, ADCIRC is partially driven by the radiation stress gradients computed by SWAN, extrapolating them forward in time [22]. 


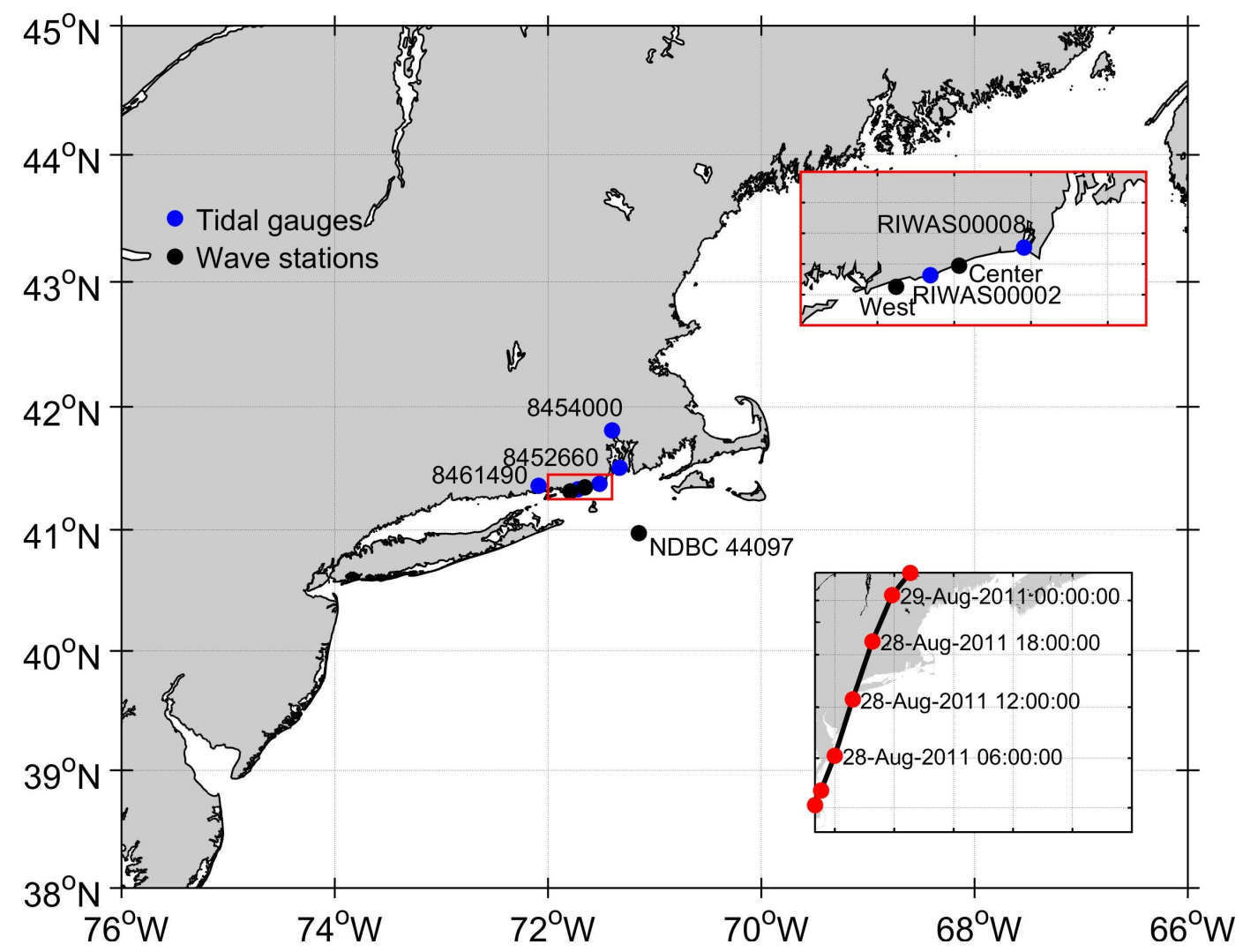

Fig. 1.4. Location of coastal tidal gauges (blue dots) and wave stations (black dots) focused in Rhode Island; subfigure in upper right-hand corner shows zoomed-in view of RI southern shore validation stations (red box); subfigure in lower right-hand corner shows track of Hurricane Irene in the computational domain from 06:00 GMT August 28, 2011 to 00:00 GMT August 29, 2011.

\subsubsection{Case study Study area}

Rhode Island is comprised of several barrier systems along its southern shore, which include dunes, coastal ponds, headlands, and inlets, and are subject to moderate to severe coastal flooding during significant storm events. Figure 1.4 displays an overview of the study area. Within the past decade, coastal communities have been impacted by the surge produced by two tropical cyclones, Hurricane Irene (2011) and Hurricane Sandy (2012). Understanding the sensitivity of hurricane-induced storm surge to environmental conditions, such as bottom friction, is important for improving surge prediction in emergency preparedness applications. 
The computational domain used in this study is based on the "North East Coastal Ocean Forecasting System" (NECOFS) FVCOM model for the Gulf of Maine, Version 4 (GOM4) mesh, developed by University of Massachusetts-Dartmouth Marine Ecosystem Dynamics Modeling Laboratory (MEDML; [23]). The original FVCOM GOM4 mesh has 53,087 nodes with a resolution of $1 \mathrm{~km}$ along the Rhode Island coastline. An unstructured ADCIRC mesh with 27,439 nodes was created for RI, with a resolution up to $200 \mathrm{~m}$ at the coast and $20 \mathrm{~m}$ within inlets and rivers. In order to preserve the domain extent for hurricane hindcast purposes and to provide enough discretization in the study area, the RI mesh was merged with the FVCOM GOM4 mesh, leading to a total 105,560 nodes. Figure 1.5 displays the combined mesh for New England and the higher resolution mesh for RI with corresponding bathymetry of the region.

\section{Sources of data}

High resolution bathymetric $(30 \mathrm{~m})$ and topographic $(1 \mathrm{~m})$ data for Rhode Island was acquired from the RI Geographical Information System (GIS) (www.rigis.org/) and applied to the ADCIRC domain around RI where the mesh has improved resolution. Digital Elevation Models (DEMs) of Connecticut and Massachusetts, provided by each state's GIS database, were used to define the outer extents of the RI mesh. The bathymetry and topography of the remaining regions were based on the NECOFS original mesh (GOM4).

Available observed and hindcast data were reviewed in the region (focused in RI; Fig. 1.4) both nearshore and offshore. Permanent observation locations include water elevation stations operated by the National Oceanic and Atmospheric Administration (NOAA) in New London, CT (8461490), Newport, RI (8452660), and Providence, RI (8454000; tidesandcurrents.noaa.gov), and the NOAA National Data Buoy Center (NDBC) wave buoy far offshore of Block Island, RI (44097; www.ndbc.noaa.gov/). Several nearshore temporary water level and wave stations were in operation during 
(a)

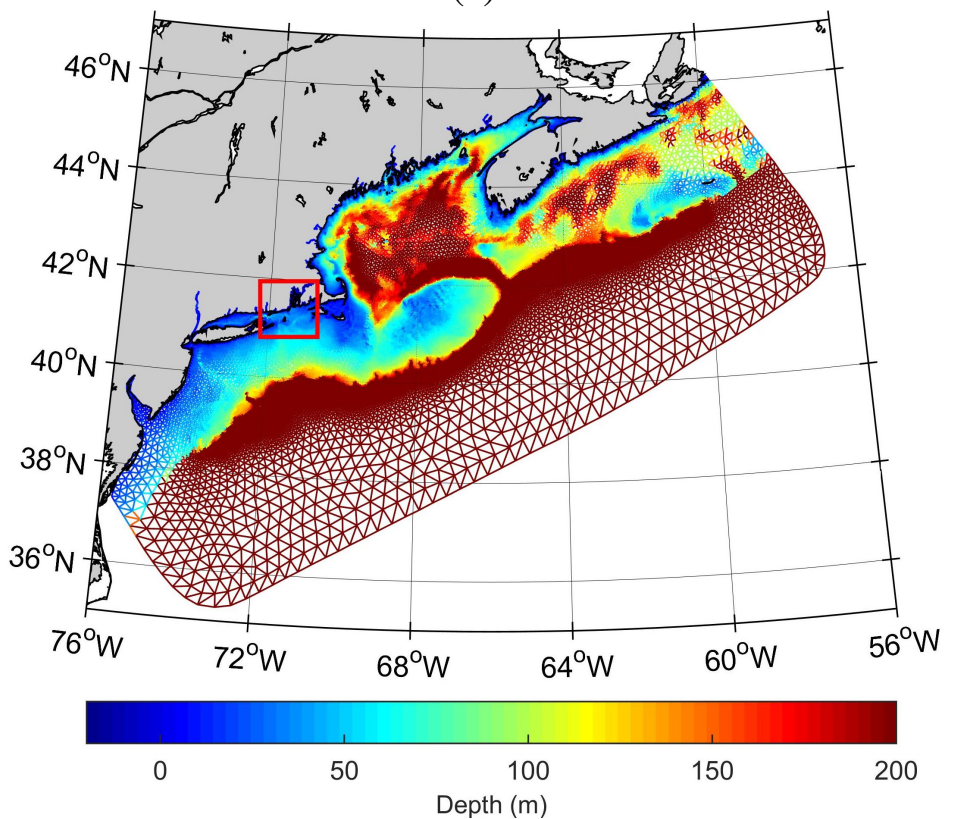

(b)

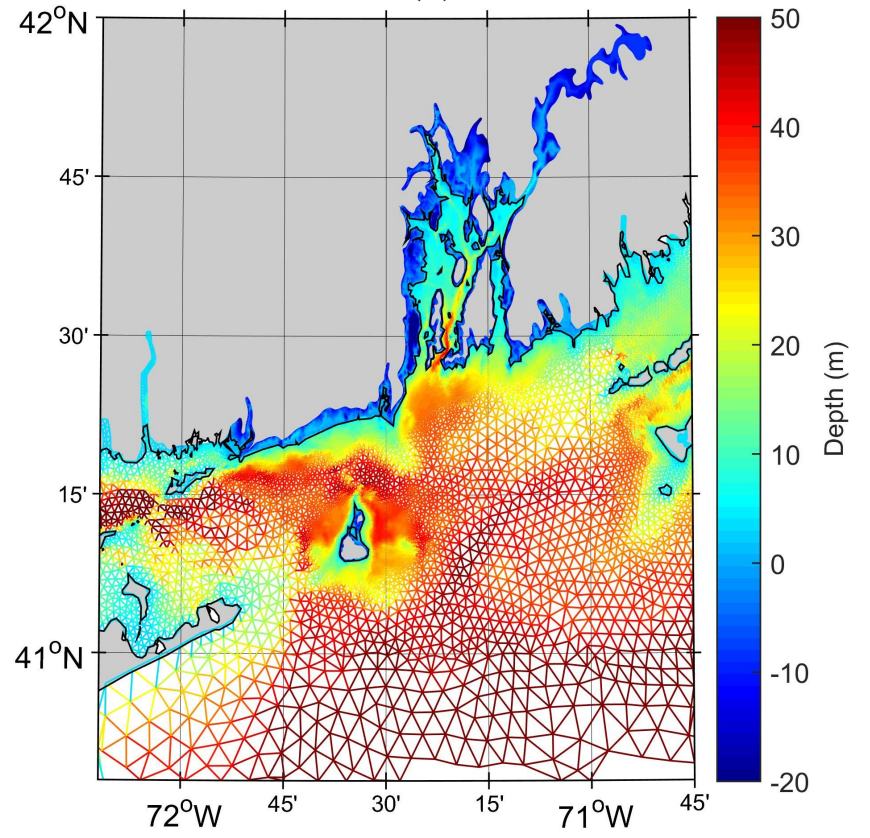

Fig. 1.5. (a) Complete ADCIRC model domain based on NECOFS GOM4 mesh (recreated with increased resolution in RI) and bathymetry (color scale in m) over the Atlantic continental shelf with the study area outlined as a red box, and (b) zoomed in view of mesh and bathymetry around Rhode Island 
Hurricane Irene, including two water elevation gauges deployed by the United States Geological Survey (USGS) at Skip's Dock in Point Judith, RI, and in Charlestown, RI, inside the Quonochontaug Breachway (wim.usgs.gov). Two Acoustic Doppler Current Profilers (ADCPs) measuring waves and currents were in operation from July 2010 to September 2011 by the Woods Hole Group (WHG; [19]) one mile southwest of the Charlestown Breachway off of the RI southern shore (Center; $\left.-71.656^{\circ} \mathrm{W}, 41.348^{\circ} \mathrm{N}\right)$, and one mile east and south of Misquamicut, RI (West; $-71.793^{\circ} \mathrm{W}, 41.317^{\circ} \mathrm{N}$ ).

\section{Hurricane Irene (2011)}

Hurricane Irene (2011) formed from a tropical wave that exited the African coast on August 15, 2011, and strengthened over the Atlantic basin, leading to a destructive landfall in North Carolina as a strong Category 1 hurricane [24]. The storm continued to travel northward along the US east coast to the west of Rhode Island with a radius of maximum wind of 100 nautical miles or $185 \mathrm{~km}$. RI experienced severe wind gusts that left much of the state without power for several days, and mild flooding in Narragansett Bay due to storm surge. Hurricane Irene was the first major storm to impact Rhode Island since Hurricane Bob in 1991. This storm was simulated using the "European Center for Medium-range Weather Forecasts" (ECMWF) wind model, a combined general circulation model and data assimilation system. More details about the ECMWF wind model can be found in $[25,26]$. The simulation took place for 7 days from August 21, 2011 00:00 to August 30, 2011 00:00 GMT. Time series of the simulated wave parameters and current velocity are compared with observations.

\section{ADCIRC+SWAN Model Settings}

The coupled ADCIRC+SWAN model is run on a CENT OS 7 Linux cluster with 60 processors and took 6.5 hours for a 6 day simulation. ADCIRC is run in 2-D mode with a time step of $0.5 \mathrm{~s}$. The "General Wave Continuity Equation" (GWCE) weighting 
factor, $\tau_{0}$, that weighs the relative contribution of the primitive and wave portions of the GWCE, was adjusted for stability from its default value of 0.03 to 0.02 . SWAN is run in non-stationary mode over the unstructured ADCIRC mesh, with 36 directional bins and 40 frequency bins with a low frequency cut-off of $0.031 \mathrm{~Hz}$, and was forced by the same wind field as ADCIRC. The default formulations are applied for breaking and whitecapping (KOMEN), with Manning's $n$ quadratic friction input from ADCIRC.

The ADCIRC+SWAN model is forced with five constituents from the LeProvost tidal database along the open boundary: $\mathrm{M} 2, \mathrm{~S} 2, \mathrm{~N} 2, \mathrm{O} 1$, and $\mathrm{K} 1$. The model has been

previously validated with historical tides and select tropical cyclones (Hurricane Bob (1991), Irene (2011), and Sandy (2012)); [25].

An initial simulation was completed with Manning's $n$ quadratic friction set to the default value (0.02). Post processing is performed on the wave parameters and current velocity from the initial run in order to calculate the increased Manning's $n^{*}$ coefficient for application in a second simulation. The water elevations are then compared between the initial and enhanced scenarios to assess the sensitivity of storm surge to enhanced bottom friction.

\subsubsection{Model validation}

In this study, simulated significant wave height and peak period from the wave model SWAN are applied in the formulation of enhanced bottom friction. Since observed surface wave parameters were not used directly, it is necessary to first compare the simulated values with those observed by a local wave buoy in Rhode Island. Figure 1.6b,d displays the time series of simulated $H_{s}$ and $T_{p}$ compared with observations from NDBC 44097 wave buoy for Hurricane Irene. We observe good agreement at the peak of the storm when comparing $H_{s}$ to observations, and moderate agreement between simulated and observed $T_{p}$. In addition, contours (i.e. a heat map) of a snapshot (i.e. a single point in time) of the simulated mean and maximum $H_{s}$ and $T_{p}$ experienced in the 
Table 1.1. Mean depth-averaged observed $u_{c, o b}$ and simulated $u_{c, s i m}$ current velocity nearshore during Hurricane Irene; percent error is computed as $\left(\frac{u_{c, o b}-u_{c, s i m}}{u_{c, o b}}\right) 100$.

\begin{tabular}{lccc}
\hline \hline Wave Station & Observed $(\mathrm{cm} / \mathrm{s})$ & Simulated $(\mathrm{cm} / \mathrm{s})$ & \% error \\
\hline West $\left(-71.793^{\circ} \mathrm{W}, 41.317^{\circ} \mathrm{N}\right)$ & 22.2 & 26.5 & $18 \%$ \\
Center $\left(-71.656^{\circ} \mathrm{W}, 41.348^{\circ} \mathrm{N}\right)$ & 18.0 & 18.6 & $2 \%$ \\
\hline \hline
\end{tabular}

RI region during Hurricane Irene (Figs. 1.6a,c) are presented. Significant wave height is shown to vary from $2 \mathrm{~m}$ to upwards of $10 \mathrm{~m}$, and the peak wave period ranges from $8 \mathrm{~s}$ to a maximum of $14 \mathrm{~s}$. Recall that a range of realistic wave climate conditions can be used to assess the sensitivity of the near-bed wave orbital velocity as a function of $H_{s}$ and $T_{p}$. Validation results for tides, surge, and wind were previously carried out in Torres et al. (2017; [25]) for this historical storm, which is also detailed in the second manuscript of this thesis.

Similarly, the simulated mean depth-averaged current velocity $u_{c, s i m}$ for the study region is compared to the observed depth-averaged current velocity $u_{c, o b}$ recorded by Woods Hole Group during Hurricane Irene (WHG; [19]). Two WHG ADCPs were deployed near shore in Westerly, RI (West; $-71.793^{\circ} \mathrm{W}, 41.317^{\circ} \mathrm{N}$ ) and Charlestown, RI (Center; $-71.656^{\circ} \mathrm{W}, 41.348^{\circ} \mathrm{N}$ ) from July 2010 to September 2011 in RI (see Fig. 1.4 for station location). Table 1.1 summarizes the mean depth-averaged observed and simulated current velocities at the respective ADCP locations. The velocity compares well at the Center station in Charlestown (error of $2 \%$ ), and slightly less so at the West station in Westerly (error of $18 \%$ ).

In the coupled ADCIRC+SWAN model, a time series of the near-bed r.m.s. wave orbital velocity can only be extracted from a single grid point at a time (i.e. an output file containing $U_{r m s}$ over the entire domain is unavailable). Therefore, comparing the solution of $U_{r m s}$ from SWAN with that of the exponential approximation proposed by Soulsby (Eq. 1.7; [9]), we can determine if the approximation is adequate in representing $U_{r m s}$ over the entire domain. Additionally, we can further apply the approximation to 
(a)

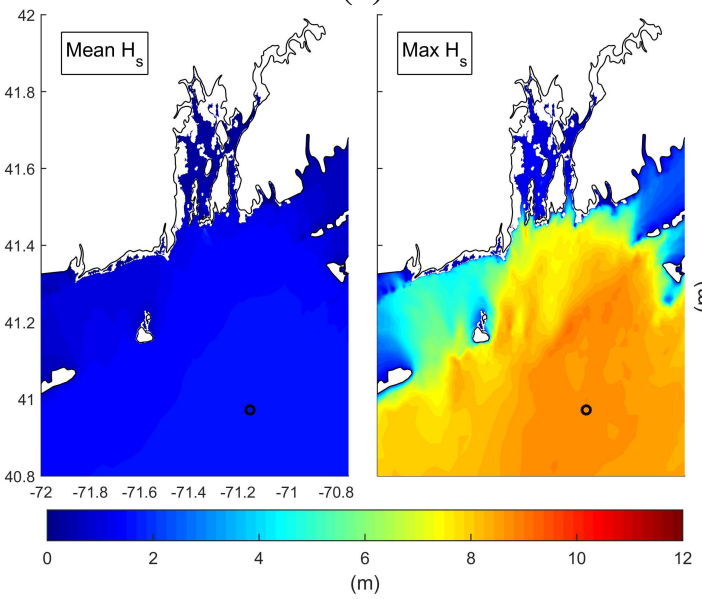

(c) (b)

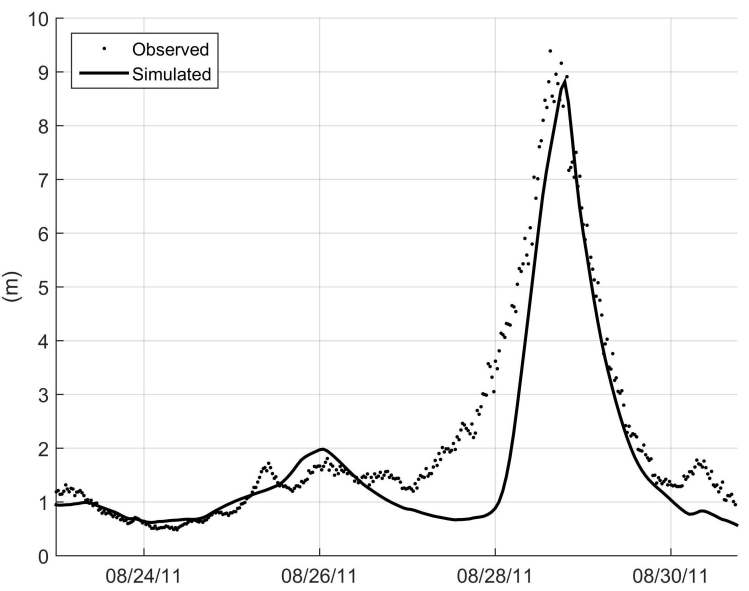

(d)
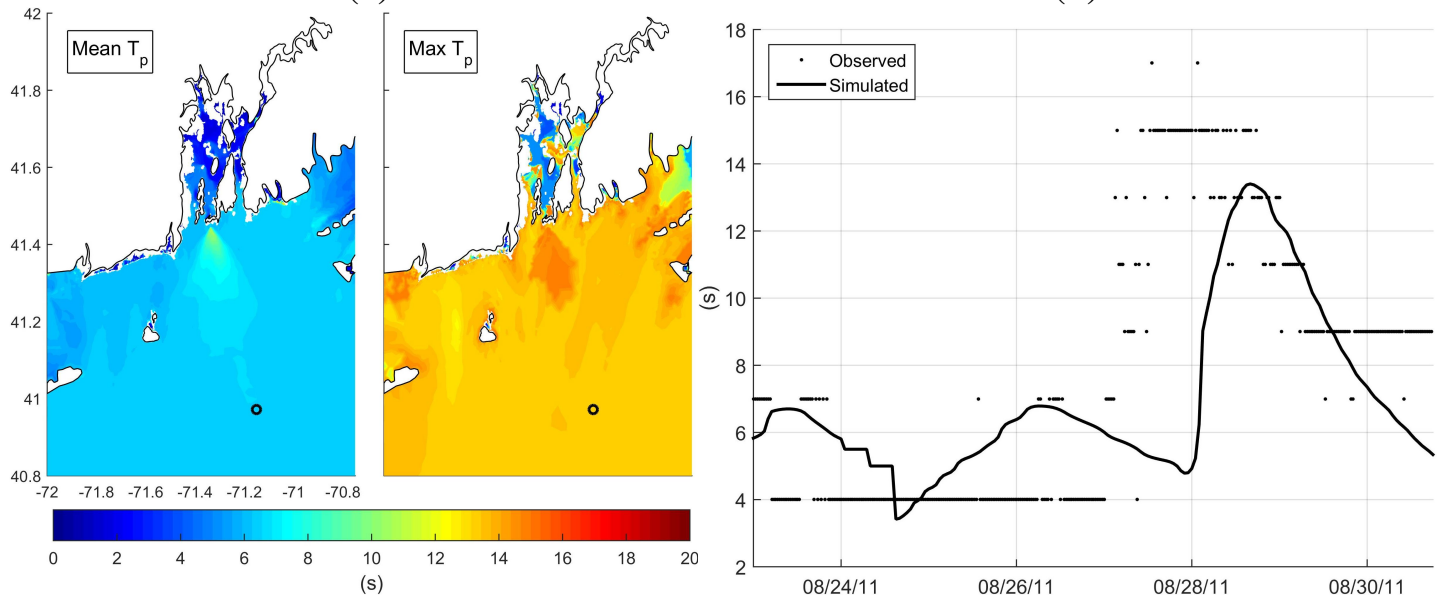

Fig. 1.6. Snapshot of simulated contours focused in Rhode Island and time series comparison with observations during Hurricane Irene; (a) average and maximum significant wave height $H_{s}[\mathrm{~m}]$ compared with (b) observations from NOAA NDBC 44097 (located at black circle); (c) average and maximum peak period $T_{p}$ [sec] compared with (d) observations at the same location. 
the sensitivity analysis of the enhanced bottom friction without incorporating the wave model. It should be noted that in using Eq. 1.7, the representation the sea state (i.e. energy density) is very simplified, which may make this method impractical for hurricane-induced storm surge applications.

The near-bed r.m.s. orbital wave velocity $U_{r m s}$ computed by SWAN (Eq. 1.9) is compared to the $U_{r m s}$ computed analytically from the exponential approximation described by Soulsby (Eq. 1.7; [9]) at a single location offshore. The time series of the surface wave parameters computed by SWAN are used in Eq. 1.7. In comparing the two time series at a single point (Fig. 1.7b), the approximation shows good agreement with the solution from SWAN. From here, the Soulsby (2006) method is concluded to be adequate for calculating the near-bed wave orbital velocity everywhere in the domain. More validation is needed at other locations, however, to confirm this conclusion.

In addition, a snapshot of the average and maximum $U_{r m s}$ is mapped over the domain (Fig. 1.7a) based on Eq. 1.7. Mean velocities between 0.1 and $0.5 \mathrm{~m} / \mathrm{s}$ are seen over the study region with maximum values ranging from 1.1 up to $1.5 \mathrm{~m} / \mathrm{s}$ near land. This estimated range of near-bed wave orbital velocity can further be used in assessing the sensitivity of bottom friction.

\subsection{Results}

The enhancement of the bottom friction is a function of several parameters that describe physical conditions such as the wave climate $\left(H_{s}, T_{p}\right)$, bottom roughness $\left(k_{s}\right)$, water depth $(h)$, wave current velocity $\left(u_{c}\right)$, and near-bed r.m.s. wave orbital velocity $\left(U_{r m s}\right)$. The response of these variables to each other and their influence on bottom friction is investigated for various scenarios. In doing so, the expected amount of enhanced bottom friction for any given water depth, wave climate, and current condition can be estimated. In addition, a sensitivity analysis was carried out to see how the increased friction affects the storm surge in the Rhode Island region. This was initially 
(a)

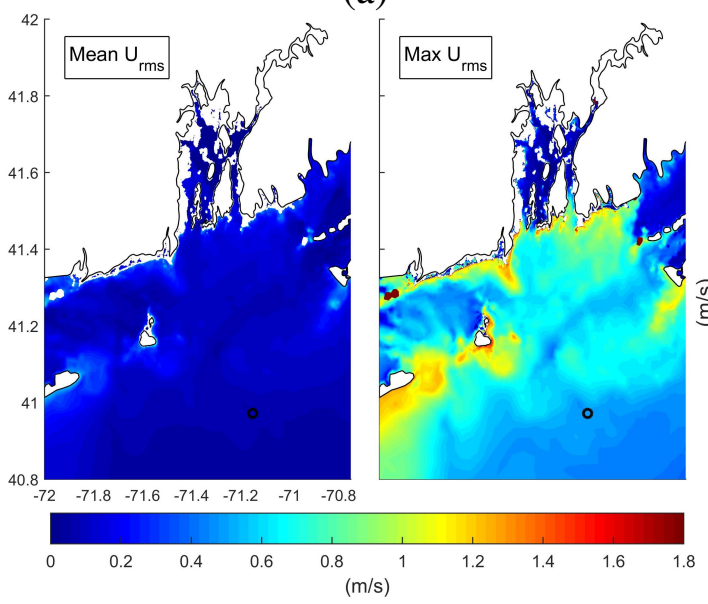

(b)

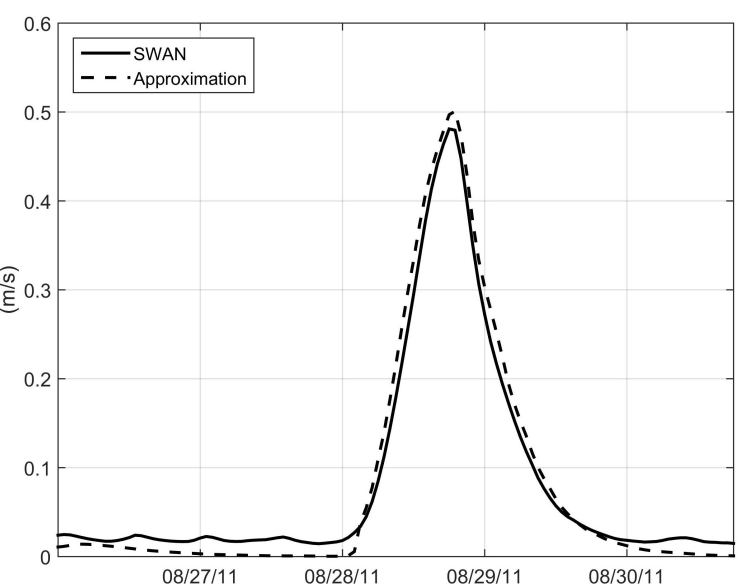

Fig. 1.7. Snapshot of simulated near-bed root-mean-square wave orbital velocity focused in Rhode Island during Hurricane Irene; (a) contours of average and maximum wave orbital velocity $U_{r m s}$ in $\mathrm{m} / \mathrm{s}$, and (b) comparison of simulated (SWAN; Eq. 1.9) and calculated (Soulsby; Eq. 1.7) $U_{r m s}$ at a single location (black circle, $h=54 \mathrm{~m}$ ).

done for the peak of storm (i.e. a snapshot) for Hurricane Irene, and can be extended to unsteady cases in future studies.

\subsubsection{Orbital velocity}

Recall that a range of wave heights and periods based on the wave climate in our region can be applied to the sensitivity of the enhancement of bottom friction via the near-bed r.m.s. orbital velocity. The corresponding near-bed r.m.s wave orbital velocity for variable wave conditions and water depth $(h=0$ to $50 \mathrm{~m})$ is presented in Figure 1.8 based on the Soulsby formulation (Eq. 1.7). Three instances of zero-crossing wave period $\left(T_{z}=6,10,14 \mathrm{~s}\right)$ are explored based on the simulated wave field generated during Hurricane Irene. A simple wave breaking criterion $(H \geq 0.78 h)$ was applied at the shallow water limit [2] for each instance. The near-bed r.m.s. orbital velocity $U_{r m s}$ is shown to increase with increasing wave height and period, and decrease with increasing water depth.

The estimated magnitude of $U_{r m s}$ extends up to $1.8 \mathrm{~m} / \mathrm{s}$ for large wave conditions ( $H_{S}$ between 8 and $10 \mathrm{~m}, T_{z}=14 \mathrm{~s}$ ) in about $10 \mathrm{~m}$ of water depth. While these wave 

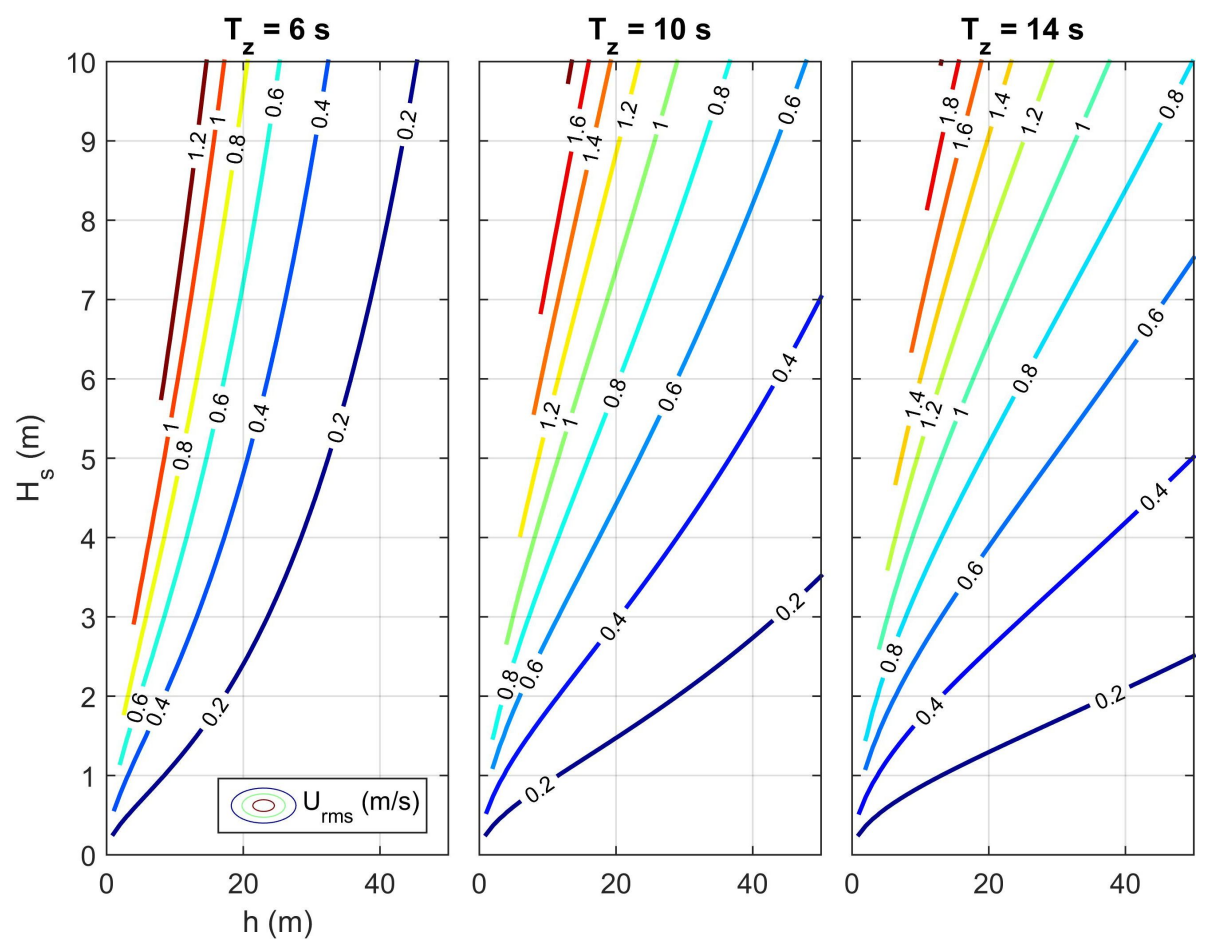

Fig. 1.8. Contour of near-bed root-mean-square wave orbital velocity $U_{r m s}$ (Eq. 1.7) as a function of significant wave height $H_{s}$, zero-crossing period $T_{z}$, and water depth $h$.

conditions are unlikely, it is plausible to experience such magnitudes during a storm event. A study by Wilberg et al. (2008; [10]), in which $U_{r m s}$ was assessed for various wave periods $(T=4,6,8,10,12$, and $14 \mathrm{~s})$ and a constant wave height $(H=1 \mathrm{~m})$, revealed that the bottom wave orbital velocity is more sensitive to wave period for water depths greater than $10 \mathrm{~m}$ compared to those within $10 \mathrm{~m}$ of shore. A similar trend is seen in our analysis (Fig. 1.7), but with slightly higher $U_{r m s}$ values (up to $0.4 \mathrm{~m} / \mathrm{s}$ versus $0.2 \mathrm{~m} / \mathrm{s})$.

\subsubsection{Enhanced bottom friction}

Recall, the major contributors to the magnitude of the enhanced bottom friction $\epsilon$ are the depth-averaged current velocity $u_{c}$ and the near-bed r.m.s. wave orbital velocity $U_{r m s}$ since the corresponding shear stresses are proportional to the square of the respective velocities. In wave-dominated conditions, or similarly in areas of low current, the ratio 

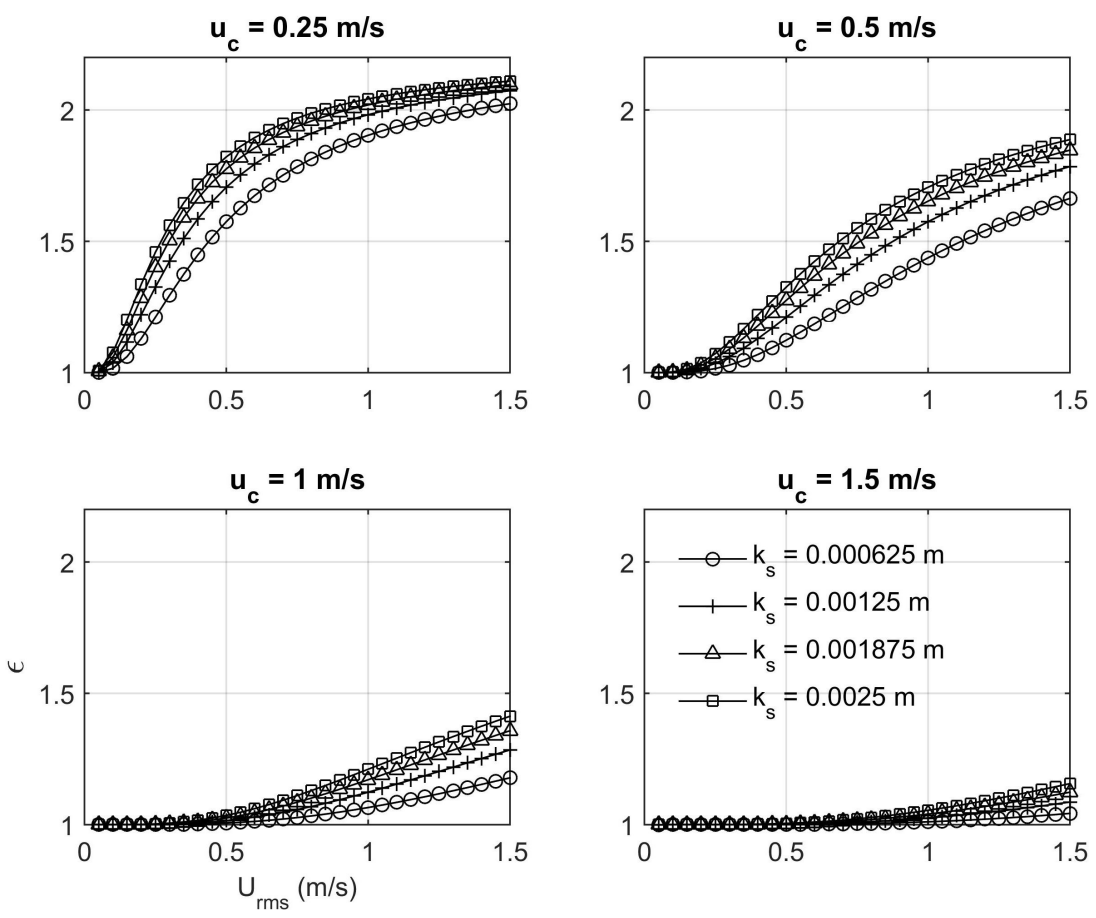

Fig. 1.9. Sensitivity of enhanced bottom drag coefficient $\epsilon$ to current velocity $u_{c}$, nearbed root-mean-square wave orbital velocity $U_{r m s}$, and bottom roughness $k_{s}$.

of the wave- to current-induced shear stress $\lambda$ approaches infinity. Thus the ratio of enhanced to pure-current bottom drag approaches its maximum value of 2.2 (Eq. 1.3). Figure 1.9 displays the anticipated behavior of $\epsilon$ for several bottom roughness cases.

It can be seen that for small current velocity $(0.25 \mathrm{~m} / \mathrm{s}), \epsilon$ quickly approaches its maximum value (2.2) with increasing near-bed r.m.s. wave orbital velocity. For stronger currents $\left(u_{c}=1.5 \mathrm{~m} / \mathrm{s}\right)$, the effect of enhanced bottom friction is less significant (i.e. $\epsilon$ is smaller), and may not be a first order impact for hurricane-induced currents nearshore. Inclusion of $\epsilon$ may be more important for simulating storms that produce large swells (i.e. large orbital velocity). Further, $\epsilon$ is only equal to 1 when $u_{c}$ is greater than $U_{r m s}$, and surpasses 1 even when $u_{c}$ and $U_{r m s}$ are equal. This highlights the increased sensitivity of enhanced bottom friction to wave orbital velocity.

With regards to bottom roughness, enhanced bottom friction is less sensitive at its minimum and maximum (i.e. when $\epsilon$ approaches 1 or 2.2). Otherwise, $\epsilon$ tends to be 
(a)

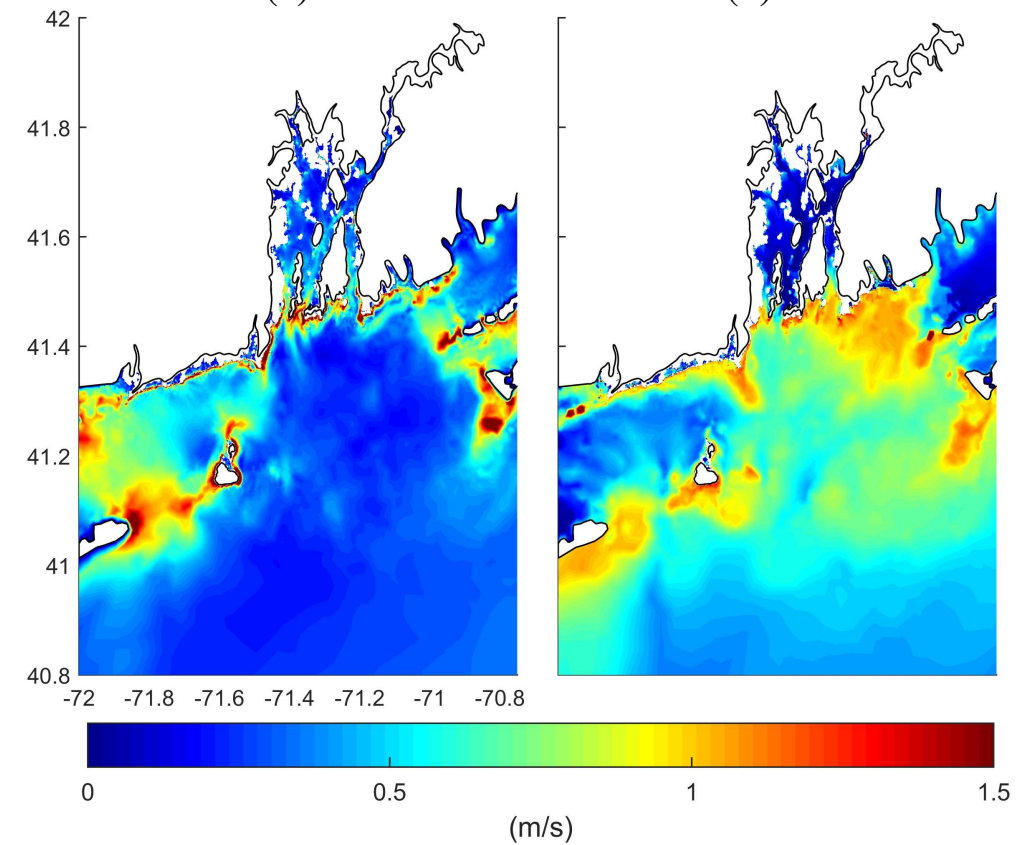

Fig. 1.10. Contours of maximum (a) simulated depth-averaged current velocity $u_{c, \max }$ $[\mathrm{m} / \mathrm{s}]$ and (b) calculated root-mean-square wave orbital velocity $U_{r \operatorname{ss}, \max }[\mathrm{m} / \mathrm{s}]($ Eq. 1.7$)$ for RI study area.

higher for larger grain size diameters by up to 0.27 . Therefore, regions with gravelly sediment $\left(d_{50}=1.0 \mathrm{~mm}\right.$ or $\left.k_{s}=0.0025 \mathrm{~m}\right)$ and relatively equal current to wave orbital velocity are subject to greater enhancements in bottom friction than in sandy regions.

\subsubsection{Case study: sensitivity of storm surge to enhanced bottom friction}

The enhancement of bottom friction is applied over the entire computational domain for the peak of the storm under maximum wave, current, and near-bed r.m.s. wave orbital velocity conditions with a constant bottom roughness. The depth-averaged current velocity $u_{c}$ (Fig. $1.10 \mathrm{a}$ ) is shown to reach a maximum value of $1.5 \mathrm{~m} / \mathrm{s}$ near the coastline and around islands. Other studies have reported the magnitude of tidal current velocity in the study area in recent years (see $[20,27,28]$ ). However, the focus of this study is in using hurricane-induced current velocity, where maximum values are expected to surpass those due to tides alone. 


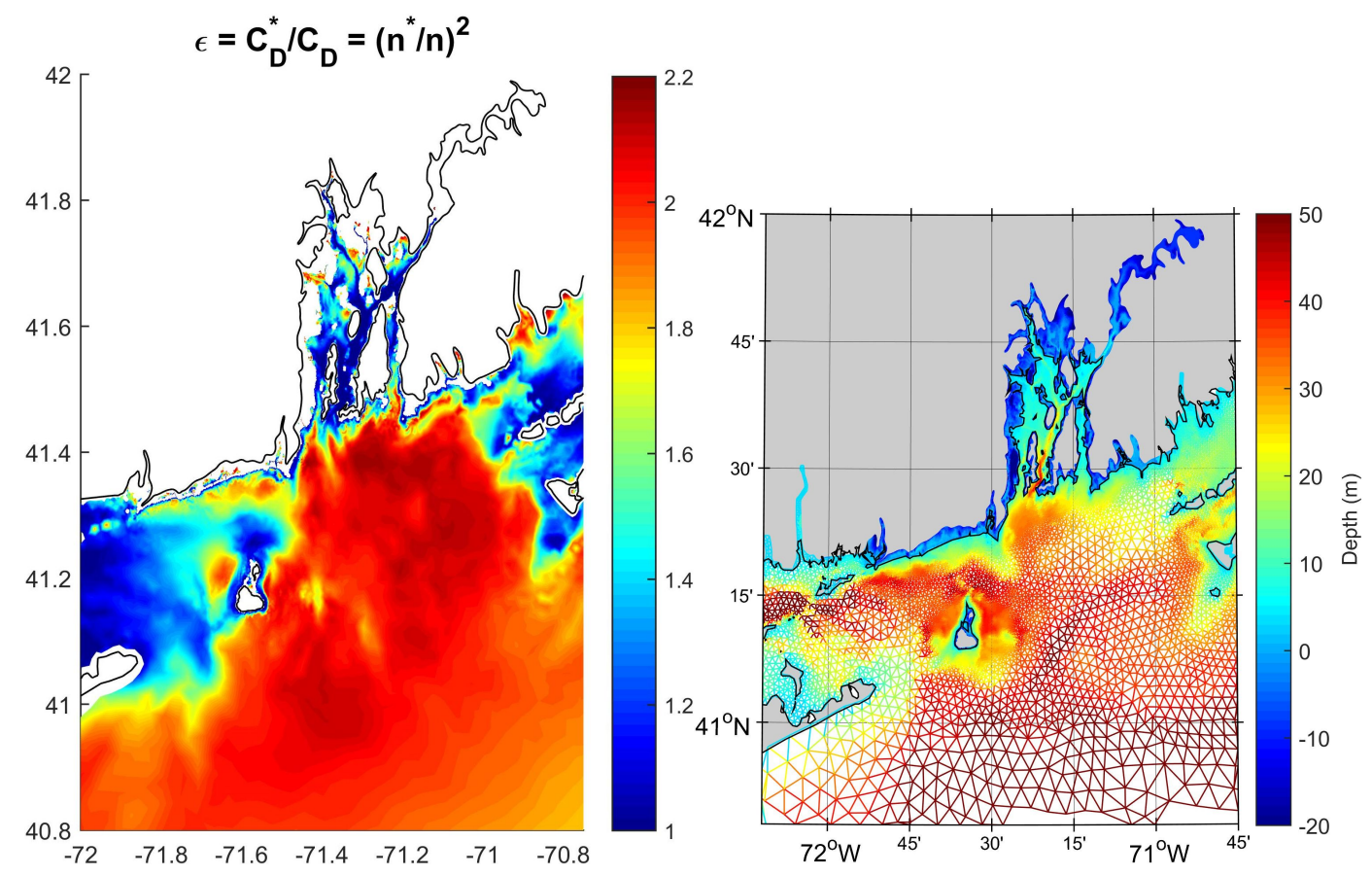

Fig. 1.11. Contour of estimated ratio of enhanced bottom friction to original bottom friction $\epsilon$ in the presence of combined waves and currents for RI study area (left); contour of water depths in RI region from Fig. 1.5b for reference (right).

The calculated maximum near-bed r.m.s. wave orbital velocity (Eq. 1.7) in the region is between 1 and $1.5 \mathrm{~m} / \mathrm{s}$ in areas near land, and between 0.5 and $1 \mathrm{~m} / \mathrm{s}$ farther offshore. Elfrink et al. (2006; [11]) also simulated r.m.s. wave orbital velocity up to $2 \mathrm{~m} / \mathrm{s}$ that agreed with observed values for a nearshore region $(h=4.7 \mathrm{~m})$ in the Netherlands. Further, You (2009; [12]) measured r.m.s. wave orbital velocity up to $1 \mathrm{~m} / \mathrm{s}$ in $23 \mathrm{~m}$ water depth in New South Wales, Australia. It is understood that the near-bed r.m.s. orbital velocities are a function of wave climate and corresponding wave spectrum of a given region, and therefore values of $U_{r m s}$ from areas of differing wave climates cannot be directly compared. Here, we are merely comparing the magnitude of $U_{r m s}$ noted in the literature to justify a reasonable range of values to apply to this study.

The enhanced bottom drag $\epsilon$ is estimated from the snapshots of maximum current velocity and maximum wave height and period (or wave orbital velocity). Preliminary results in Figure 1.11 show that in areas of low wave orbital velocity and higher currents 
(near shore), there is no enhancement of bottom friction. The inverse is observed in areas of low current velocity (farther offshore). The depth contours of the Rhode Island area (Fig. 1.5b) is shown again here to better observe the enhanced bottom drag coefficient with respect to water depth. Taking a closer look at the RI southern shore, moderate enhancement (1.5 up to 2.0 times increase of friction) is observed a few hundred meters from the immediate coastline, which is expected in a shoaling region. However, this effect can be better represented under temporally varying velocity and spatially varying bottom roughness conditions, which is not considered in this study.

The enhanced Manning's $n *$ quadratic friction coefficient is applied in the coupled ADCIRC+SWAN model for Hurricane Irene. Relatively no significant change in maximum water elevation is observed between the original simulation (Fig. 1.12a) and the simulation which is based on the enhanced bottom friction (Fig. 1.12b) in RI. Taking the difference in elevation between $1.12 \mathrm{~b}$ and $1.12 \mathrm{a}$ reveals that the original simulation predicts higher storm surge near the coastline and in Narragansett Bay (Fig. 1.12c), as expected due to increased friction. In other words, inclusion of this effect leads to slightly less storm surge (i.e. less conservative) near shore.

\subsection{Discussion}

Recall that the estimation of the enhanced bottom friction was based on an analytical expression of the near-bed r.m.s. orbital velocity and empirical formulation of the mean bed shear stress in the presence of combined waves and currents for a single point in time. The current methodology includes the exponential approximation for spectral waves proposed by Soulsby (2006; [9]), which implements the significant wave height and zero-crossing period of a representative JONSWAP spectrum to the bottom velocity spectrum. This spectrum is based on a North sea study which does not have hurricanes.

The influence of waves on local bottom friction can be further assessed by considering other formulations of near-bed r.m.s. orbital velocity, specifically those that consider 


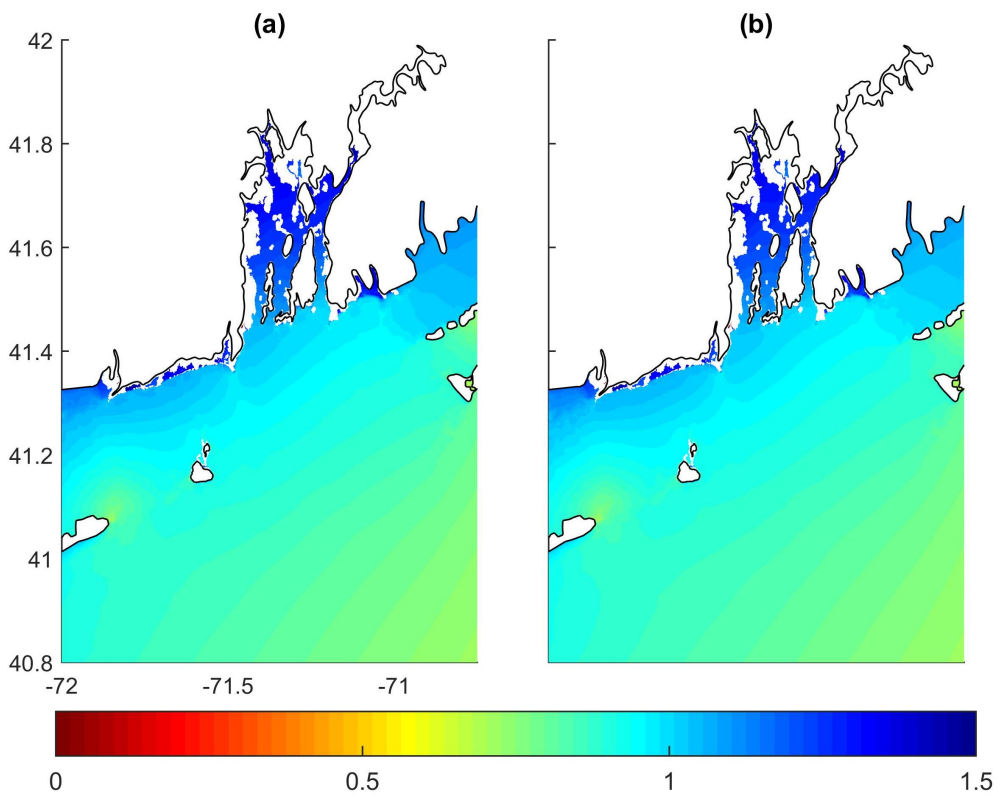

(m)

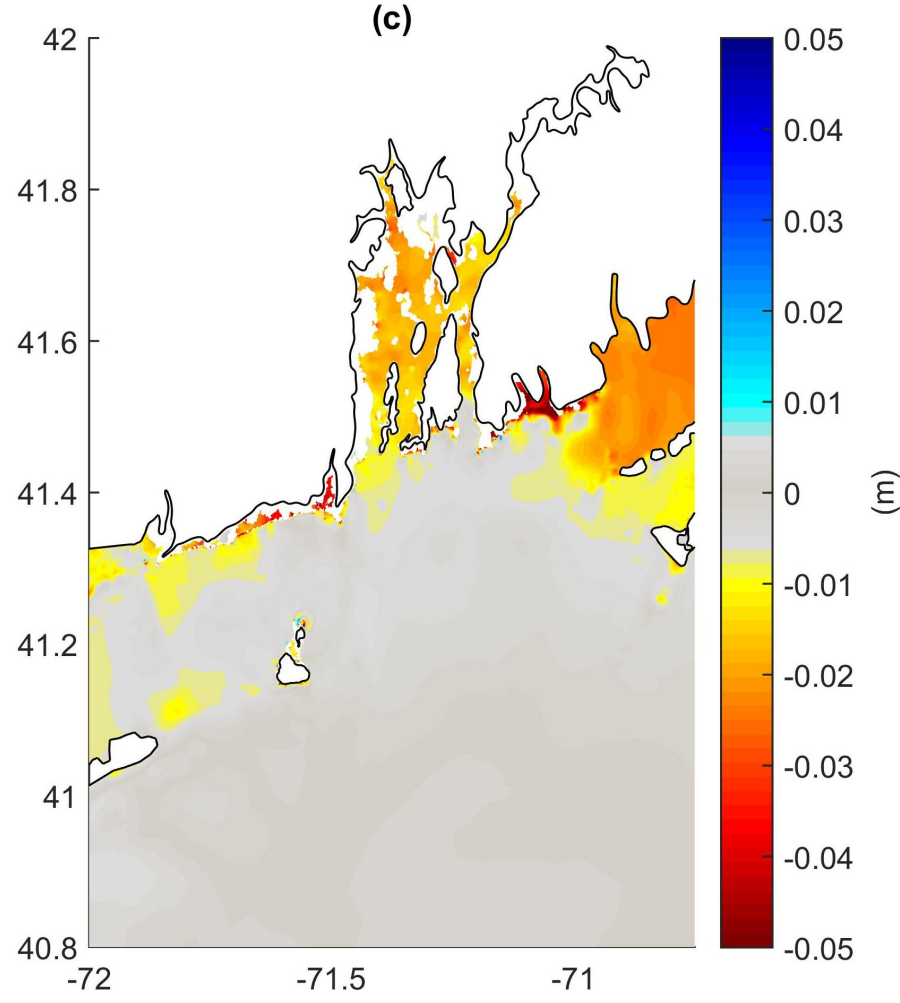

Fig. 1.12. Maximum water elevation for Hurricane Irene in RI without (a) and with (b) enhanced bottom friction; (c) shows water elevation of (b)-(a); areas of no change are gray for emphasis. 
irregular waves, such as solutions discussed in Wilberg (2008; [10]) and Elfrink (2006; [11]). In practice, this process can be automated in the coupled ADCIRC+SWAN model by changing the source code to extract near-bed orbital velocities and apply the bottom friction formulation at each time step.

The variability of near-bed r.m.s. orbital velocity and current velocity with water depth is of particular interest, as the orbital velocity controls how much the bottom friction is enhanced in a given area. To highlight this relationship in our region, a transect of water depth, orbital velocity, current velocity, and enhanced bottom drag coefficient are taken from the domain during the peak of Hurricane Irene (Fig. 1.13a,b). The water depths considered in this study (up to $30 \mathrm{~m}$ in Rhode Island) can be considered relatively deep or intermediate water. In this region, small tidal currents are felt near the sea floor $\left(u_{c} \approx 0.2 \mathrm{~m} / \mathrm{s}\right)$, but the effect of waves (i.e. orbital velocities) has a greater presence over larger water depths, causing the bottom friction to increase significantly (Fig. 1.13b) with not much affect on the storm surge (Fig. 1.12c). In very deep water (e.g. > $150 \mathrm{~m}$ ), this is not the case because waves do not generally penetrate to near-bed, save for times of long period waves. In shallow water near shore, current velocities are greater than in deep water, which reduces the amount of enhanced bottom friction; however, storm surge is impacted in these regions (Fig. 1.12c).

The wave-current interaction studies discussed by Huang et al (2010; [6]) and Sun et al. (2013; [7]) incorporate the 3D FVCOM-SWAVE coupled model. In the 3D coupled model, radiation stresses are included in the momentum equations to define wave-driven motions. Also in some 3D models, the bottom-boundary layer could be resolved, which means that enhanced bottom friction could be explicitly included. The use of ADCIRC 3DL (three-dimensional, local) and other 3D models is suggested for assessing nearbed interactions between waves and currents, as well as turbulent mixing of the water column. Accordingly, while using 2D models, the wave-current interaction processes 
(a)

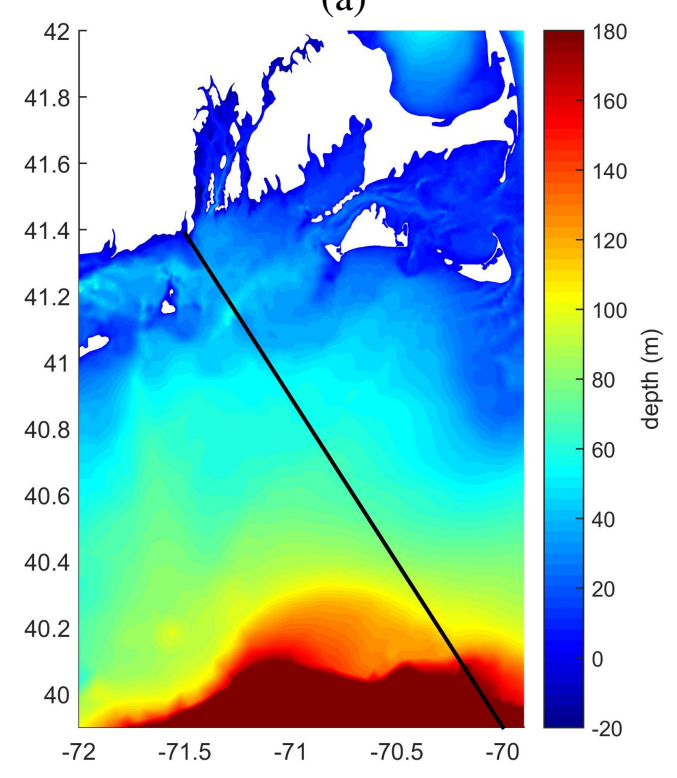

(b)
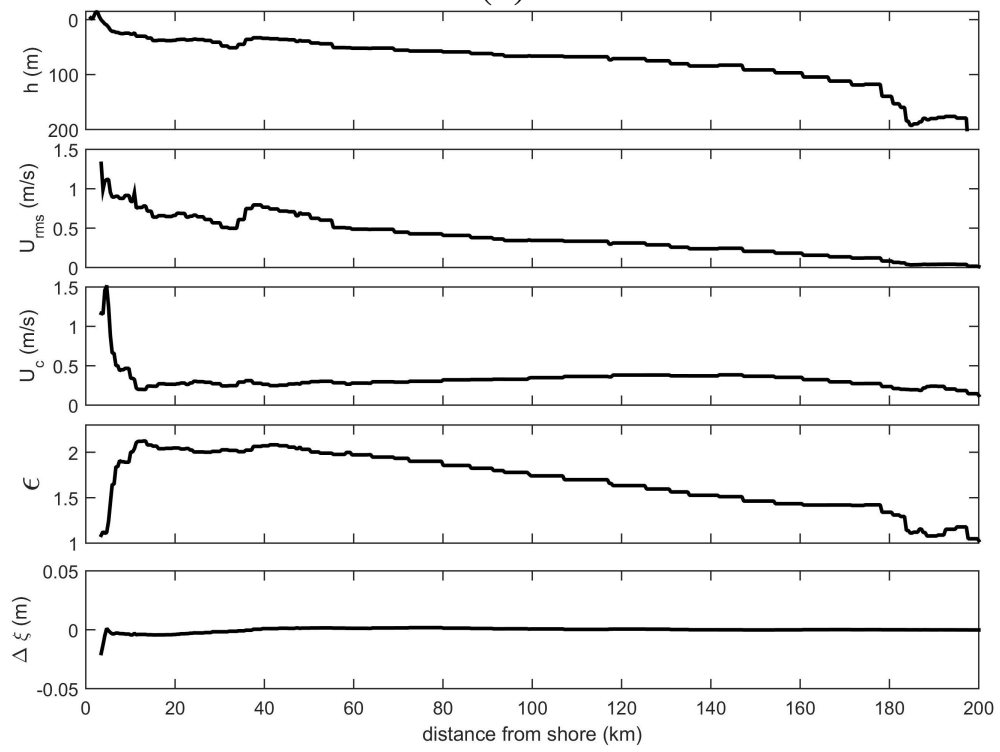

Fig. 1.13. Transect of bathymetry, root-mean-square orbital velocity, current velocity, ratio of bottom drag coefficient $\epsilon$, and difference in water elevation between the enhanced and original simulation $\Delta \xi$ during the peak of Hurricane Irene; (a) transect line over bathymetry contour and (b) water depth, orbital and current velocities, and $\epsilon$ as a function of distance from beginning of transect line. 
can be parameterized for the sake of computational cost.

\subsection{Conclusion}

Waves interact with the bottom boundary layer and increase the apparent roughness felt by ocean currents. Therefore, they can potentially change the storm surge. A sensitivity analysis was carried out to examine how the bottom friction felt by currents (or storm surge) is affected by waves for a set of current and bottom roughness characteristics in Rhode Island coastal waters.

The interaction between waves and currents are partially incorporated in the coupled ADCIRC+SWAN model (e.g. radiation stress gradients are implemented in the momentum equations), but effects of waves on increased bottom friction are neglected. The near-bed turbulent shear stresses in the presence of both waves and currents is most important for sediment transport applications. However, the contributions of enhanced bottom friction to storm surge prediction is of particular interest in this study.

The sensitivity of storm surge prediction to the inclusion of enhanced bottom friction was assessed. Depth-averaged current velocities were extracted at each grid point from ADCIRC, and the root-mean-square wave orbital velocities were computed by SWAN at each grid point. A constant sandy bottom $\left(d_{50}=0.5 \mathrm{~mm}\right)$ is assumed in the region based on a USGS study [29]. The enhancement of the bottom drag coefficient is calculated based on a formulation proposed by Soulsby (1993), using current- and wave-induced bed shear stresses, and converted to an enhanced Manning's $n^{*}$ quadratic friction coefficient for implementation in the coupled model. The sensitivity of storm surge to the enhanced bottom friction was then assessed in Rhode Island for Hurricane Irene (2011).

As water depth increased, the r.m.s. orbital velocity is seen to decrease. However, the orbital velocity is also seen to increase for longer period waves (e.g. $14 \mathrm{~s}$ ), more significantly in deeper water $(<20 \mathrm{~m})$. In wave-dominate conditions, or similarly in areas of low current, the ratio of the wave- to current-induced shear stress approaches infinity. 
Thus the ratio of enhanced to pure current bottom friction approaches its maximum value (2.2). Therefore, an area with a strong wave climate and weak currents will experience significant increases in friction.

Prior to applying the enhanced bottom friction to the coupled model, an initial simulation of Hurricane Irene is performed with default Manning coefficient (0.02). The simulated depth-average current velocity during the peak of the storm is greatest $(1.5$ $\mathrm{m} / \mathrm{s}$ ) in regions of water depths less than $15 \mathrm{~m}$. On the other hand, the calculated rootmean-square orbital velocity is shown to be $1.4 \mathrm{~m} / \mathrm{s}$ in areas between 5 and $15 \mathrm{~m}$ and up to $0.8 \mathrm{~m} / \mathrm{s}$ in water depths up to $50 \mathrm{~m}$, which influences the enhancement of bottom friction to be maximum (2.2) in deeper water $(h=30-50 \mathrm{~m})$.

The impact on the bottom friction is greater in regions of low currents (offshore and open areas), while the impact on the surge is more nearshore and in enclosed areas. The variation in maximum water elevation between the enhanced and initial simulation reveals no significant change over the domain, particularly offshore. The net difference of storm surge towards the initial simulation is observed in Narragansett Bay and along the southern shore between 0 and $0.05 \mathrm{~m}$, which is very small.

The results and conclusions discussed in this research are preliminary. Further study includes examining other methods of computing wave orbital velocity, utilizing a three-dimensional circulation model such as ADCIRC 3DL, and comparing with the 2D case. In addition, this research performed a sensitivity analysis assuming only the peak of the storm while time varying bottom friction may lead to different results. Nevertheless, it is expected that the enhanced bottom friction will reduce hurricane-induced storm surge predictions nearshore, leading to less conservative estimates, though this may be more realistic and may lead to better model validations. 


\section{List of References}

[1] R. L. Soulsby, L. Hamm, G. Klopman, D. Myrhaug, R. R. Simmons, and G. P. Thomas, "Wave-current interaction within and outside the bottom boundary layer," Coastal Engineering, vol. 21, pp. 41-69, 1993.

[2] R. L. Soulsby, Dynamics of marine sands. Thomas Telford Publications, 1997.

[3] A. Davies, R. Soulsby, and H. King, "A numerical model of the combined wave and current bottom boundary layer," Journal of Geophysical Research, vol. 93, no. C1, pp. 491-508, 1988.

[4] R. Luettich, J. Westerink, and N. Scheffner, "ADCIRC: an Advanced ThreeDimensional Circulation Model for Shelves, Coasts, and Estuaries, Report 1: Theory and Methodology of ADCIRC-2DDI and ADCIRC03DL," U.S. Army Engineers Waterways Experiment Station, Tech. Rep. Dredging Research Program Technical Report DRP-92-6, 1992.

[5] N. Booij, R. Ris, and L. Holthuijsen, "A third-generation wave model for coastal regions, Part 1, model description and validation," Journal of Geophysical Research, vol. 104, pp. 7649-7666, 1999.

[6] Y. Huang, R. H. Weisberg, and L. Zheng, "Coupling of surge and waves for Ivanlike hurricane impacting the Tampa Bay, Florida region," Journal of Geophysical Research, vol. 115, no. C12009, 2010.

[7] Y. Sun, C. Chen, R. C. Beardsley, Q. Xu, J. Qi, and H. Lin, "Impact of current-wave interactions on storm surge simulation: A case study for Hurricane Bob," Journal of Geophysical Research: Oceans, vol. 118, pp. 2685-2701, 2013.

[8] R. L. Soulsby, "Calculating bottom orbital velocity beneath waves," Coastal Engineering, vol. 11, pp. 371-380, 1987.

[9] R. Soulsby, "Simplified calculation of wave orbital velocities," HR Wallingford, Tech. Rep. 155, 2006.

[10] P. L. Wilberg and C. R. Sherwood, "Calculation wave-generated bottom orbital velocities from surface-wave parameters," Computers \& Geosciences, vol. 34, pp. 1243-1262, 2008.

[11] B. Elfrink, D. M. Hanes, and B. G. Ruessink, "Parameterization and simulation of near bed orbital velocities under irregular waves in shallow water," Coastal Engineering, vol. 34, pp. 915-927, 2006.

[12] Z.-J. You, "The statistical distribution of nearbed wave orbital velocity in intermediate coastal water depth," Coastal Engineering, vol. 56, pp. 844-852, 2009. 
[13] P. Rosales, F. J. Ocampo-Torres, P. Osuna, J. Monbaliu, and R. Padilla-Hernández, "Wave-current interaction in coastal waters: Effects on the bottom-shear stress," Journal of Marine Systems, vol. 71, pp. 131-148, 2008.

[14] L. Bing-chen and L. Hua-jun, "Bottom shear stress under wave-current interaction," Journal of Hydrodynamics, vol. 20, no. 1, pp. 88-95, 2007.

[15] W. D. Grant and O. S. Madsen, "Combined wave and current interaction with a rough bottom," Journal of Geophysical Research, vol. 84, no. C4, pp. 1797-1808, 1979 .

[16] L. V. Rijn", "Unified view of sediment transport by currents and waves. I: initiation of motion, bed roughness, and bed-load transport," Journal of Hydraulic Engineering, vol. 133, pp. 649-667, 2007.

[17] M. R. Hashemi, S. P. Niel, P. E. Robins, A. G. Davies, and M. J. Lewis, "Effect of waves on the tidal energy resource at a planned tidal stream array," Renewable Energy, vol. 75, pp. 626-639, 2015.

[18] United States Army Corps of Engineering; Coastal Engineering Research Center, Coastal Engineering Manual, 2002.

[19] Woods Hole Group, Wave, Tide and Current Data Collection Contract No. W912WJ-09-D-0001-0026, 2012, US Army Corps of Engineers: New England District, MA, USA.

[20] Q. Lui, "Dynamics of Rhode Island Coastal Waters," 2015, PhD Thesis Dissertation.

[21] SWAN Team, "SWAN Technical Documentation," Delft University of Technology, the Netherlands, Tech. Rep. Cycle III version 40.51, 2006.

[22] J. Dietrich, M. Zijlema, J. Westerink, L. Holthuijsen, C. Dawson, and R. Luettich, "Modeling hurricane waves and storm surge using integrally-coupled scalable computations," Coastal Engineering, vol. 58, pp. 45-65, 2011.

[23] C. Chen, R. C. Beardsley, and G. Cowles, "An unstructured grid, finite-volume coastal ocean model (FVCOM) system," Oceanography, vol. 19, no. 1, pp. 78-89, 2006.

[24] L. A. Avila and J. Cangialosi, “Tropical Cyclone Report Hurricane Irene,” National Hurricane Center, Tech. Rep., 2011.

[25] M. J. Torres, M. R. Hashemi, S. Hayward, M. Spaulding, I. Ginis, and S. Grilli, "The Role of Hurricane Wind Models in the Accurate Simulation of Storm Surge and Waves," ASCE Journal of Waterway, Port, Coastal and Ocean Engineering Online Collection, vol. in review, 2017. 
[26] M. Tomassini, D. LeMeur, and R. W. Saunders, "Near-Surface Satellite Wind Observations of Hurricanes and Their Impact on ECMWF Model Analyses and Forecasts," Monthly Weather Review, vol. 126, no. 5, pp. 1274-1286, 1998.

[27] L. Zhao, C. Chen, and G. Cowles, "Tidal flushing and eddy shedding in Mount Hope Bay and Narragansett Bay: An applicaiton of FVCOM,' Journal of Geophysical Research, vol. 111, 2006.

[28] S. Grilli, J. Harris, R. Sharma, L. Decker, D. Stuebe, D. Mendelsohn, D. Crowly, and S. Decker, "High resolution modeling of meteorological, hydrodynamic, wave and sediment processes in the Rhode Island Ocean SAMP study area," Ocean Special Area Management Plan, Tech. Rep. 6, 2010.

[29] L. Poppe, V. Paskevich, S. Williams, M. Hastings, J. Kelley, D. Belknap, L. Ward, D. FitzGerald, and P. Larsen, "Surficial Sediment Data from the Gulf of Maine, Georges Bank, and Vicinity: A GIS Compilation," U.S. Geological Survey, Tech. Rep. OFR03-001, 2003. 


\section{MANUSCRIPT 2}

\section{The role of hurricane wind models in accurate simulation of storm surge and waves}

\subsection{Introduction}

Tropical cyclones pose a risk to coastal communities around the globe. In the western North Pacific, typhoons plague the Philippines, China and Japan during the peak season (August to October), leaving residents inundated from combined rain and storm surge. More commonly known as hurricanes in the United States, these storm events have caused an annual average of \$10 billion in damage between 1900 and 2005, the costliest of which (\$81 billion) being Hurricane Katrina in 2005 [1]. New England is not a frequent location for land-falling hurricanes, though it has weathered its share of storms over the past several decades. However, the storms that have made landfall in New England since the 1900s have caused moderate to severe damage, the most notable of which being the Great Hurricane of 1938 that came without warning and produced in excess of 4 meter storm surge in some areas [2], in part due to its large displacement speed and track to the west of the state. Accordingly, even storms with tracks farther away from the coast can lead to significant damage, such as the most recent Hurricane Sandy in 2012, which led to major economic loss in this region [3].

Climate scientists have been studying the frequency and intensity of hurricanes over time and space, and have developed global and regional climate models to better predict the characteristics of future hurricanes. In parallel, similar efforts have been

made, by ocean scientists/engineers, to predict storm surge and waves generated by these storms. The primary model used by the National Weather Service for predicting storm surge due to hurricanes is the "Sea, Lake, and Overland Surges from Hurricanes" (SLOSH) model [4]. On a local scale, SLOSH's curvilinear grid does not resolve complex coastal geometry. A popular tool for numerical simulation of storm surge is the 
"ADvanced CIRCulation" (ADCIRC) model, which solves the problem over a flexible, unstructured, computational domain [5]. In terms of wave generation during hurricanes, the "Simulating WAves Nearshore" (SWAN) model is a popular spectral wave model that solves the spectral action balance equation, usually coupled with ADCIRC as will be done in this study [6]. With regard to wind forcing of tropical storms, ADCIRC has a wide range of options, including the Holland (1980; [7]) parametric wind model to compute wind velocities at each node, or using actual wind field data (wind velocity and surface pressure) over a regular grid, from which ADCIRC can interpolate this forcing onto its domain.

Models for accurately predicting storm surge and waves require reliable wind data for hindcast/forecast purposes. Hurricane wind information is available from the National Hurricane Center "HURricane DATabase" (HURDAT) (www.nhc.noaa.gov), and the "Extended Best Track" (EBT) database (rammb.cira.colostate.edu/) based on HURDAT. The HURDAT and EBT databases provide hurricane track, intensity and structure information, and can be converted to a wind field via a parametric wind model such as that of Holland [7]. In practice, the modified "Dynamic Holland Model" (DHM) better captures the surface level winds for developing hurricanes [8]. Alternately, global numerical weather hindcast/forecast models such as "European Center for Medium-Range Weather Forecasts" (ECMWF; www.ecmwf.int) that provide meteorological hindcast/forecast data with temporal resolution of 3 hours and spatial resolution of $1 / 8^{\circ}(\sim 9 \mathrm{~km})$, can be used for wind forcing. The current ECMWF monthly wind database cannot fully represent the center of a tropical cyclone as it doesn't include a synthetic vortex in the analysis, causing an underestimation of minimum sea level pressure and maximum wind speed in the storm center [9]; on the other hand, the DHM only includes the winds resulting from the hurricane, and not those due to background meteorological conditions. The Northeast Coastal Ocean Forecasting System (NECOFS) is an atmosphere-ocean model 
covering the northeast U.S. coastal region comprised of meteorological input from the "Weather Research and Forecasting" (WRF) model over an unstructured "Finite-Volume Community Ocean Model" (FVCOM) mesh with hourly forecast fields of surface winds, air pressure, sea level, and wave heights (fvcom.smast.umassd.edu/necofs), and is an alternate source for tropical storm wind forcing. FVCOM incorporates both fluid motion (e.g. water elevation and current) and waves (variation of SWAN; [10]) in 3D, and is primarily used for hindcast/forecasting purposes in New England. NECOFS contains several FVCOM unstructured meshes of varying resolutions from global to regional to local scales.

The sensitivity of storm surge models to wind forcing has been studied in earlier work. Houston et al. (1999; [11]) evaluated the statistical differences between the "Hurricane Research Division" (HRD) surface winds and those computed by the parametric wind model used in SLOSH, for several hurricanes including Hurricane Bob (1991), and concluded that storm surge computations could be improved by using real-time wind observations in the parametric wind model. Dietrich et al. (2015; [12]) discussed the performance of WRF compared to the "Generalized Asymmetric Holland Model" (GAHM) for Hurricane Isaac (2012) in the Gulf of Mexico, and concluded that WRF forcing produced a better match to pressure, wind speed, and water level observations. Following Hurricane Sandy (2012), Bennett and Mulligan (2017; [13]) investigated the spatial and temporal distribution of bulk wave parameters simulated using three wind fields (2D Holland, 2D GAHM, and 3D WeatherFlow Regional Atmospheric Modelling System, WRAMS), and determined that a regional atmospheric wind model with the most accurate wind field description is best for hurricane hindcast simulations. Cardone and Cox (2009; [14]) addressed the concern of surface wind measurement practice and explored the surge sensitivity to dynamic, kinematic, and blended wind fields, for Hurricane Katrina (2005) in the Gulf of Mexico; they concluded that real-time wind fields 
generated from warning center advisories had an uncertainty of up to about $20 \%$ in the inner core surface wind speed.

In this work, we investigate the accurate prediction of storm surge and waves from three wind models - EBT DHM, ECMWF and NECOFS WRF - in New England, particularly in the coastal waters of Rhode Island, which have experienced severe coastal flooding during past hurricanes. We first introduce the study region and sources of observational/hindcast data at offshore and near shore locations, as well as the numerical models used. We then discuss details of the wind models and their implementation in the coupled ADCIRC+SWAN modeling system. Finally, we compare the wind, wave, and surge predictions against observed data for the three wind models and several hurricanes. Conclusions are provided at the end.

\subsection{Methods}

\subsubsection{Study area}

In the past century, Rhode Island has been impacted by five significant storm events, all hurricanes; Table 2.1 lists these hurricanes which were selected as their extreme water levels surpassed the 10-year exceedance probability from NOAA (tidesandcurrents.noaa.gov). Of these five storms, Hurricane Bob was the only one to make landfall not once, but twice in RI, causing considerable coastal flooding along the southern shore and up Narragansett Bay in Providence, RI. Hurricane Irene (2011) is of particular interest given the fact that wind, wave, and water level gauges and stations had been temporarily deployed nearshore in RI at the time; this is further discussed in the following Data Section (Fig. 2.1). Hurricane Bob was also selected in this study due to its significance in RI history, and Hurricane Sandy because it caused the most recent impacts along the southern shore of RI, leading to significant damage and destruction.

The computational domain used in this study was based on the NECOFS FVCOM model for the Gulf of Maine, Version 4 (GOM4) mesh, developed by Univer- 
Table 2.1. Extreme water levels recorded in Newport, RI for significant storm surge events (tidesandcurrents.noaa.gov).

\begin{tabular}{ll}
\hline \hline \multicolumn{1}{c}{ Storm Event } & Water Level (m, msl) \\
\hline Great Hurricane of 1938 & 3.6 \\
Great Atlantic Hurricane (1944) & 1.9 \\
Hurricane Carol (1954) & 2.7 \\
Hurricane Bob (1991) & 1.9 \\
Hurricane Irene (2011) & 1.4 \\
Hurricane Sandy (2012) & 2.0 \\
\hline \hline
\end{tabular}

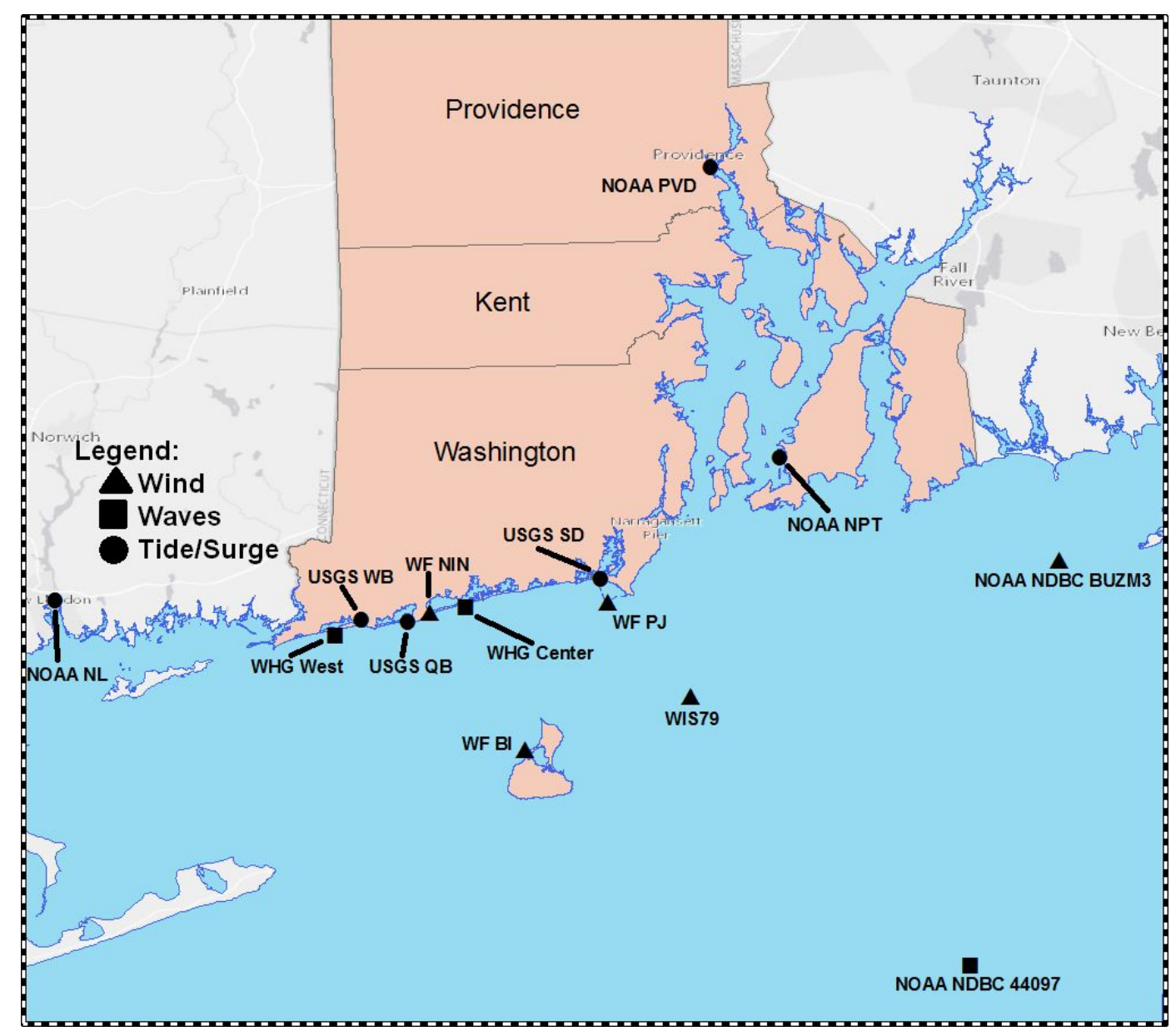

Fig. 2.1. Study area including locations of wind, wave, and surge observations/hindcast stations; note most coastal stations along southern RI coastline are only available for Hurricane Irene; see Appendix for list of abbreviations. 
sity of Massachusetts-Dartmouth Marine Ecosystem Dynamics Modeling Laboratory (MEDML; [15]). The original FVCOM GOM4 mesh has 53,087 nodes with a resolution of $1 \mathrm{~km}$ along the Rhode Island coastline. An unstructured ADCIRC mesh with 27,439 nodes was created for RI, with a resolution up to $200 \mathrm{~m}$ at the coast and $20 \mathrm{~m}$ within inlets and rivers. In order to preserve the domain extent for hurricane hindcast purposes and to provide enough discretization in the study area, the RI mesh was merged with the FVCOM GOM4 mesh, leading to a total 105,560 nodes. Figure 2.2 displays the combined mesh for New England and the higher resolution mesh for RI with corresponding bathymetry of the region.

\subsubsection{Details of the Selected Hurricanes}

Hurricane Bob (1991) developed from an area of low pressure near the Bahamas on August 16, 1991. The storm's partial track is shown in Figure 2.3(a); the full track can be found on the NHC website (www.nhc.noaa.gov/archive). By August 19, the storm intensified to a Category 3 (Saffir-Simpson scale) hurricane with maximum sustained winds of $51.4 \mathrm{~m} / \mathrm{s}$ (115 mph), and made landfall in RI - once on Block Island and again in Newport. The peak storm surge was recorded as 1.8 and $2.4 \mathrm{~m}$ above mean sea level in Newport and Providence, respectively.

Hurricane Irene (2011) formed from a tropical wave that exited the African coast on August 15, 2011, and was strengthened by favorable environmental conditions, leading to a destructive landfall in North Carolina as a strong Category 1 hurricane [16]. The storm continued to travel northward along the U.S. east coast to the west of Rhode Island (Fig. 2.3(b)). RI experienced severe wind gusts that left much of the state without power for several days, and mild flooding in Narragansett Bay due to storm surge. Hurricane Irene was the first major storm to impact Rhode Island since Hurricane Bob in 1991.

Hurricane Sandy (2012) matured from a tropical wave that exited the African coast on October 11, 2012, making landfall in Jamaica as a Category 1 hurricane and 
(a)

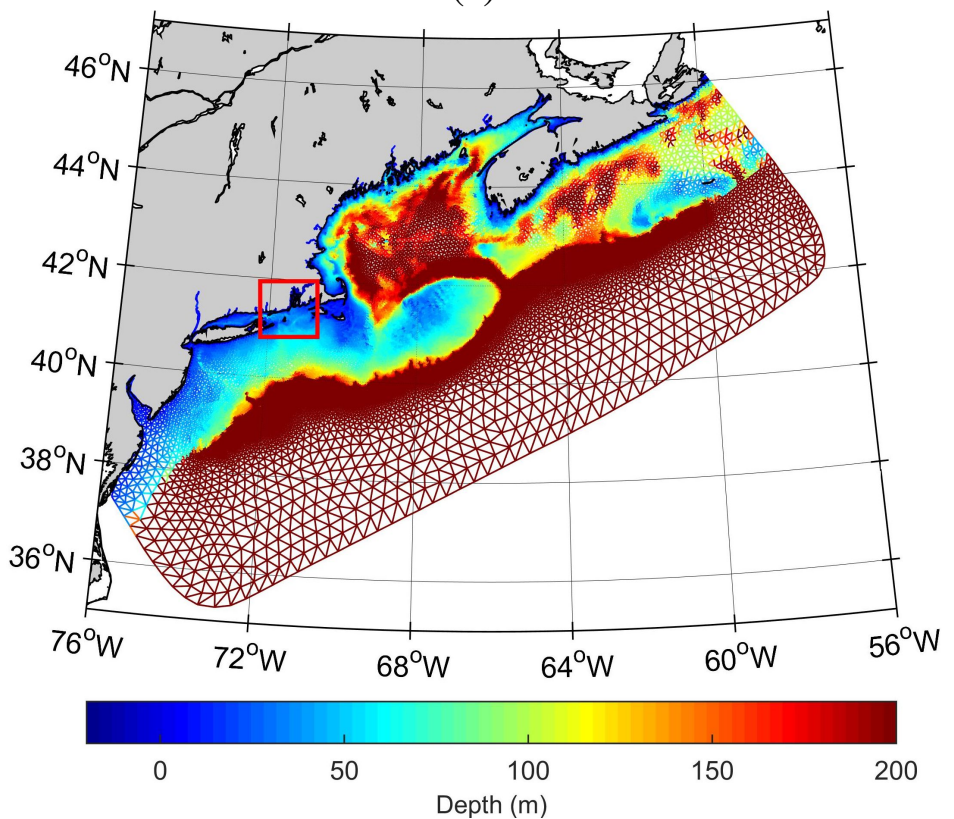

(b)

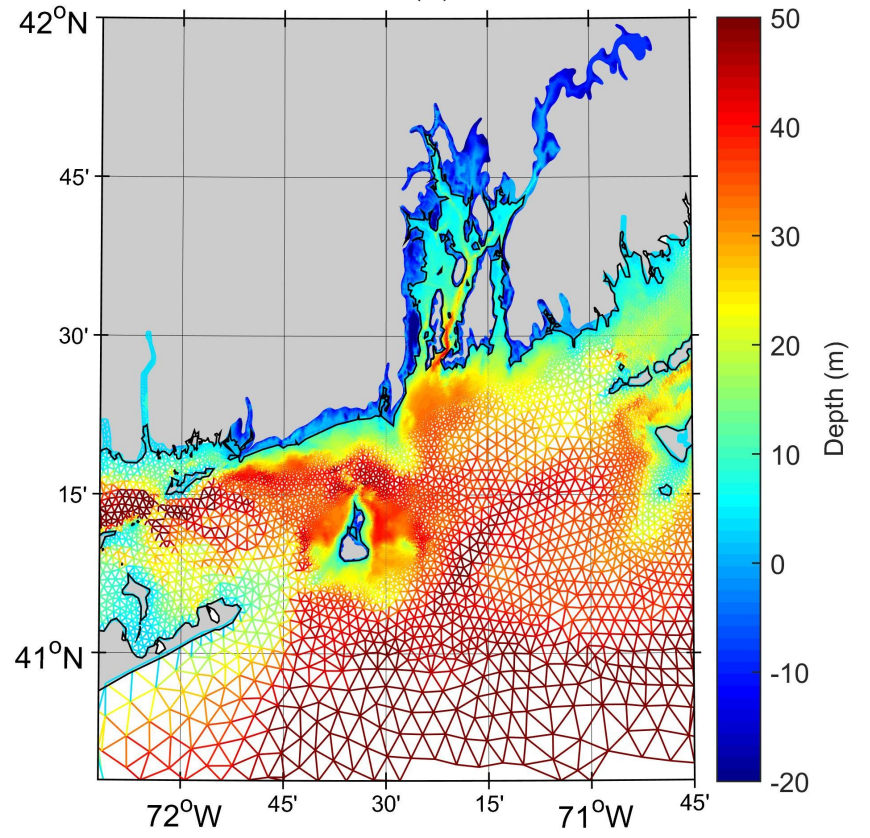

Fig. 2.2. (a) Complete ADCIRC model domain based on NECOFS GOM4 mesh (recreated with increased resolution in RI) and bathymetry (color scale in m) over the Atlantic continental shelf with the study area outlined as a red box, and (b) zoomed in view of mesh and bathymetry around Rhode Island 
(a)

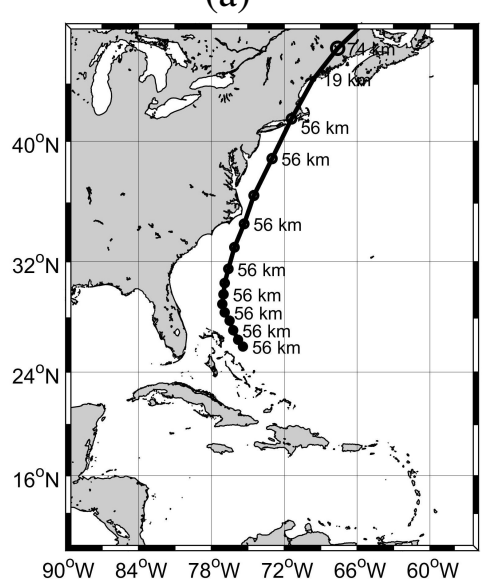

(b)

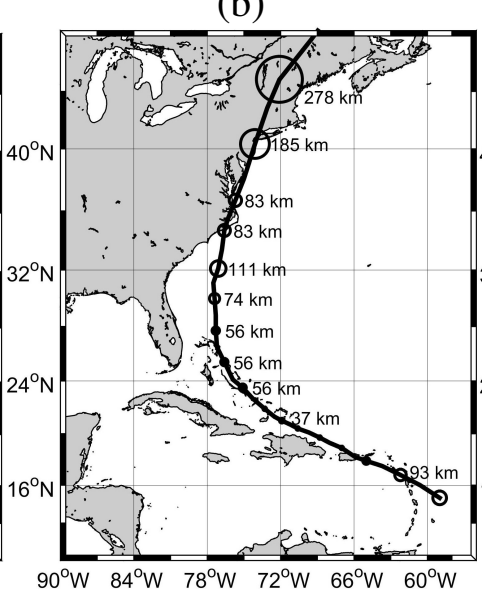

(c)

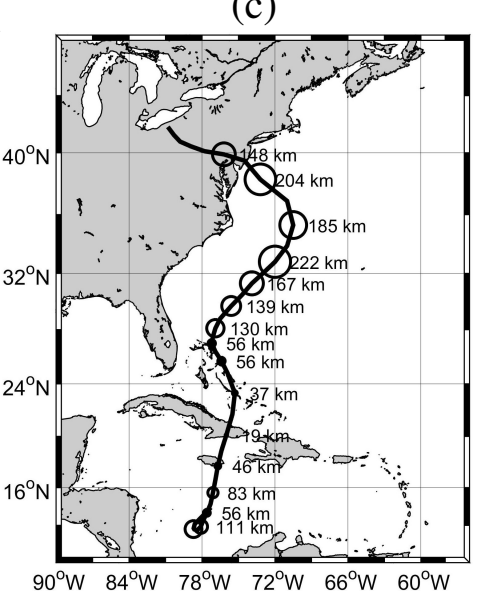

Fig. 2.3. Track of (a) Hurricane Bob (1991) with radius of maximum wind (RMW) in $(\mathrm{km})$ presented for each position along the U.S. east coast, (b) Hurricane Irene (2011) with RMW presented for every other position, and (c) Hurricane Sandy (2012) with RMW for every other position; Tracks and RMW were defined by NHC EBT for each respective storm.

Cuba as a Category 3 [17]. The storm underwent a complex evolution as it weakened over the Bahamas, growing in size as it traveled northeastward and ended up turning northwestward, making landfall in New Jersey as a post-tropical cyclone (Fig. 2.3(c)). The tropical to extratropical cyclone transition was caused by the presence of a shallow low-pressure trough combined with cool temperatures [18]. As a result, significant storm surge along the U.S. east coast, and up to $2 \mathrm{~m}$ above mean sea level along the southern shore of RI and lower Narragansett Bay, rivaled the coastal flooding caused by Hurricane Bob.

Table 2.2 provides an outline of the historical hurricanes, wind models, and observation/hindcast stations we used. Location and sources of observational data, as well as descriptions of the wind models are provided in the following sections.

\subsubsection{Sources of data}

High resolution bathymetric $(30 \mathrm{~m})$ and topographic $(1 \mathrm{~m})$ data for Rhode Island was acquired from the RI Geographical Information System (GIS) (www.rigis.org/) and 
Table 2.2. Outline of the historical hurricanes, wind models, and observation/hindcast stations used in this research; see Fig. 2.1 for observations/hindcast locations.

\begin{tabular}{|c|c|c|c|c|}
\hline Hurricane & Wind model & Wind stations & Tide stations & Wave stations \\
\hline \multirow{2}{*}{ Bob (1991) } & EBT DHM & Buzzards Bay, MA & Newport, RI & \multirow{2}{*}{ WIS 63079} \\
\hline & ECMWF & WIS 63079 & Providence, RI & \\
\hline \multirow{5}{*}{ Irene (2011) } & \multirow{5}{*}{$\begin{array}{l}\text { EBT DHM } \\
\text { ECMWF }\end{array}$} & Buzzards Bay, MA & Newport, RI & Charlestown, RI \\
\hline & & WIS 63079 & Providence, RI & Westerly, RI \\
\hline & & Ninigret Pond (RI) & New London, CT & NDBC 44097 \\
\hline & & Skip's Dock (RI) & Skip's Dock (RI) & WIS 63079 \\
\hline & & & Q. Inlet (RI) & \\
\hline \multirow{5}{*}{ Sandy (2012) } & & Buzzards Bay, MA & Newport, RI & \multirow{5}{*}{$\begin{array}{l}\text { NDBC } 44097 \\
\text { WIS } 63079\end{array}$} \\
\hline & EBT DHM & WIS 63079 & Providence, RI & \\
\hline & ECMWF & New London, CT & New London, CT & \\
\hline & NECOFS WRF & Providence, RI & Skip's Dock (RI) & \\
\hline & & & Weekapaug (RI) & \\
\hline
\end{tabular}

applied to the ADCIRC domain around RI where the mesh has improved resolution. Digital Elevation Models (DEMs) of Connecticut and Massachusetts, provided by each state's GIS database, were used to define the outer extents of the RI mesh. The bathymetry and topography of the remaining regions were based on the NECOFS original mesh (GOM4).

Available observed and hindcast data was reviewed in the region (focusing on RI) both nearshore and offshore (see Fig. 2.1). Permanent observation locations include water elevation stations operated by the National Oceanic and Atmospheric Administration (NOAA; tidesandcurrents.noaa.gov/) in New London, CT (8461490), Newport, RI (8452660), and Providence, RI (8454000), and the NOAA National Data Buoy Center (NDBC; www.ndbc.noaa.gov/) wind and wave buoys located outside of Buzzards Bay, MA (BUZM3) and far offshore of Block Island, RI (44097). Several nearshore temporary wind, water level, and wave stations were in operation during Hurricane Irene, including two wind gauges along the southern coast of Rhode Island maintained by WeatherFlow (WF) - one in Charlestown, RI outside of Ninigret Pond, and one in Point Judith, RI 
on the breakwater (www.weatherflow.com); three water elevation gauges deployed by the United States Geological Survey (USGS) at Skip's Dock in Point Judith, RI, in Charlestown, RI, inside the Quonochontaug Breachway, and in Westerly, RI inside the Weekapaug Breachway (wim.usgs.gov/); and two wave gauges in operation from July 2010 to September 2011 by the Woods Hole Group (WHG; [19]) one mile southwest of the Charlestown Breachway off of the RI southern shore (Center; $\left.-71.656^{\circ} \mathrm{W}, 41.348^{\circ} \mathrm{N}\right)$, and one mile east and south of Misquamicut, RI (West; $-71.793^{\circ} \mathrm{W}, 41.317^{\circ} \mathrm{N}$ ). All temporary data stations described here, except for that measuring water elevation in Westerly, RI, were in operation during Hurricane Irene. During Hurricane Sandy, the USGS water elevation gauges in Skip's Dock and Weekapaug inlet were still in operation, in addition to NOAA's permanent wind and wave stations. The only data available for Hurricane Bob was from the Newport and Providence NOAA tidal gauges for water elevation, the Wave Information Studies (WIS) hindcast for wind and waves, and the Buzzard's Bay NDBC station for winds. The WIS database is based on a coastal wave hindcast model (WISWAVE, WAVEWATCHIII, and WAM) that utilizes the combined marine planetary boundary layer (MPBL), and kinematic reanalysis of wind fields from Oceanweather Inc., for its estimates (http://wis.usace.army.mil).

The main tidal constituents that dominate the study area are listed in Table 2.3 in Newport and Providence, RI. The ADCIRC+SWAN model was forced with five constituents from the LeProvost tidal database: M2, S2, N2, O1, and K1.

\subsubsection{Model}

The risk posed by coastal storms results from a combination of wave action and storm surge; therefore it is important to simulate both in a coupled manner. Studies showed that computing wave-surge interactions (wave set-up and set-down) in coupled models [20] results in more accurate predictions of waves and storm surge. The ADCIRC+SWAN coupled model was used in this study. ADCIRC is a two dimensional (2-D) (optional 
3D), finite-element, free surface circulation model, which is described in [5] and [20]. SWAN is an open-source third-generation spectral wave model as described by Booij et al. $(1999 ;[6])$.

In short, SWAN's formulation is based on the conservation of wave action density $N=E(\sigma, \theta) / \sigma$, where $E(\sigma, \theta)$ is the directional wave spectrum with $\sigma$ the relative angular frequency and $\theta$ the direction. SWAN takes into account interactions between waves and currents via radiation stresses, and includes parameterizations and equations for wave generation by wind, propagation, nonlinear wave-wave interactions, and dissipation due to whitecapping, bottom friction, and depth-induced breaking. Water elevation and the effect of ambient currents on waves are not explicitly computed in SWAN, but are solved implicitly by coupling it with a hydrodynamic circulation model, such as ADCIRC. The coupling of ADCIRC and SWAN is carried out in parallel on identical sub-meshes using intra-model communication on the same computational core [20]. At each grid point, SWAN is passed wind speeds, water levels, and currents computed by ADCIRC, which are period averaged at each time step and used to recalculate the water depth and related wave processes such as wave propagation/refraction and depth-induced breaking. In turn, ADCIRC is partially driven by radiation stress gradients computed by SWAN, extrapolating them forward in time [20].

ADCIRC was run in 2-D mode with a default Manning's $n$ coefficient of 0.02 , and a time step of $0.5 \mathrm{~s}$. The "General Wave Continuity Equation" (GWCE) weighting factor, $\tau_{0}$, that weighs the relative contribution of the primitive and wave portions of the GWCE, was adjusted for stability from its default value of 0.03 to 0.02 . SWAN was run in non-stationary mode over the unstructured ADCIRC mesh, with 36 directional bins and 40 frequency bins with a low frequency cut-off of $0.031 \mathrm{~Hz}$, and was forced by the same wind field as ADCIRC. The default formulations were applied for breaking and whitecapping (KOMEN), with Manning's $n$ quadratic friction input from ADCIRC. 


\subsubsection{Wind Forcing}

Fleming et al. (2008; [8]) addressed the challenges of acquiring and applying meteorological wind forcing for operational storm surge forecasting, including the uncertainty of hurricane forecasts, the lack of prompt availability of data at high resolution, and the computational expense of using large datasets. The reliability of wind forcing is crucial for accurate storm surge prediction. With regards to the application of hurricane hindcasts for storm surge validation purposes, the same challenges of acquiring accurate wind data and processing large datasets are present. There are several options available for meteorological forcing input in ADCIRC; common inputs include either wind velocity and pressure on a regular grid which are interpolated in space onto the ADCIRC domain, or storm parameters formatted as the "Automated Tropical Cyclone Forecasting" (ATCF) Best Track (BT) file published by the NHC. For this format, wind stress and pressure is calculated by the DHM parametric wind model. The latter approach does include wind forcing outside the immediate area impacted by the storm.

NHC maintains an archive of hurricane hindcasts containing six-hourly storm parameters such as location, maximum sustained wind speed, central pressure, etc. in the ATCF Best Track format. HURDAT does not always contain storm size, which is necessary for parametric wind models. Alternately, the "Risk Prediction Initiative" (RPI) developed the EBT dataset with additional wind structure parameters appended to the post-storm best track files from NHC (rammb.cira.colostate.edu). Maintaining the same format, EBT wind input provides a better source for hurricane hindcast purposes than the standard HURDAT input. Parametric wind models are advantageous in hurricane forecasting and hindcasting due to the relatively small amount of storm input data required and the ability to calculate wind stress and pressure on the fly as a subroutine [8]. The current parametric model used by ADCIRC is the DHM, a modification of the original Holland model [7] by Fleming [8] to address dynamically developing hurricane 
parameters. The DHM generates the storm vortex following Schloemer's (1954) hyperbolic hurricane pressure profile and the gradient wind equations. From there, the wind is separated into north and east components at each grid point and adjusted for boundary layer (10 m wind velocity) and time (10 min winds).

Global weather hindcast/forecast systems combine several models covering the atmosphere, land, and ocean in order to accurately predict weather conditions across the globe. ECMWF is a combined general circulation model and data assimilation system that includes a set of physical parameterizations to represent processes such as convection, radiation, friction, and diffusion, for real-time, climate analyses [21]. The advantage of a global weather forecast for storm surge modeling is the inclusion of environmental wind speeds outside of the hurricane circumference; however current ECMWF monthly wind datasets do not fully capture the center of tropical cyclones because the ensemble does not include synthetic vortex parameters in its analyses. The technique of inserting of a synthetic vortex from a tropical cyclone of similar location, strength, and motion into the initialization of model simulations is employed by some weather centers such as the U.S. National Meteorological Center [9]; both Aberson (2001; [22]) and Elsberry et al. (2010; [23]) disregarded the ECMWF wind model due to this limitation. However, ECMWF is widely used in the meteorological community, and efforts to improve quality forecasts and reanalysis wind fields are continuously being sought (i.e. Dee et al. (2011); [24]). In this study, the ECMWF wind velocities (m/s) and surface pressure $(\mathrm{Pa})$ are input onto a rectangular grid that completely covers the ADCIRC domain, and interpolated in space onto the ADCIRC mesh. The default wind drag law initially used in this study was Garratt's formula (1967) to calculate wind stress from the input wind velocities.

In addition to the above models, NECOFS utilizes WRF driven by the "North American Meso-scale" (NAM) weather model for meteorological input, with a horizontal 
resolution up to $3 \mathrm{~km}$, and a two-way nesting method from basin to regional to local scales [15]. Hindcasts are run daily using updated conditions from meteorological observations from buoys, when available. Ocean modeling is completed via coupled FVCOM-SWAVE, where SWAVE is a version of SWAN developed onto the FVCOM framework, in which a flux-corrected transport algorithm is numerically solved with boundary conditions provided by a larger WAVEWATCH-III (WWIII) domain. More details can be found in Qi et al. (2009; [10]). For hindcast simulations, NECOFS incorporates parameters from synthetic storms to better represent the inner structure of tropical cyclones, increasing the accuracy of the peak wind of the storm. NECOFS' outputs are limited to the FVCOM unstructured mesh (GOM4), and are interpolated onto a regular grid before wind speed and pressure can be applied to the high resolution ADCIRC domain covering RI. The output of the NECOFS WRF model for Hurricane Sandy (2012) was provided on a $10 \mathrm{~km}$ resolution regular grid directly from NECOFS [25]. The WRF wind model was not available to simulate Hurricanes Bob and Irene.

\subsection{Results}

The performance of ADCIRC in predicting tides was first assessed at the NOAA Newport and Providence water elevation stations. The model was run for 20 days from May 1, 2016 to May 21, 2016 with a one day ramping period, covering a spring-neap cycle. The observed and modeled elevations were processed using T_Tide [26] to compute the amplitude and phases of tidal constituents, and are presented in Table 2.3

for the Newport and Providence, RI locations. The root-mean-square error (RMSE) of the amplitude and phase for the tidal constituents M2 and S2 at both locations are 0.0013 $\mathrm{m}$ and $4.74^{\circ}$, and $0.0194 \mathrm{~m}$ and $3.63^{\circ}$, respectively.

Figure 2.4 displays a snapshot of the wind field for the EBT DHM parametric wind and the ECMWF wind models for Hurricanes Bob and Irene, with the additional NECOFS WRF wind for Hurricane Sandy. For Hurricane Bob, the ECMWF wind field 
Table 2.3. Skill assessment of ADCIRC for tides at the Newport and Providence stations with root-mean-square errors shown; RMSE for M2 tidal constituent $(0.0013 \mathrm{~m}$ amplitude, $4.74^{\circ}$ phase $)$ and $\mathrm{S} 2$ constituent $\left(0.0194 \mathrm{~m}\right.$ and $\left.3.63^{\circ}\right)$.

\begin{tabular}{lllllll}
\hline \hline & \multicolumn{5}{c}{ Newport } \\
Constituents & \multicolumn{3}{c}{$\begin{array}{c}\text { Modeled } \\
\text { Observed }\end{array}$} & \multicolumn{2}{c}{ Difference } \\
& Amp (m) & Phase (deg) & Amp (m) & Phase (deg) & Amp (m) & Phase (deg) \\
\hline M2 & 0.53 & 2 & 0.53 & 1 & 0 & 1 \\
S2 & 0.09 & 11 & 0.10 & 17 & 0.01 & 6 \\
N2 & 0.12 & 342 & 0.15 & 341 & 0.03 & 1 \\
O1 & 0.05 & 175 & 0.04 & 203 & 0.01 & 28 \\
K1 & 0.01 & 96 & 0.07 & 141 & 0.06 & 45 \\
\hline \hline & & & Providence & & & \\
Constituents & & Modeled & & Observed & & Difference \\
& Amp (m) & Phase (deg) & Amp (m) & Phase (deg) & Amp (m) & Phase (deg) \\
\hline M2 & 0.61 & 5 & 0.63 & 8 & 0.02 & 3 \\
S2 & 0.10 & 8 & 0.12 & 25 & 0.02 & 7 \\
N2 & 0.13 & 340 & 0.17 & 350 & 0.04 & 10 \\
O1 & 0.06 & 174 & 0.03 & 202 & 0.03 & 28 \\
K1 & 0.01 & 97 & 0.08 & 141 & 0.07 & 44 \\
\hline \hline
\end{tabular}




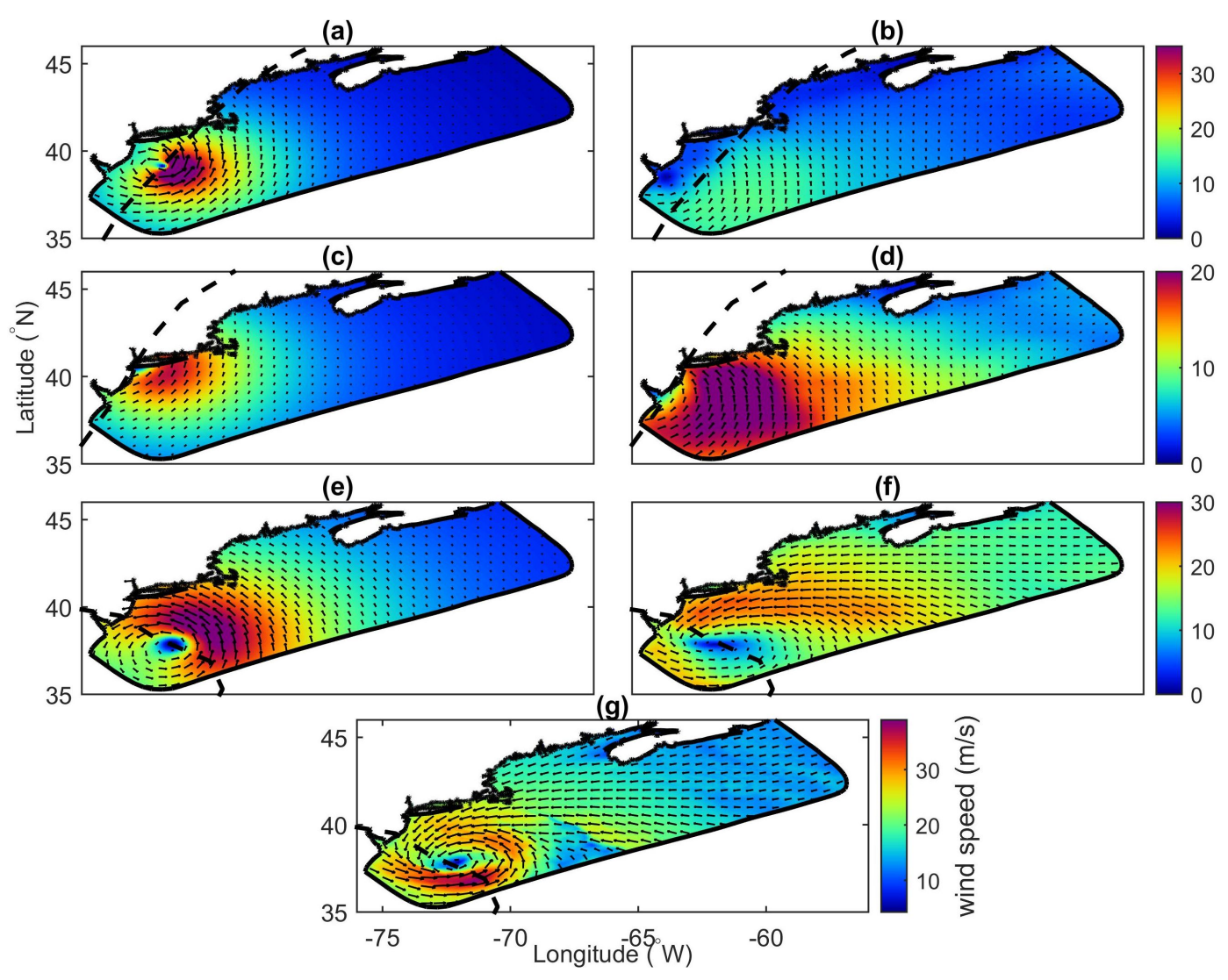

Fig. 2.4. Simulated wind fields for various hurricanes based on three wind models; Hurricane Bob for (a) NHC Extended Best Track (EBT) and (b) ECMWF wind models; Hurricane Irene for (c) NHC EBT and (d) ECMWF wind models; (e,f,g) Hurricane Sandy for (e) NHC EBT, (f) ECMWF, and (g) NECOFS WRF wind models; Tracks shown by the dashed line were defined by NHC EBT for each respective storm.

was very weak compared to the EBT DHM parametric wind, peaking at $16 \mathrm{~m} / \mathrm{s}$ instead of $35 \mathrm{~m} / \mathrm{s}$, which can further be seen in the time series of Figure 2.5. In addition, previous research $[9,27]$ found that the center of the cyclone depicted by ECMWF is often represented to be a few degrees away from the position specified by the track data, which can be seen for Hurricanes Bob (Fig. 2.4b) and Sandy (Fig. 2.4f).

\subsubsection{Simulation of historical hurricanes}

The simulation setup for three historical hurricanes - Hurricane Bob (1991), Hurricane Irene (2011), and Hurricane Sandy (2012) - and their resulting wind, surge, and wave time series compared with observations are presented below. 
Hurricane Bob passed directly over RI, making landfall on the south side of Block Island and again in Newport, with a radius of maximum wind of 30 nautical miles or 56 $\mathrm{km}$. Storm parameters from the NHC EBT database were simulated for a period of 3.5 days starting on August 16, 1991 12:00 to August 20, 1991 00:00 GMT. Wind speed and surface pressure from ECMWF was simulated for 7 days from August 15, 1991 00:00 to August 22, 1991 00:00 GMT. The WRF wind model was not used for Hurricane Bob.

Hurricane Irene traveled west of Rhode Island through New York state with a radius of maximum wind of 100 nautical miles or $185 \mathrm{~km}$. Forced by DHM parametric and ECMWF wind models, the simulation took place for 7 days from August 21, 2011 00:00 to August 30, 2011 00:00 GMT. The WRF wind model was not used for Hurricane Irene.

The infamous 'left hook' taken by Hurricane Sandy occurred southwest of Rhode Island, with a radius of maximum wind of 110 nautical miles, or $204 \mathrm{~km}$. The simulation duration was dependent on the wind data set used to represent the storm forcing. The NHC EBT database contained storm parameters for a period of 9.75 days from October 21, 2012 18:00 to October 31, 2012 12:00, and ECMWF winds were simulated for 10 days from October 21, 2012 00:00 to October 31, 2012 23:00 GMT. The NECOFS WRF wind model was available for three days during the peak of the storm from October 28, 2012 to October 31, 2012, and was simulated for a total of 6 days. The resulting wind, surge, and wave time series for the selected hurricanes are compared with observations below.

\section{Wind}

During Hurricane Bob, the DHM parametric wind model predicted the peak wind speed within 10\% (Table 2.4) when compared with observations from meteorological station BUZM3 (Fig. 2.5a,b). Note that the parametric wind time series is zero until the storm enters the domain. On the other hand, the ECMWF wind model significantly underestimated the peak wind and minimum pressure by nearly $20 \mathrm{~m} / \mathrm{s}$ and $20 \mathrm{~Pa}$, 
respectively.

For Hurricane Irene, comparisons between simulated and observed wind speed and pressure were made at the BUZM3 station offshore (Fig. 2.5c,d), and meteorological stations in Charlestown and Point Judith, RI nearshore (Fig. 2.6a,b). The ECMWF wind model better predicted wind speeds (within 15\%) at all wind station locations (Table 2.4) compared to the performance of the parametric wind, which varied significantly for peak wind speed $(6.3-40 \%)$. The time series of the parametric wind model was similar across each wind station location. In particular, the difference in peak wind speed between offshore and nearshore stations was minimal due to the inability of the DHM to account for the presence of land. Both the parametric and ECMWF wind models estimated the minimum pressure accurately.

Looking at Hurricane Sandy, the NECOFS WRF wind predicted the maximum wind speed within $18 \%$ when compared to wind speed and pressure observations at NDBC C-MAN station BUZM3 (Fig. 2.5e,f). Table 2.4 provides the wind speed comparisons at the other wind station locations. The ECMWF wind model is shown to consistently underestimate the peak wind speed up to $25 \%$, and the parametric wind varied significantly between offshore and nearshore locations $(8-30 \%)$. The pressure was in good agreement among the wind models. The largest overestimation of peak wind speed occurred at the New London meteorological station by the WRF and DHM wind models. This can be associated with the proximity of the station to land and the reduced mesh resolution in that area.

\section{Storm Surge}

For Hurricane Bob, the time series of water elevation at NOAA tidal stations in Newport and Providence, RI are compared with water levels simulated by each wind model in Figure 2.7. The corresponding RMSE values for surge are presented in Figure 2.9, and are discussed later in the paper. The parametric wind model overestimated the 
(a)

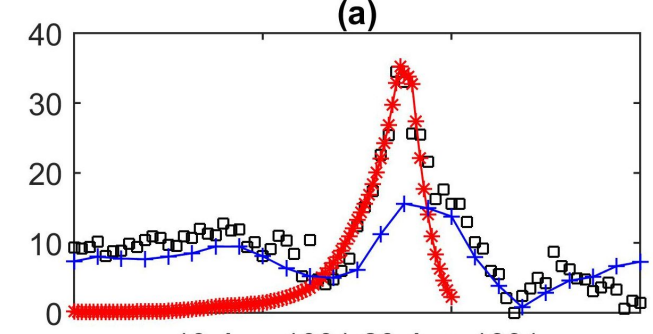

19-Aug-1991 20-Aug-1991

(c)

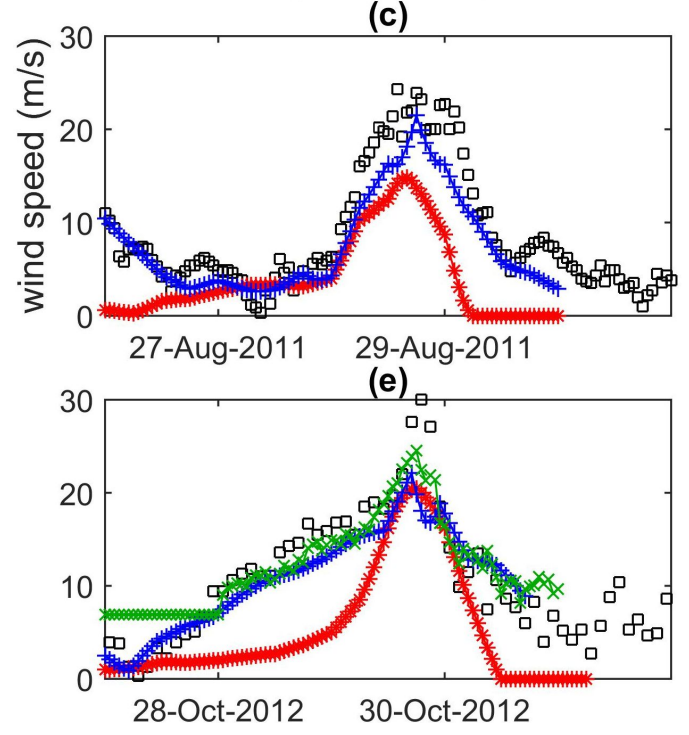

(b)

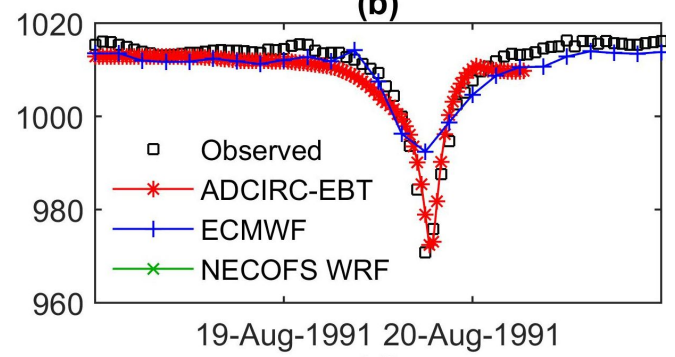

(d)
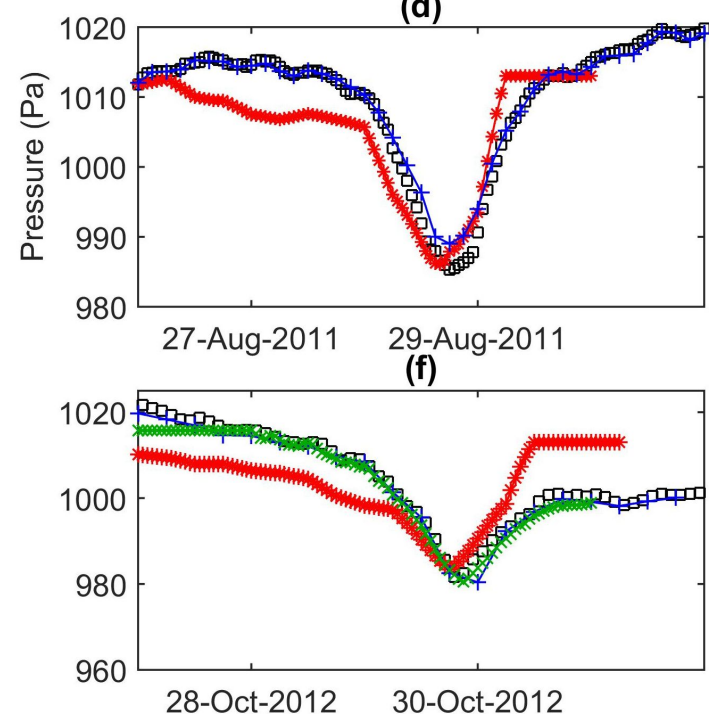

Fig. 2.5. Comparison of observed and simulated wind speed and atmospheric pressure at the sea surface time series, respectively, at BUZM3 for Hurricane Bob (a,b), Hurricane Irene (c,d), and Hurricane Sandy (e,f); see Fig. 2.1 for wind observation/hindcast locations. 
- Observed — ADCIRC-EBT —ECMWF
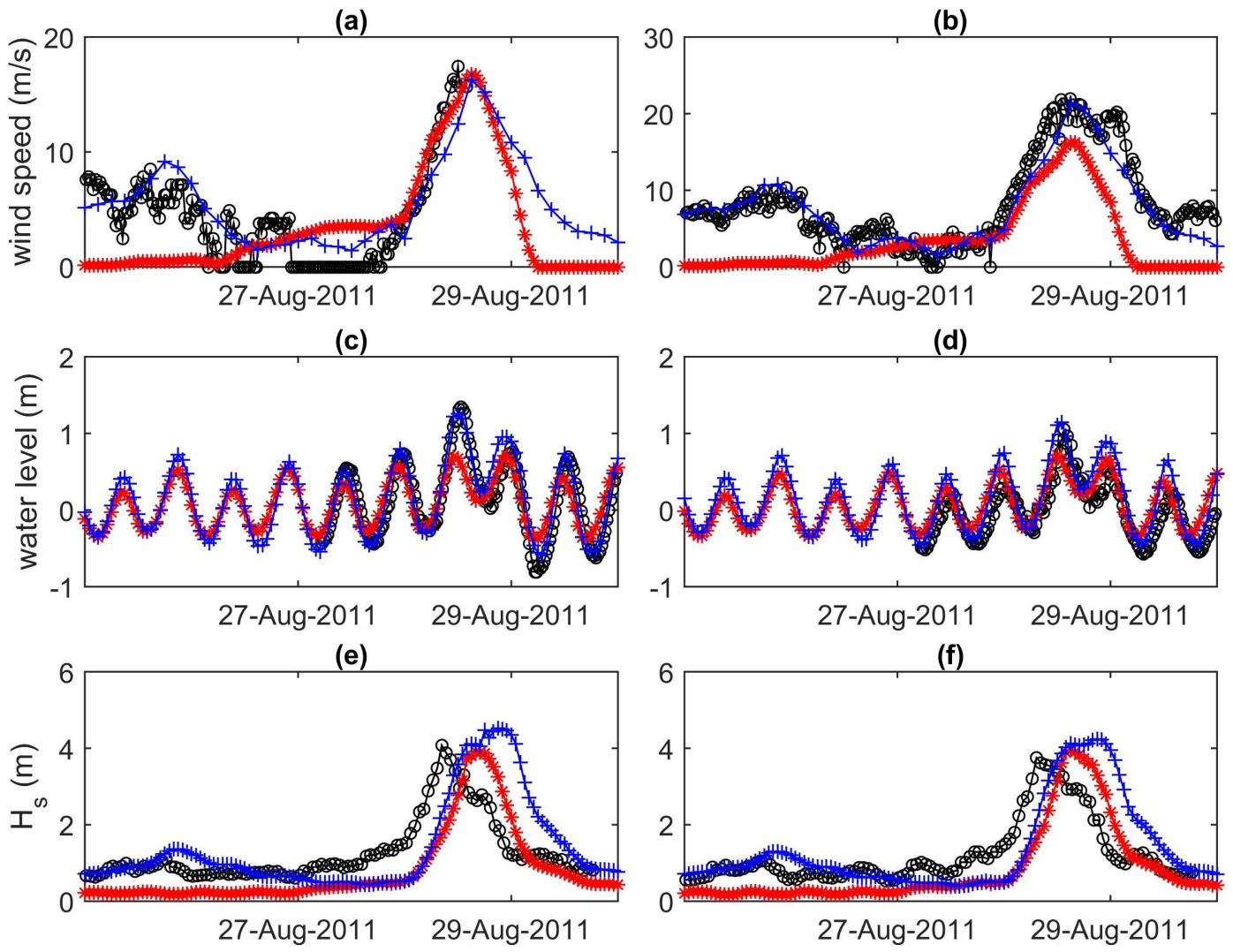

Fig. 2.6. Hurricane Irene nearshore comparisons of observed and simulated wind speeds, water elevation, and significant wave height; $(a, b)$ wind speed at WF stations in Ninigret Pond and Point Judith, RI; (c,d) water elevation at USGS tidal gauges in Skip's Dock and Quonochontaug Breachway (RI); (e,f) wave height at WHG wave gauges in Charlestown and Westerly, RI; see Fig. 2.1 for nearshore observation/hindcast locations; see Figure 2.9 for RMSE values. 
Table 2.4. Comparison of maximum observed and modeled wind speeds $(\mathrm{m} / \mathrm{s})$ for various hurricanes at selected wind stations; percent error in parentheses (negative value signify underestimation, and positive values overestimation); see Fig. 2.1 for observation/hindcast locations.

\begin{tabular}{llcccc}
\hline \hline Hurricane & \multicolumn{1}{c}{ Station } & Observed & EBT & ECMWF & WRF \\
\cline { 2 - 5 } Bob & Buzzards Bay, MA & 34.5 & $35.2(+2 \%)$ & $15.6(-55 \%)$ & - \\
& WIS 63079 (hindcast) & 34.3 & $30.9(-10 \%)$ & $14.7(-57 \%)$ & - \\
\hline \multirow{4}{*}{ Irene } & Buzzards Bay, MA & 25.0 & $14.8(-40 \%)$ & $21.5(-14 \%)$ & - \\
& WIS 63079 (hindcast) & 21.2 & $16.0(-24 \%)$ & $22.1(-4 \%)$ & - \\
& Ninigret Pond (RI) & 17.9 & $16.8(-6 \%)$ & $16.2(-9 \%)$ & - \\
& Skip's Dock (RI) & 23.6 & $16.3(-31 \%)$ & $20.5(-13 \%)$ & - \\
\hline \multirow{4}{*}{ Sandy } & Buzzards Bay, MA & 29.5 & $20.5(-31 \%)$ & $22.1(-25 \%)$ & $24.5(-17 \%)$ \\
& WIS 63079 (hindcast) & 29.6 & $21.8(-26 \%)$ & $22.2(-25 \%)$ & $25.2(-15 \%)$ \\
& New London, CT & 16.8 & $21.9(+30 \%)$ & $14.2(-15 \%)$ & $19.7(+18 \%)$ \\
& Providence, RI & 17.7 & $19.1(+8 \%)$ & $13.9(-21 \%)$ & $16.2(-8 \%)$ \\
\hline \hline
\end{tabular}

peak storm surge up to $20 \%$ for both stations, and the ECMWF wind model underestimated the peak surge more than 50\% (Table 2.5). As a result, the RMSE of the surge in Newport was lower when simulated by the DHM wind model. At the Providence station, the RMSE of the DHM surge simulation was greater than that of ECMWF, and was attributed to its peak surge occurring earlier than that of the observations.

During Hurricane Irene, water elevation was recorded at NOAA tidal gauges in Newport and Providence, RI (Fig. 2.7c,d), as well as at USGS stations in Quonochontaug Inlet and Skip's Dock, which were deployed for the year 2011 (Fig. 2.6(c,d)). In Figure 2.9, the RMSE is presented for each wind model at each surge station. The EBT DHM parametric wind underestimated the peak storm surge by $50 \%$ for a majority of the surge locations (Table 2.5), where the ECMWF wind model underestimated the peak surge within $25 \%$ at each location. The RMSE between the simulated and observed water elevation during the peak surge (August 27, 2011 - August 30, 2011) was lower when forced with the ECMWF wind model in all but one location. In Quonochontaug Inlet, the storm surge amplitude was better estimated by the parametric model, resulting in a 

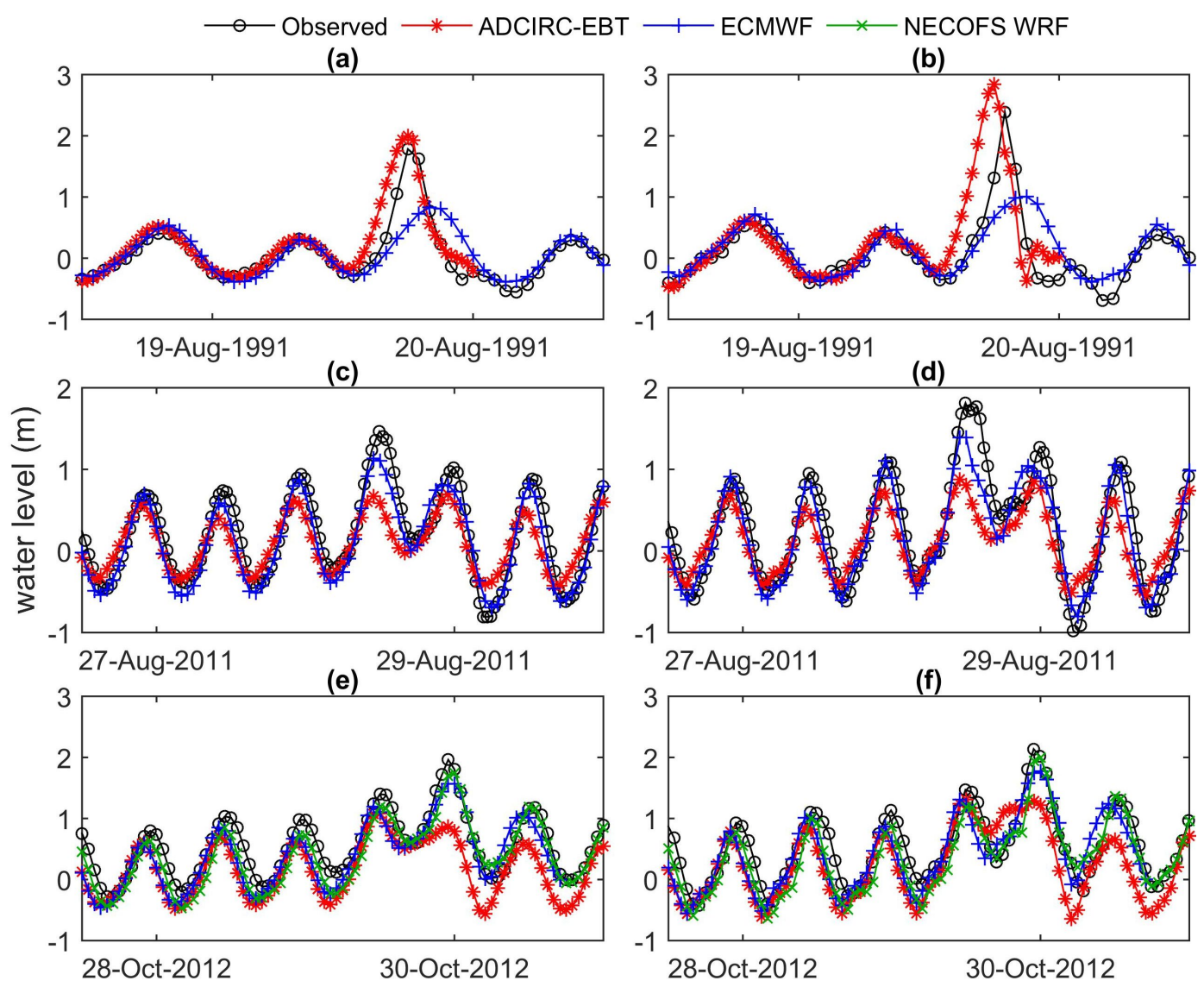

Fig. 2.7. Comparison of observed and simulated water elevation time series (m,msl) at NOAA tidal gauges in Newport and Providence, RI, respectively, for Hurricane Bob (a,b), Hurricane Irene (c,d), and Hurricane Sandy (e,f); see Fig. 2.1 for surge observation/hindcast locations.

lower RMSE.

For Hurricane Sandy, the NECOFS WRF wind model estimated the peak water level within $11 \%$ when compared observed elevations at NOAA tidal stations in Newport and Providence, RI (Fig. 2.7e,f; Table 2.5). At each surge station location, the EBT DHM and ECMWF wind models underestimated the peak surge up to $45 \%$ and $20 \%$, respectively. The corresponding RMSE for each wind model at each surge station location is presented in Figure 2.9. As a result, the WRF wind forcing produced the lowest error during the surge caused by Hurricane Sandy, and the EBT DHM forcing produced the highest errors. Consult the Discussion Section for further evaluation of wind forcing performance. 
Table 2.5. Comparison of maximum observed and simulated water levels (tide + surge; $\mathrm{m}, \mathrm{msl}$ ) for various hurricanes at selected surge stations; percent error in parentheses (negative value signify underestimation, and positive values overestimation); see Fig. 2.1 for observation/hindcast locations; see Fig. 2.9 for RMSE values.

\begin{tabular}{llcccc}
\hline \hline Hurricane & \multicolumn{1}{c}{ Station } & Observed & EBT & ECMWF & WRF \\
\hline \multirow{2}{*}{ Bob } & Newport, RI & 1.78 & $1.99(+11 \%)$ & $0.83(-53 \%)$ & - \\
& Providence, RI & 2.39 & $2.84(+19 \%)$ & $1.00(-58 \%)$ & - \\
\hline \multirow{3}{*}{ Irene } & Newport, RI & 1.46 & $0.69(-52 \%)$ & $1.13(-22 \%)$ & - \\
& Providence, RI & 1.83 & $0.87(-52 \%)$ & $1.39(-24 \%)$ & - \\
& New London, CT & 1.53 & $0.75(-51 \%)$ & $1.24(-18 \%)$ & - \\
& Skip's Dock (RI) & 1.49 & $0.71(-52 \%)$ & $1.25(-16 \%)$ & - \\
& Q. Inlet (RI) & 1.11 & $0.71(-35 \%)$ & $1.14(+2.6 \%)$ & - \\
\hline \multirow{3}{*}{ Sandy } & Newport, RI & 1.96 & $1.08(-45 \%)$ & $1.57(-20 \%)$ & $1.75(-11 \%)$ \\
& Providence, RI & 2.17 & $1.31(-39 \%)$ & $1.77(-18 \%)$ & $1.99(-8 \%)$ \\
& New London, CT & 1.94 & $1.22(-37 \%)$ & $1.79(-7 \%)$ & $1.87(-3 \%)$ \\
& Skip's Dock (RI) & 2.09 & $1.34(-36 \%)$ & $1.81(-13 \%)$ & $1.95(-6 \%)$ \\
& Weekapaug (RI) & 2.05 & $1.35(-34 \%)$ & $1.87(-10 \%)$ & $1.98(-3 \%)$ \\
\hline \hline
\end{tabular}

\section{Waves}

For Hurricane Bob, wave hindcast from WIS station 63079 are compared with DHM and ECMWF simulated significant wave heights in Figure 2.8a. No other wave data was available for this time period. The maximum hindcast wave height was 7.76 m, ECMWF predicted $3.48 \mathrm{~m}(-55 \%)$, and EBT predicted $11.8 \mathrm{~m}(+53 \%)$; Table 2.6. The ECMWF wind model underestimated the peak wave height when compared with the WIS hindcast, and the parametric wind significantly overestimated the peak. Since the WIS program is an operational hindcast model itself (see wis.usace.army.mil), it is unclear which wind model accurately predicted the significant wave height for Hurricane Bob. By comparing the WIS hindcast for Hurricanes Irene and Sandy to the observed wave height at the NDBC Buoy 44097, we can observe the prediction of WIS to the prediction of the wind models used in this study. Table 2.6 shows that the WIS hindcast predicts a slightly lower peak wave height (up to $2 \mathrm{~m}$ during Hurricane Irene). Assuming the actual observed wave height during Hurricane Bob was higher than predicted by 
WIS, the EBT DHM wind model would provide the better estimate of the significant wave height in the region.

Observations for Hurricane Irene from the offshore NDBC Buoy 44097 (Fig. 2.8b), from nearshore USGS wave gauges in Westerly, RI (Fig. 2.6e,f), and hindcast from WIS 63079 (Fig. 2.8c) are compared with DHM and ECMWF simulated significant wave heights. These two wind models best predicted the wave height at the USGS locations nearshore (within 15\%; Table 2.6). At Buoy 44097 offshore, the EBT DHM wind model underestimated the peak wave height by $40 \%$, which can be attributed to the lack of background winds outside of the radius of maximum winds in the EBT database. The DHM and ECMWF wind models equally under- and over-estimated the peak wave height by $22 \%$, respectively, when compared to the WIS hindcast at station 63079 .

During Hurricane Sandy, the maximum significant wave height observed at the NDBC Buoy 44097 was $9.48 \mathrm{~m}$. Comparing the simulated wave heights to observations (Fig. 2.8d) reveals that the DHM wind model overestimated the peak wave height by 14\% (10.8 m), ECMWF underestimated the peak wave height by $22 \%(7.4 \mathrm{~m})$, and the NECOFS WRF winds underestimated the peak wave height by only $10 \%(8.5 \mathrm{~m})$; these are listed in Table 2.6. When compared to the WIS 63079 hindcast, the resulting simulated peak wave heights varied among the three wind models, with errors as high as $25 \%$ (EBT DHM forcing) and as low as $1.5 \%$ (NECOFS WRF forcing).

\subsection{Discussion}

The performance of the three wind models with respect to storm surge prediction was assessed by computing the RMSE during the surge event, and comparing differences between the maximum peak surge of observations and simulations. Figure 2.9 visualizes the RMSE of surge predictions for the various wind models and hurricanes, at each station where surge was measured. For Hurricane Bob, the RMSE of the DHM parametric wind model in Newport, RI is $42 \%$ lower than that of the ECMWF wind model (RMSE $<0.19$ 


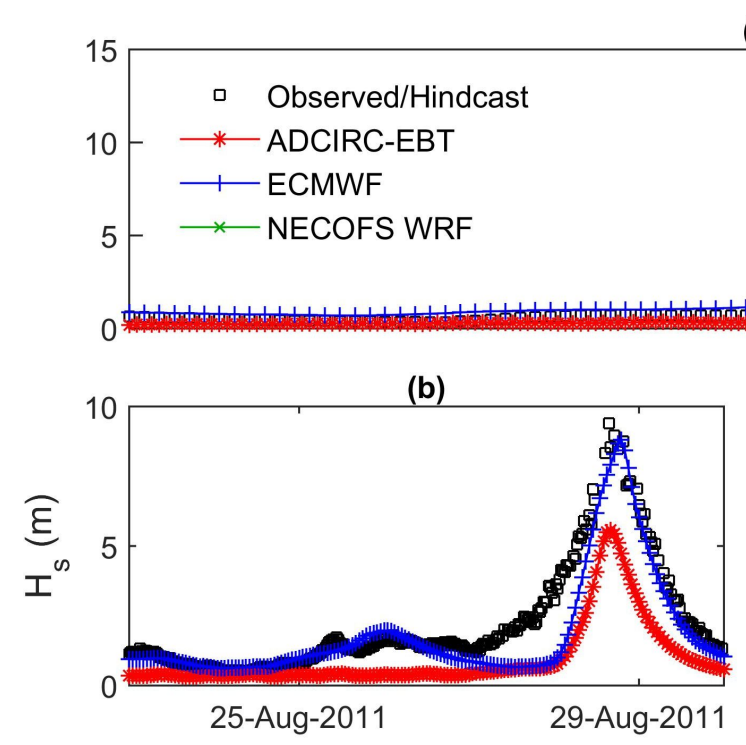

(a)

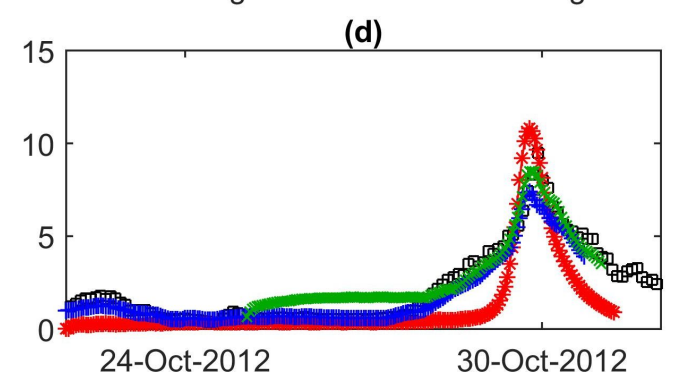

19-Aug-1991

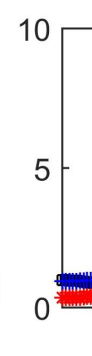

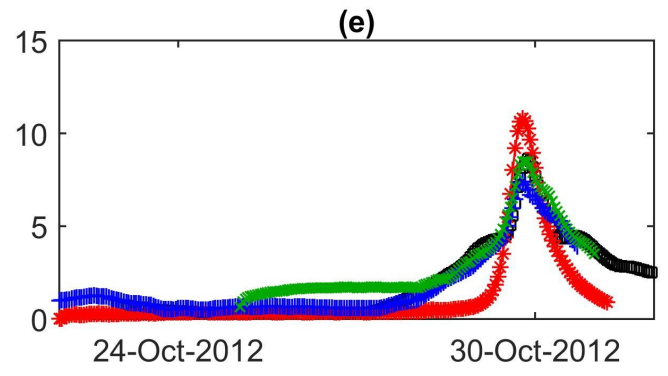

Fig. 2.8. Comparison of observed/hindcast and simulated wave time series at WIS Station 63079 and NDBC Buoy 44097; (a) Hurricane Bob WIS hindcast comparison, $(b, c)$ Hurricane Irene NDBC Buoy and WIS hindcast comparison, respectively, and $(d, e)$ Hurricane Sandy NDBC Buoy and WIS hindcast comparison, respectively; see Fig. 2.1 for wave observation/hindcast locations. 
Table 2.6. Comparison of maximum observed and simulated significant wave height (m) for various hurricanes at selected wave stations; percent error in parentheses (negative value signify underestimation, and positive values overestimation); see Fig. 2.1 for observation/hindcast locations.

\begin{tabular}{llcccc}
\hline \hline Hurricane & \multicolumn{1}{c}{ Station } & Observed & EBT & ECMWF & WRF \\
\hline Bob & WIS 63079 (hindcast) & 7.76 & $11.8(+53 \%)$ & $3.48(-55 \%)$ & - \\
\hline \multirow{3}{*}{ Irene } & Charlestown, RI & 4.08 & $3.92(-4 \%)$ & $4.52(+10 \%)$ & - \\
& Westerly, RI & 3.75 & $3.95(+5 \%)$ & $4.24(+13 \%)$ & - \\
& NDBC 44097 & 9.39 & $5.57(-41 \%)$ & $8.81(-6 \%)$ & - \\
& WIS 63079 (hindcast) & 7.20 & $5.57(-23 \%)$ & $8.81(+22 \%)$ & - \\
\hline \multirow{2}{*}{ Sandy } & NDBC 44097 & 9.48 & $10.8(+14 \%)$ & $7.4(-22 \%)$ & $8.5(-10 \%)$ \\
& WIS63079 (hindcast) & 8.63 & $10.8(+25 \%)$ & $7.4(-14 \%)$ & $8.5(-2 \%)$ \\
\hline \hline
\end{tabular}

$\mathrm{m}$ versus $\mathrm{RMSE}<0.27 \mathrm{~m})$. In Providence, RI, a slight phase shift causes the RMSE of DHM forcing to be higher than that of ECMWF (Fig. 2.7b), however, the difference in peak surge between observations and simulations for the DHM wind model (19\%) is smaller than for the ECMWF wind $(-58 \%)$. These were the only two surge stations available during Hurricane Bob. Concerning Hurricane Irene, the ECMWF wind model produced smaller errors in surge than the EBT DHM forcing (RMSE $<0.3 \mathrm{~m}$ versus 0.4 m) for a majority of the surge stations. Differences at the Quonochontaug Breachway station can be attributed to the phasing differences between the USGS observations and the simulated time series (Fig. 2.6a,b), however, the ECMWF wind model more closely matched observations $(2.6 \%)$ than the DHM forcing (-35\%) in that area. Similar results were observed for Hurricane Sandy, where the ECMWF wind better estimates the surge at all stations with errors less than $0.35 \mathrm{~m}$ when compared to the DHM wind model (RMSE $<0.57 \mathrm{~m}$ ). When comparing the NECOFS WRF wind model to observations, errors in simulated surge are less than $0.25 \mathrm{~m}$. Dietrich (2015; [12]) had similar results for Hurricane Isaac (2012) where the WRF wind forcing was a better match to observations for pressure and water level measurements along the Louisiana coastline.

The resulting time series of storm surge simulations suggest that the EBT DHM wind model provides good surge prediction to the extent that dominant hurricane winds 
(a)

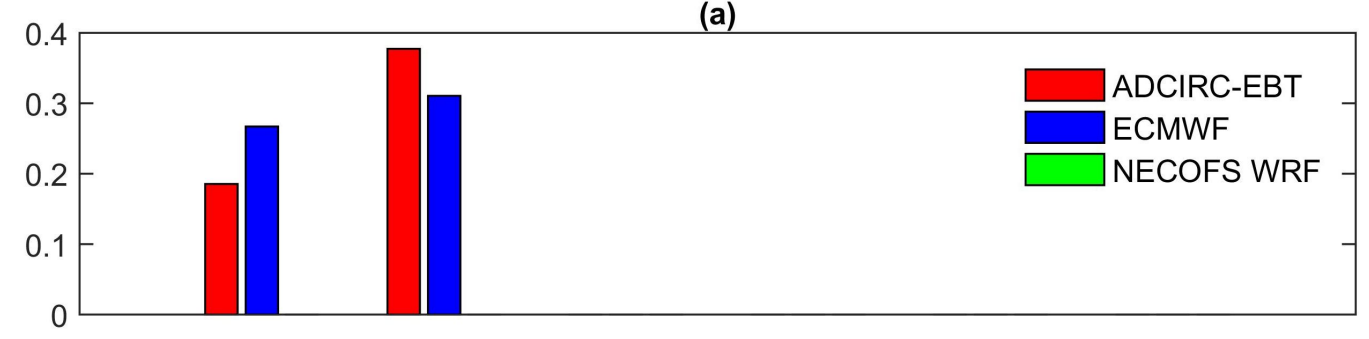

(b)

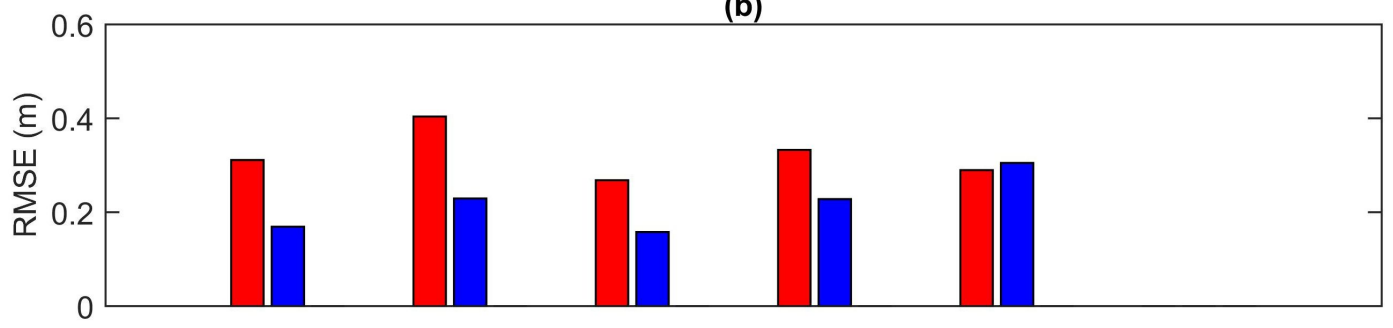

(c)

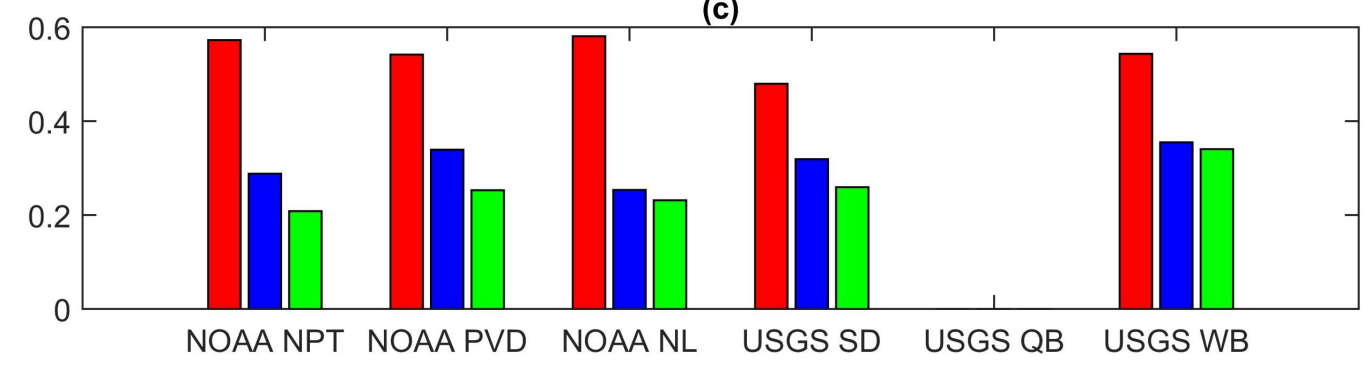

Fig. 2.9. Bar graph of root-mean-square error (RMSE) between observed and simulated storm surge (sampled 12 hours prior to and post peak surge) for each wind model by station location for Hurricanes (a) Bob (1991), (b) Irene (2011) and (c) Sandy (2012). 
and spatial scales in the area of interest are within the radius of maximum winds of the storm. The ECMWF wind model performance seems to be better for larger, less intense storms such as Hurricanes Irene and Sandy where the storm center is away from the area. The DHM wind model best predicts the surge caused by Hurricane Bob, which had a radius of maximum wind of $30 \mathrm{~nm}(55.5 \mathrm{~km})$, compared to Hurricane Irene with a radius of $100 \mathrm{~nm}(185 \mathrm{~km})$ or Hurricane Sandy with a radius $110 \mathrm{~nm}(204 \mathrm{~km})$. Figure 2.10(a) takes a closer look at the horizontal resolution of the ECMWF grid with respect to the three hurricane radii of maximum winds. Here, the relatively low number of grid points within the radius of Hurricane Bob, compared to those of Hurricanes Irene and Sandy, show the limited spatial coverage of Hurricane Bob over the study area. The small radius of maximum winds for Hurricane Bob provides insight to the larger errors in surge prediction (differences in peak values and RMSE) when simulated by the ECMWF wind model. The horizontal resolution of the NECOFS WRF (2.10b) grid is slightly higher than ECMWF, and as a result, produces smaller errors in surge simulation during Hurricane Sandy.

The formulation of the wind drag coefficient is significant in accurate storm surge prediction. Bryant (2016; [28]) provided the complex history of the various wind drag coefficient formulations and corresponding wind stress used in storm surge simulations, and pointed out the common technique of capping a linear drag coefficient at a certain threshold. For sensitivity analyses, the wind drag law was adjusted from the ADCIRC default value of Garrett (1977), to Powell (2006) for Hurricane Sandy using the NECOFS WRF wind forcing. As previously described, the Garrett formulation calculates wind drag at each grid point in the domain based on the local wind speed. Powell's method divides the storm into three sectors (right, rear, and left) and applies different drag formulations for each sector. Grid points that do not fall within the three sectors are defaulted to Garrett. Powell's method has been claimed to perform better for tropical 
(a)

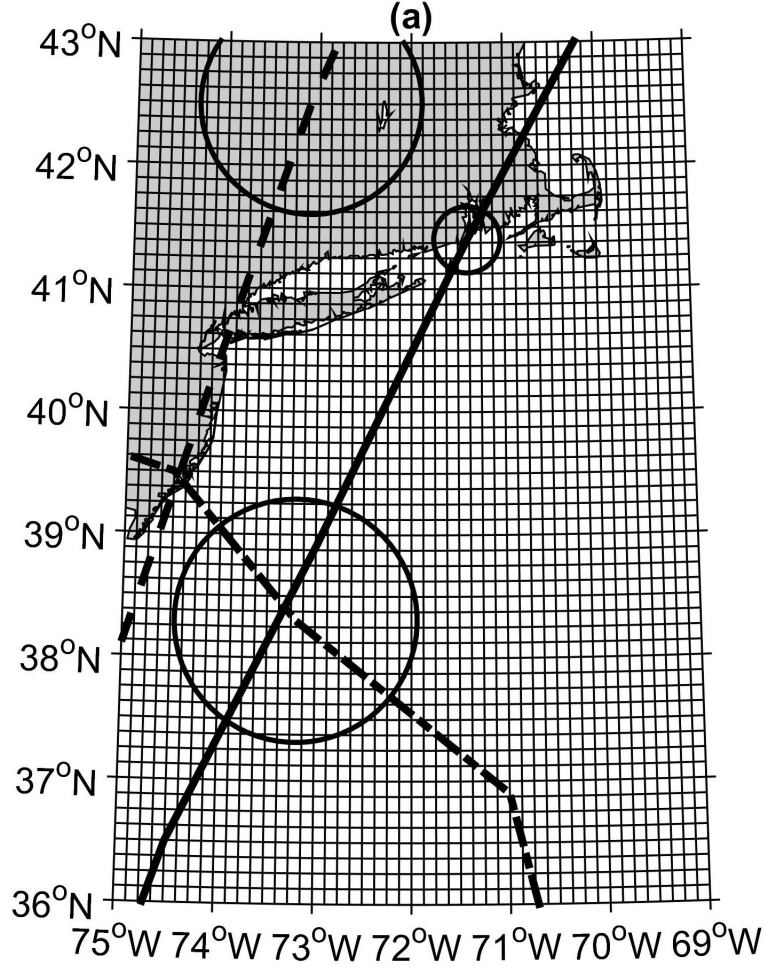

(b)

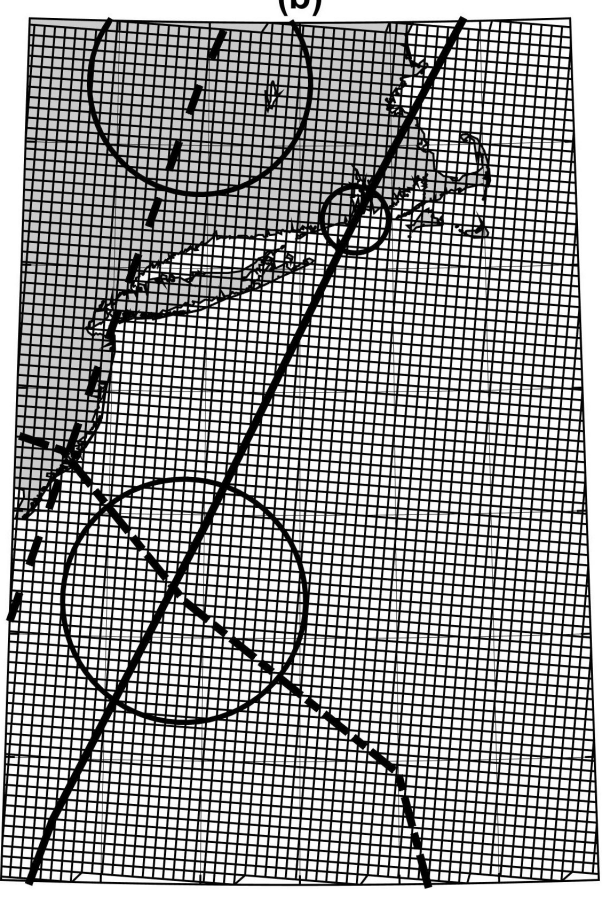

Fig. 2.10. Close up of the storm tracks for Hurricane Bob (solid line) on August 18, 1991 at 1800 GMT, Hurricane Irene (dashed line) on August 28, 2012 at 1800, and Hurricane Sandy (dash-dotted line) on October 29, 2012 at 1800 with radius of maximum wind circumferences shown over the study area with (a) ECMWF and (b) NECOFS WRF wind model grids shown; Tracks and RMW were defined by NHC EBT for each respective storm.

storms [29]. However, the sensitivity analysis we performed did not lead to considerable impact on the maximum storm surge or significant wave height. The Powell formulation underestimated the peak storm surge at Skip's Dock and Weekapaug Inlet by $6.9 \%$ and $3.7 \%$, respectively, compared to the original underestimate of $6.5 \%$ and $3 \%$ using the Garrett formulation; additionally, the estimation of peak significant wave height decreased by $2.5 \%$ from Garrett $(10 \%)$ to Powell $(12.5 \%)$. In response to this, we investigated the storm surge sensitivity to limiting the wind drag coefficient, for values 0.002, 0.0025, and 0.003. Comparisons at surge locations in Newport, Providence, Point Judith, and Westerly, RI revealed little (within $10 \mathrm{~cm}$ ) to no change in the peak water level during Hurricane Sandy. Therefore, the default wind drag formulation used in 
ADCIRC was deemed satisfactory for the simulations presented in this study.

The error of simulated storm surge for different wind models was quantified in Rhode Island coastal waters. Results at neighboring states were not considered due to the limited model resolution in other areas, as it was unclear whether the error stemmed from the wind models themselves or from the low resolution of the FVCOM mesh. Focusing on RI, the parametric wind model provides a good representation of hurricane winds, significant wave height, and storm surge for Hurricane Bob. Houston (1999; [11]) reached the same conclusion about the SLOSH parametric model results as compared to the NOAA Hurricane Research Division (HRD) surface winds, and determined that the wind fields observed during and after a hurricane landfall are best simulated using parametric wind forcing. For other hurricanes with tracks farther from the study area, the NECOFS WRF wind model is preferred.

\subsection{Conclusions}

A coupled ADCIRC+SWAN model was forced with three wind models, where storm surge and wave height predictions were observed in the U.S. northeast coast. Hurricanes Bob (1991), Irene (2011), and Sandy (2012) were simulated using a parametric wind model based on the National Hurricane Center Extended Best Track database, a global wind model based on the European Center for Medium-Range Weather Forecast (ECMWF), and a regional wind model from the Northeast Coastal Ocean Forecasting System (NECOFS) Weather Research and Forecast (WRF) hindcast.

Parametric wind models are advantageous in hurricane forecasting and hindcasting due to the relatively small amount of storm input data required such as the hurricane track, intensity and structure information provided in the NHC EBT database. Missing from this database is the definition of environmental/background winds outside of the

hurricane center. Global weather hindcast/forecast systems, such as ECMWF, combine several models covering the atmosphere, land, and ocean in a general circulation model, 
and include environmental wind speeds outside of the hurricane radius. However, without the implementation of a synthetic vortex in the model, the maximum wind speeds in the cyclone center are not fully captured in ECMWF. The combination of a hindcast/forecast system with inserted synthetic vortices (i.e. a blended wind model) is achieved by NECOFS WRF, providing regional wind fields for the U.S. northeast coast. Access to this wind model was limited and was only available for Hurricane Sandy in this research.

Observation/hindcast stations for wind, surge, and waves were available both offshore and nearshore in Rhode Island coastal waters. Permanent station locations included three tidal gauges operated by NOAA in New London, CT, Newport, RI, and Providence, RI, as well as two NDBC wind and wave buoys located outside of Buzzards Bay, MA (BUZM3) and offshore of Block Island, RI (44097). Several nearshore temporary wind, water level, and wave stations were in operation during Hurricane Irene, including two wind gauges, three water elevation gauges, and two wave gauges along the southern coast of RI. Hindcasts from the USACE WIS program were also available for wind and waves.

Hurricane Bob passed directly over Rhode Island with a radius of maximum wind of 30 nautical miles $(56 \mathrm{~km})$. As a result, the EBT DHM parametric wind model estimated the peak wind speed within $10 \%$ at the BUZM3 wind station, peak surge within $20 \%$ at the tidal gauge in Providence, RI, and peak significant wave height within $53 \%$ at the WIS 63079 location. At these same locations, the ECMWF wind model underestimated the maximum wind speed, surge, and wave height more than $50 \%$.

Hurricane Irene traveled west of RI through New York state with a radius of maximum wind of 100 nautical miles $(185 \mathrm{~km})$. The resulting ECMWF wind model simulation estimated peak wind speed within $15 \%$ when compared with observed wind speeds both offshore and nearshore; differences were as high as $40 \%$ for the EBT DHM wind model. Peak storm surge was within $25 \%$ and up to $52 \%$ for the ECMWF and DHM 
wind models, respectively. Peak significant wave heights were estimated by the ECMWF wind model within $15 \%$, and varied considerably between offshore and nearshore wave station locations when forced by the DHM wind model.

Hurricane Sandy stayed southwest of RI as it made landfall in New Jersey with a radius of maximum wind of 110 nautical miles $(204 \mathrm{~km})$. As a result, the NECOFS WRF wind model simulated peak surge within $11 \%$, peak wind speed within $18 \%$, and peak significant wave height within $10 \%$ when compared with offshore and nearshore observations. At the same locations, the ECMWF wind predicted all peaks within $20 \%$ and the EBT DHM parametric wind model underestimated peak wind and surge up to $30 \%$ and $45 \%$, respectively, and overestimated peak wave height up to $14 \%$.

When modeling storm surge and waves, the selection of a wind model is a crucial step that can affect the results significantly, even more than other parameters such as bottom friction or wind drag. There is no unique "best" wind model for all hindcast applications. This choice depends on the nature of the hurricane, in particular, the size of the storm (i.e. radius of maximum wind) and its storm track relative to the measurement locations. We have quantified that a wind model, which has an error in peak wind speed less than $20 \%$ when compared with observations, can successfully be used for storm surge and wave simulations, and the impact of using a poor wind model can result in error as high as $50 \%$ in storm surge and wave predictions. The parametric wind model based on the NHC EBT database has significant shortcomings, however it is best used for small storms. In addition, we have proposed the best wind model for our region is the NECOFS WRF blended wind model that addresses background winds as well as the vortex winds of tropical cyclones. 


\section{List of References}

[1] R. A. Piekle, J. Gratz, C. W. Landsea, D. Collins, M. A. Saunders, and R. Musulin, "Normalized hurricane damage in the United States: 1900-2005," Natural Hazards Review, vol. 29, pp. 1527-6988, 2008.

[2] P. Grossi, "The 1938 Great New England Hurricane Looking to the Past to Understand Today's Risk," Risk Management Solutions, Inc. 7015 Gateway Blvd Newark, CA USA, Tech. Rep., 2008.

[3] E. S. Blake, T. B. Kimberlain, R. J. Berg, J. P. Cangialosi, and J. L. B. II, “Tropical Cyclone Report Hurricane Sandy,” National Hurricane Center, Tech. Rep., 2013.

[4] C. P. Jelesnianski, J. Chen, and W. A. Shaffer, "SLOSH: Sea, Lake, and Overland Surges from Hurricanes," National Oceanic and Atmospheric Administration, Tech. Rep. NWS 48, 1992.

[5] R. Luettich, J. Westerink, and N. Scheffner, "ADCIRC: an Advanced ThreeDimensional Circulation Model for Shelves, Coasts, and Estuaries, Report 1: Theory and Methodology of ADCIRC-2DDI and ADCIRC03DL," U.S. Army Engineers Waterways Experiment Station, Tech. Rep. Dredging Research Program Technical Report DRP-92-6, 1992.

[6] N. Booij, R. Ris, and L. Holthuijsen, "A third-generation wave model for coastal regions, Part 1, model description and validation," Journal of Geophysical Research, vol. 104, pp. 7649-7666, 1999.

[7] G. J. Holland, "An analytic model of the wind and pressure profiles in hurricanes," Monthly Weather Reivew, vol. 108(8), pp. 1212-1218, 1980.

[8] J. G. Fleming, C. W. Fulcher, R. A. Luettich, B. D. Estrade, G. D. Allen, and H. S. Winer, "A Real Time Storm Surge Forecasting System using ADCIRC," Estuarine and Coastal Modeling, pp. 893-912, 2008.

[9] K. Walsh, "Objective Detection of Tropical Cyclones in High-Resolution Analyses," Monthly Weather Review, vol. 125, no. 8, pp. 1767-1779, 1997.

[10] J. Qi, C. Chen, R. C. Beardsley, W. Perrie, G. W. Cowles, and Z. Lai, "An unstructured-grid finite-volume surface wave model (FVCOM-SWAVE): Implementation, validations and applications," Ocean Modelling, vol. 28, no. 1-3, pp. 153 - 166, 2009, the Sixth International Workshop on Unstructured Mesh Numerical Modelling of Coastal, Shelf and Ocean Flows.

[11] S. H. Houston, W. A. Shaffer, M. D. Powell, and J. Chen, "Comparisons of HRD and SLOSH Surface Wind Fields in Hurricanes: Implications for Storm Surge Modeling," Weather and Forecasting, vol. 14, pp. 671-686, 1999. 
[12] J. Dietrich, A. Muhammad, M. Curcic, A. Fathi, C. Dawson, S. Chen, and R. L. Jr., "Sensitivity of Storm Surge Predictions to Meteorological Forcing for Hurricane Isaac (2012)," Journal of Geophysical Research - Oceans, vol. in review, 2016.

[13] V. C. Bennett and R. P. Mulligan, "Evaluation of surface wind fields for prediction of directional ocean wave spectra during Hurricane Sandy," Coastal Engineering, vol. 125, pp. 1-15, 2017.

[14] V. Cardone and A. Cox, "Tropical cyclone wind field forcing for surge models: critical issues and sensitivies," Oceanweather, Inc., 2009.

[15] C. Chen, R. C. Beardsley, and G. Cowles, "An unstructured grid, finite-volume coastal ocean model (FVCOM) system," Oceanography, vol. 19, no. 1, pp. 78-89, 2006.

[16] L. A. Avila and J. Cangialosi, “Tropical Cyclone Report Hurricane Irene,” National Hurricane Center, Tech. Rep., 2011.

[17] E. S. Blake, T. B. Kimberlain, R. J. Berg, J. P. Cangialosi, and J. L. B. II, “Tropical Cyclone Report Hurricane Sandy,” National Hurricane Center, Tech. Rep., 2013.

[18] T. J. Galarneau, C. A. Davis, and M. A. Shapiro, "Intensification of Hurricane Sandy (2012) through Extratropical Warm Core Seclusion," Monthly Weather Review, vol. 41, pp. 4296-4321, 2013.

[19] Woods Hole Group, Wave, Tide and Current Data Collection Contract No. W912WJ-09-D-0001-0026, 2012, US Army Corps of Engineers: New England District, MA, USA.

[20] J. Dietrich, M. Zijlema, J. Westerink, L. Holthuijsen, C. Dawson, and R. Luettich, "Modeling hurricane waves and storm surge using integrally-coupled scalable computations," Coastal Engineering, vol. 58, pp. 45-65, 2011.

[21] M. Tomassini, D. LeMeur, and R. W. Saunders, "Near-Surface Satellite Wind Observations of Hurricanes and Their Impact on ECMWF Model Analyses and Forecasts," Monthly Weather Review, vol. 126, no. 5, pp. 1274-1286, 1998.

[22] S. D. Aberson, "The Ensemble of Tropical Cyclone Track Forecasting Models in the North Atlantic Basin (1976-2000)," Bulletin of the American Meteorological Society, vol. 82, no. 9, pp. 1895-1904, 2001.

[23] R. L. Elsberry, M. S. Jordan, and F. Vitart, "Predictability of tropical cyclone events on intraseasonal timescales with the ECMWF monthly forecast model," Asia-Pacific Journal of Atmospheric Sciences, vol. 46, no. 2, pp. 135-153, 2010.

[24] D. P. Dee, S. M. Uppala, A. J. Simmons, P. Berrisford, P. Poli, S. Kobayashi, U. Andrae, M. A. Balmaseda, G. Balsamo, P. Bauer, P. Bechtold, A. C. M. Beljaars, L. van de Berg, J. Bidlot, N. Bormann, C. Delsol, R. Dragani, M. Fuentes, A. J. 
Geer, L. Haimberger, S. B. Healy, H. Hersbach, E. V. Hólm, L. Isaksen, P. Kållberg, M. Köhler, M. Matricardi, A. P. McNally, B. M. Monge-Sanz, J.-J. Morcrette, B.K. Park, C. Peubey, P. de Rosnay, C. Tavolato, J.-N. Thépaut, and F. Vitart, "The ERA-Interim reanalysis: configuration and performance of the data assimilation system," Quarterly Journal of the Royal Meteorological Society, vol. 137, no. 656, pp. 553-597, 2011.

[25] C. Chen, "The hindcast wind data for Hurricane Sandy based on WRF output," January 122017.

[26] R. Pawlowicz, B. Beardsley, and S. Lentz, "Classical tidal harmonic analysis including error estimates in MATLAB using TTIDE," Computational Geosciences, vol. 28, pp. 929-937, 2002.

[27] W. A. Landman, A. Seth, and S. J. Camargo, “The Effect of Regional Climate Model Domain Choice on the Simulation of Tropical Cyclone-Like Vortices in the Southwestern Indian Ocean," Journal of Climate, vol. 18, no. 8, pp. 1263-1274, 2005.

[28] K. M. Bryant and M. Akbar, "An Exploration of Wind Stress Calculation Techniques in Hurricane Storm Surge Modeling," Journal of Marine Science and Engineering, vol. 4, 2016.

[29] M. D. Powell, "Final Report to the National Oceanic and Atmospheric Administration (NOAA) Joint Hurricane Testbed (JHT) Program,” p. 26, 2006. 


\section{APPENDIX A}

\section{List of variables in Manuscript 1}

$\tau_{m}$ - mean bed shear stress

$\tau_{c}$ - current-induced bed shear stress

$\tau_{w}$ - wave-induced bed shear stress

$u_{c}$ - depth-averaged current velocity

$U_{r m s}$ - root-mean-square wave orbital velocity

r.m.s. - root-mean-square

$C_{D}$ - pure current bottom drag coefficient

$C_{D}^{*}$ - combined wave-current bottom drag coefficient

$\epsilon$ - ratio of combined wave-current bottom drag coefficient to pure current bottom drag coefficient

$\lambda$ - ratio of pure wave shear stress to pure current shear stress

$n$ - Manning's quadratic friction coefficient

$n^{*}$ - modified Manning's quadratic friction coefficient

$h, d$ - water depth

$g$ - gravitational acceleration $\left(g=9.81 \mathrm{~m} / \mathrm{s}^{-2}\right)$

$\rho, \rho_{0}$ - density of sea water $\left(\rho=1025 \mathrm{~kg} / \mathrm{m}^{-3}\right)$

$H_{s}$ - significant wave height of surface waves

$H_{m o}$ - significant wave height of wave spectrum

$T_{p}$ - peak wave period of surface waves

$T_{m}$ - peak wave period of wave spectrum

$k_{s}$ - Nikuradse bed roughness

$d_{50}$ - mean sediment grain size diameter

$A$ - semi-orbital wave excursion 
$T_{z}$ - zero-crossing wave period $\left(T_{z}=0.781 T_{p}\right)$

$f_{w}$ - friction factor

$\zeta$ - surface water elevation

$H$ - total water depth $(H=h+\zeta)$

$U, V$ - current velocities in $\mathrm{x}$ - and y-directions, respectively

$Q_{x}, Q_{y}$ - volumetric flux in x- and y-directions, respectively $\left(Q_{x}=U H, Q_{y}=V H\right)$

$\tau_{0}$ - numerical weighting factor

$f$ - Coriolis parameter

$p_{s}$ - atmospheric pressure at the free surface

$(\eta+\gamma)$ - Newtonian tidal potential, Earth ride, self-attraction and load tide

$\tau_{s x}, \tau_{s y}$ - applied free surface stresses in $\mathrm{x}$ - and $\mathrm{y}$-directions, respectively

$\tau_{b x}, \tau_{b y}$ - bottom shear stresses in $\mathrm{x}$ - and y-directions, respectively

$B_{x}, B_{y}-2$ DDI baroclinic pressure gradients

$D_{x}, D_{y}-2 \mathrm{DDI}$ momentum diffusion/dispersion terms

$E(\sigma, \theta)$ - wave energy density

$\sigma$ - relative angular frequency

$\theta$ - wave direction

$N(x, t, \sigma, \theta)$ - wave action density

$c_{g}$ - group wave velocity 


\title{
APPENDIX B
}

\section{List of abbreviations/acronyms in Manuscript 2}

\author{
ADCIRC - ADvanced CIRCulation hydrodynamic model \\ BI - Block Island, RI \\ Center - Charlestown, RI wave gauge $\left(-71.656^{\circ} \mathrm{W}, 41.348^{\circ} \mathrm{N}\right)$ \\ C-MAN - Coastal-Marine Automated Network \\ DHM - Dynamic Holland Model \\ EBT - Extended Best Track \\ ECMWF - European Center for Medium-range Weather Forecasts \\ FVCOM - Finite-Volume Community Ocean Model \\ GAHM - Generalized Asymmetric Holland Model \\ GOM4 - Gulf of Maine Version 4 mesh \\ HURDAT - Hurricane Database \\ msl - mean sea level \\ NDBC - National Data Buoy Center \\ NECOFS - Northeast Coastal Ocean Forecasting System \\ NHC - National Hurricane Center \\ NIN - Ninigret Pond (Charlestown, RI) \\ NL - New London, CT \\ NOAA - National Oceanic and Atmospheric Administration \\ NPT - Newport, RI \\ PJ - Point Judith, RI \\ PVD - Providence, RI \\ QB - Quonochontaug Breachway (Charlestown, RI)
}


RMSE - Root Mean Square Error $\left(\mathrm{RMSE}=\left[\frac{1}{N_{p}} \sum_{i}\left(x_{i}-y_{i}\right)^{2}\right]^{1 / 2} ; x_{i}\right.$, observed; $y_{i}$, simulated; $N_{p}$, total number of points)

RMW - Radius of maximum wind

SD - Skip's Dock (Point Judith, RI)

SWAN - Simulating WAves Nearshore wave model

USGS - United States Geological Survey

WB - Weekapaug Breachway (Westerly, RI)

West - Westerly, RI wave gauge $\left(-71.793^{\circ} \mathrm{W}, 41.317^{\circ} \mathrm{N}\right)$

WF - WeatherFlow

WHG - Woods Hole Group

WIS - Wave Information Studies

WIS79 - WIS station 63079

WRF - Weather Research and Forecasting model 


\section{BIBLIOGRAPHY}

Aberson, S. D., "The Ensemble of Tropical Cyclone Track Forecasting Models in the North Atlantic Basin (1976-2000)," Bulletin of the American Meteorological Society, vol. 82, no. 9, pp. 1895-1904, 2001.

Avila, L. A. and Cangialosi, J., "Tropical Cyclone Report Hurricane Irene," National Hurricane Center, Tech. Rep., 2011.

Bennett, V. C. and Mulligan, R. P., "Evaluation of surface wind fields for prediction of directional ocean wave spectra during Hurricane Sandy," Coastal Engineering, vol. 125, pp. 1-15, 2017.

Bing-chen, L. and Hua-jun, L., "Bottom shear stress under wave-current interaction," Journal of Hydrodynamics, vol. 20, no. 1, pp. 88-95, 2007.

Blake, E. S., Kimberlain, T. B., Berg, R. J., Cangialosi, J. P., and II, J. L. B., "Tropical Cyclone Report Hurricane Sandy,” National Hurricane Center, Tech. Rep., 2013.

Blake, E. S., Kimberlain, T. B., Berg, R. J., Cangialosi, J. P., and II, J. L. B., "Tropical Cyclone Report Hurricane Sandy,” National Hurricane Center, Tech. Rep., 2013.

Booij, N., Ris, R., and Holthuijsen, L., "A third-generation wave model for coastal regions, Part 1, model description and validation," Journal of Geophysical Research, vol. 104, pp. 7649-7666, 1999.

Bryant, K. M. and Akbar, M., "An Exploration of Wind Stress Calculation Techniques in Hurricane Storm Surge Modeling," Journal of Marine Science and Engineering, vol. 4, 2016.

Cardone, V. and Cox, A., "Tropical cyclone wind field forcing for surge models: critical issues and sensitivies," Oceanweather, Inc., 2009.

Chen, C., Beardsley, R. C., and Cowles, G., "An unstructured grid, finite-volume coastal ocean model (FVCOM) system,” Oceanography, vol. 19, no. 1, pp. 78-89, 2006.

Chen, C., "The hindcast wind data for Hurricane Sandy based on WRF output," January 122017.

Davies, A., Soulsby, R., and King, H., "A numerical model of the combined wave and current bottom boundary layer," Journal of Geophysical Research, vol. 93, no. C1, pp. 491-508, 1988. 
Dee, D. P., Uppala, S. M., Simmons, A. J., Berrisford, P., Poli, P., Kobayashi, S., Andrae, U., Balmaseda, M. A., Balsamo, G., Bauer, P., Bechtold, P., Beljaars, A. C. M., van de Berg, L., Bidlot, J., Bormann, N., Delsol, C., Dragani, R., Fuentes, M., Geer, A. J., Haimberger, L., Healy, S. B., Hersbach, H., Hólm, E. V., Isaksen, L., Kållberg, P., Köhler, M., Matricardi, M., McNally, A. P., Monge-Sanz, B. M., Morcrette, J.-J., Park, B.-K., Peubey, C., de Rosnay, P., Tavolato, C., Thépaut, J.-N., and Vitart, F., "The ERA-Interim reanalysis: configuration and performance of the data assimilation system," Quarterly Journal of the Royal Meteorological Society, vol. 137, no. 656, pp. 553-597, 2011.

Dietrich, J., Zijlema, M., Westerink, J., Holthuijsen, L., Dawson, C., and Luettich, R., "Modeling hurricane waves and storm surge using integrally-coupled scalable computations," Coastal Engineering, vol. 58, pp. 45-65, 2011.

Dietrich, J., Muhammad, A., Curcic, M., Fathi, A., Dawson, C., Chen, S., and Jr., R. L., "Sensitivity of Storm Surge Predictions to Meteorological Forcing for Hurricane Isaac (2012)," Journal of Geophysical Research - Oceans, vol. in review, 2016.

Elfrink, B., Hanes, D. M., and Ruessink, B. G., "Parameterization and simulation of near bed orbital velocities under irregular waves in shallow water," Coastal Engineering, vol. 34, pp. 915-927, 2006.

Elsberry, R. L., Jordan, M. S., and Vitart, F., "Predictability of tropical cyclone events on intraseasonal timescales with the ECMWF monthly forecast model," Asia-Pacific Journal of Atmospheric Sciences, vol. 46, no. 2, pp. 135-153, 2010.

Fleming, J. G., Fulcher, C. W., Luettich, R. A., Estrade, B. D., Allen, G. D., and Winer, H. S., "A Real Time Storm Surge Forecasting System using ADCIRC," Estuarine and Coastal Modeling, pp. 893-912, 2008.

Galarneau, T. J., Davis, C. A., and Shapiro, M. A., "Intensification of Hurricane Sandy (2012) through Extratropical Warm Core Seclusion," Monthly Weather Review, vol. 41, pp. 4296-4321, 2013.

Grant, W. D. and Madsen, O. S., "Combined wave and current interaction with a rough bottom," Journal of Geophysical Research, vol. 84, no. C4, pp. 1797-1808, 1979.

Grilli, S., Harris, J., Sharma, R., Decker, L., Stuebe, D., Mendelsohn, D., Crowly, D., and Decker, S., "High resolution modeling of meteorological, hydrodynamic, wave and sediment processes in the Rhode Island Ocean SAMP study area," Ocean Special Area Management Plan, Tech. Rep. 6, 2010.

Grossi, P., "The 1938 Great New England Hurricane Looking to the Past to Understand Today's Risk," Risk Management Solutions, Inc. 7015 Gateway Blvd Newark, CA USA, Tech. Rep., 2008. 
Hashemi, M. R., Niel, S. P., Robins, P. E., Davies, A. G., and Lewis, M. J., "Effect of waves on the tidal energy resource at a planned tidal stream array," Renewable Energy, vol. 75, pp. 626-639, 2015.

Holland, G. J., "An analytic model of the wind and pressure profiles in hurricanes," Monthly Weather Reivew, vol. 108(8), pp. 1212-1218, 1980.

Houston, S. H., Shaffer, W. A., Powell, M. D., and Chen, J., "Comparisons of HRD and SLOSH Surface Wind Fields in Hurricanes: Implications for Storm Surge Modeling," Weather and Forecasting, vol. 14, pp. 671-686, 1999.

Huang, Y., Weisberg, R. H., and Zheng, L., "Coupling of surge and waves for Ivanlike hurricane impacting the Tampa Bay, Florida region," Journal of Geophysical Research, vol. 115, no. C12009, 2010.

Jelesnianski, C. P., Chen, J., and Shaffer, W. A., "SLOSH: Sea, Lake, and Overland Surges from Hurricanes," National Oceanic and Atmospheric Administration, Tech. Rep. NWS 48, 1992.

Landman, W. A., Seth, A., and Camargo, S. J., "The Effect of Regional Climate Model Domain Choice on the Simulation of Tropical Cyclone-Like Vortices in the Southwestern Indian Ocean," Journal of Climate, vol. 18, no. 8, pp. 1263-1274, 2005.

Luettich, R., Westerink, J., and Scheffner, N., "ADCIRC: an Advanced ThreeDimensional Circulation Model for Shelves, Coasts, and Estuaries, Report 1: Theory and Methodology of ADCIRC-2DDI and ADCIRC03DL,' U.S. Army Engineers Waterways Experiment Station, Tech. Rep. Dredging Research Program Technical Report DRP-92-6, 1992.

Lui, Q., “Dynamics of Rhode Island Coastal Waters,” 2015, PhD Thesis Dissertation.

Pawlowicz, R., Beardsley, B., and Lentz, S., "Classical tidal harmonic analysis including error estimates in MATLAB using TTIDE," Computational Geosciences, vol. 28, pp. 929-937, 2002.

Piekle, R. A., Gratz, J., Landsea, C. W., Collins, D., Saunders, M. A., and Musulin, R., "Normalized hurricane damage in the United States: 1900-2005," Natural Hazards Review, vol. 29, pp. 1527-6988, 2008.

Poppe, L., Paskevich, V., Williams, S., Hastings, M., Kelley, J., Belknap, D., Ward, L., FitzGerald, D., and Larsen, P., "Surficial Sediment Data from the Gulf of Maine, Georges Bank, and Vicinity: A GIS Compilation," U.S. Geological Survey, Tech. Rep. OFR03-001, 2003.

Powell, M. D., "Final Report to the National Oceanic and Atmospheric Administration (NOAA) Joint Hurricane Testbed (JHT) Program,” p. 26, 2006. 
Qi, J., Chen, C., Beardsley, R. C., Perrie, W., Cowles, G. W., and Lai, Z., "An unstructured-grid finite-volume surface wave model (FVCOM-SWAVE): Implementation, validations and applications," Ocean Modelling, vol. 28, no. 1-3, pp. 153 - 166, 2009, the Sixth International Workshop on Unstructured Mesh Numerical Modelling of Coastal, Shelf and Ocean Flows.

Rijn", L. V., "Unified view of sediment transport by currents and waves. I: initiation of motion, bed roughness, and bed-load transport," Journal of Hydraulic Engineering, vol. 133, pp. 649-667, 2007.

Rosales, P., Ocampo-Torres, F. J., Osuna, P., Monbaliu, J., and Padilla-Hernández, R., "Wave-current interaction in coastal waters: Effects on the bottom-shear stress," Journal of Marine Systems, vol. 71, pp. 131-148, 2008.

Soulsby, R. L., "Calculating bottom orbital velocity beneath waves," Coastal Engineering, vol. 11, pp. 371-380, 1987.

Soulsby, R. L., Dynamics of marine sands. Thomas Telford Publications, 1997.

Soulsby, R. L., Hamm, L., Klopman, G., Myrhaug, D., Simmons, R. R., and Thomas, G. P., "Wave-current interaction within and outside the bottom boundary layer," Coastal Engineering, vol. 21, pp. 41-69, 1993.

Soulsby, R., "Simplified calculation of wave orbital velocities," HR Wallingford, Tech. Rep. 155, 2006.

Sun, Y., Chen, C., Beardsley, R. C., Xu, Q., Qi, J., and Lin, H., "Impact of current-wave interactions on storm surge simulation: A case study for Hurricane Bob," Journal of Geophysical Research: Oceans, vol. 118, pp. 2685-2701, 2013.

SWAN Team, "SWAN Technical Documentation," Delft University of Technology, the Netherlands, Tech. Rep. Cycle III version 40.51, 2006.

Tomassini, M., LeMeur, D., and Saunders, R. W., "Near-Surface Satellite Wind Observations of Hurricanes and Their Impact on ECMWF Model Analyses and Forecasts," Monthly Weather Review, vol. 126, no. 5, pp. 1274-1286, 1998.

Torres, M. J., Hashemi, M. R., Hayward, S., Spaulding, M., Ginis, I., and Grilli, S., "The Role of Hurricane Wind Models in the Accurate Simulation of Storm Surge and Waves," ASCE Journal of Waterway, Port, Coastal and Ocean Engineering Online Collection, vol. in review, 2017.

United States Army Corps of Engineering; Coastal Engineering Research Center, Coastal Engineering Manual, 2002.

Walsh, K., "Objective Detection of Tropical Cyclones in High-Resolution Analyses," Monthly Weather Review, vol. 125, no. 8, pp. 1767-1779, 1997. 
Wilberg, P. L. and Sherwood, C. R., "Calculation wave-generated bottom orbital velocities from surface-wave parameters," Computers \& Geosciences, vol. 34, pp. 1243-1262, 2008.

Woods Hole Group, Wave, Tide and Current Data Collection Contract No. W912WJ09-D-0001-0026, 2012, US Army Corps of Engineers: New England District, MA, USA.

You, Z.-J., "The statistical distribution of nearbed wave orbital velocity in intermediate coastal water depth," Coastal Engineering, vol. 56, pp. 844-852, 2009.

Zhao, L., Chen, C., and Cowles, G., "Tidal flushing and eddy shedding in Mount Hope Bay and Narragansett Bay: An applicaiton of FVCOM," Journal of Geophysical Research, vol. 111, 2006. 